\title{
Modifying the organic/electrode interface in Organic Solar Cells (OSCs) and improving the efficiency of solution-processed phosphorescent Organic Light-Emitting Diodes (OLEDs)
}

by

\author{
Teng Xiao \\ A dissertation submitted to the graduate faculty \\ in partial fulfillment of the requirements for the degree of \\ DOCTOR OF PHILOSOPHY
}

\author{
Major: Condensed Matter Physics \\ Program of Study Committee: \\ Joseph Shinar, Co-Major Professor \\ Ruth Shinar, Co- Major Professor \\ Rana Biswas \\ Vikram Dalal \\ Adam Kaminski \\ John Lajoie
}

Iowa State University

Ames, Iowa

2012

Copyright (C) Teng Xiao, 2012. All rights reserved. 


\section{TABLE OF CONTENTS}

Abstract

Chapter 1. Dissertation Organization 1

Chapter 2. Introduction to Organic Solar Cells (OSCs) 3

Brief history to OSCs

Brief introduction to $\pi$ conjugated materials

$\begin{array}{ll}\text { Working principles and common parameters } & 10\end{array}$

$\begin{array}{ll}\text { Device Structure of OSCs } & 21\end{array}$

$\begin{array}{ll}\text { Fabrication methods } & 27\end{array}$

$\begin{array}{ll}\text { Applications of OSCs } & 28\end{array}$

$\begin{array}{ll}\text { References } & 30\end{array}$

Chapter 3. Introduction to Organic Light-Emitting Diodes (OLEDs) 36

Brief history of OLED technology 36

Basic OLED photophysics and operation $\quad 39$

$\begin{array}{ll}\text { Phosphorescent OLEDs (PHOLEDs) } & 40\end{array}$

References $\quad 45$

Chapter 4. Simple routes for improving polythiophene:fullerene-based

$\begin{array}{ll}\text { Organic Solar Cells } & 51\end{array}$

$\begin{array}{ll}\text { Abstract } & 51\end{array}$ 
Introduction $\quad 52$

Experimental procedures $\quad 55$

Results and discussion $\quad 56$

$\begin{array}{ll}\text { Conclusions } & 66\end{array}$

$\begin{array}{ll}\text { Acknowledgements } & 67\end{array}$

$\begin{array}{ll}\text { References } & 67\end{array}$

Chapter 5. Thin air-plasma-treated alkali fluoride layers for improved hole extraction in copper phthalocyanine/ $\mathbf{C}_{70}$-based solar cells $\quad 71$

$\begin{array}{ll}\text { Abstract } & 71\end{array}$

$\begin{array}{ll}\text { Introduction } & 72\end{array}$

$\begin{array}{ll}\text { Experimental procedures } & 74\end{array}$

$\begin{array}{ll}\text { Results and discussion } & 75\end{array}$

$\begin{array}{ll}\text { Conclusions } & 86\end{array}$

$\begin{array}{ll}\text { Acknowledgements } & 87\end{array}$

$\begin{array}{ll}\text { References } & 87\end{array}$

Chapter 6. A novel hybrid inorganic-organic tandem junction solar cell 91

$\begin{array}{ll}\text { Abstract } & 91\end{array}$

$\begin{array}{ll}\text { Introduction } & 91\end{array}$

$\begin{array}{ll}\text { Experimental procedures } & 93\end{array}$

$\begin{array}{ll}\text { Results and discussion } & 95\end{array}$

$\begin{array}{ll}\text { Conclusions } & 101\end{array}$

$\begin{array}{ll}\text { Acknowledgements } & 102\end{array}$ 
$\begin{array}{lr}\text { Author contributions } & 102\end{array}$

$\begin{array}{lr}\text { References } & 102\end{array}$

Chapter 7. Fabrication and properties of hybrid polymer/small molecular phosphorescent OLEDs based on $\begin{array}{ll}\operatorname{poly}(N \text {-vinyl carbazole }) & 106\end{array}$

$\begin{array}{ll}\text { Abstract } & 106\end{array}$

$\begin{array}{ll}\text { Introduction } & 106\end{array}$

$\begin{array}{lr}\text { Experimental procedures } & 108\end{array}$

$\begin{array}{ll}\text { Results and discussion } & 109\end{array}$

$\begin{array}{lr}\text { Conclusions } & 121\end{array}$

$\begin{array}{ll}\text { Acknowledgements } & 121\end{array}$

$\begin{array}{lr}\text { References } & 121\end{array}$

Chapter 8. High efficiency solution-processed small molecule

$\begin{array}{ll}\text { electrophosphorescent OLEDs } & 124\end{array}$

$\begin{array}{ll}\text { Abstract } & 124\end{array}$

$\begin{array}{lr}\text { Introduction } & 125\end{array}$

$\begin{array}{ll}\text { Experimental procedures } & 127\end{array}$

$\begin{array}{lr}\text { Results and discussion } & 128\end{array}$

$\begin{array}{ll}\text { Conclusions } & 139\end{array}$

$\begin{array}{lr}\text { Acknowledgements } & 140\end{array}$

$\begin{array}{ll}\text { Author contributions } & 140\end{array}$

$\begin{array}{ll}\text { References } & 140\end{array}$ 
Chapter 9. Summary

Acknowledgements 


\begin{abstract}
Organic semiconductors devices, such as, organic solar cells (OSCs), organic lightemitting diodes (OLEDs) and organic field-effect transistors (OFETs) have drawn increasing interest in recent decades. As organic materials are flexible, light weight, and potentially low-cost, organic semiconductor devices are considered to be an alternative to their inorganic counterparts. This dissertation will focus mainly on OSCs and OLEDs.

As a clean and renewable energy source, the development of OSCs is very promising. Cells with $9.2 \%$ power conversion efficiency (PCE) were reported this year, compared to $<8 \%$ two years ago. OSCs belong to the so-called third generation solar cells and are still under development. While OLEDs are a more mature and better studied field, with commercial products already launched in the market, there are still several key issues: (1) the cost of OSCs/OLEDs is still high, largely due to the costly manufacturing processes; (2) the efficiency of OSCs/OLEDs needs to be improved; (3) the lifetime of OSCs/OLEDs is not sufficient compared to their inorganic counterparts; (4) the physics models of the behavior of the devices are not satisfactory. All these limitations invoke the demand for new organic materials, improved device architectures, low-cost fabrication methods, and better understanding of device physics.

For OSCs, we attempted to improve the PCE by modifying the interlayer between active layer/metal. We found that ethylene glycol (EG) treated poly(3,4-ethylenedioxythiophene):polystyrenesulfonate (PEDOT: PSS) improves hole collection at the metal/polymer interface, furthermore it also affects the growth of the poly(3hexylthiophene) (P3HT):phenyl- $\mathrm{C}_{61}$-butyric acid methyl ester (PCBM) blends, making the phase segregation more favorable for charge collection. We then studied
\end{abstract}


organic/inorganic tandem cells. We also investigated the effect of a thin LiF layer on the hole-collection of copper phthalocyanine $(\mathrm{CuPc}) / \mathrm{C}_{70}$-based small molecular OSCs. A thin $\mathrm{LiF}$ layer serves typically as the electron injection layer in OLEDs and electron collection interlayer in the OSCs. However, several reports showed that it can also assist in holeinjection in OLEDs. Here we first demonstrate that it assists hole-collection in OSCs, which is more obvious after air-plasma treatment, and explore this intriguing dual role.

For OLEDs, we focus on solution processing methods to fabricate highly efficient phosphorescent OLEDs. First, we investigated OLEDs with a polymer host matrix, and enhanced charge injection by adding hole- and electron-transport materials into the system. We also applied a hole-blocking and electron-transport material to prevent luminescence quenching by the cathode. Finally, we substituted the polymer host by a small molecule, to achieve more efficient solution processed small molecular OLEDs (SMOLEDs); this approach is cost-effective in comparison to the more common vacuum thermal evaporation.

All these studies help us to better understand the underlying relationship between the organic semiconductor materials and the OSCs and OLEDs' performance and will subsequently assist in further enhancing the efficiencies of OSCs and OLEDs. With better efficiency and longer lifetime, the OSCs and OLEDs will be competitive with their inorganic counterparts. 


\section{Chapter 1. Dissertation Organization}

This dissertation comprises 9 chapters and consists mainly of papers published, submitted or prepared for submission. Chapter 1 describes the organization of this dissertation. Chapters 2 and 3 provide a brief introduction on OSC and OLED technology, respectively. Chapters 4, 5, 7, and 8 are based on published papers. Chapter 6 is based on a submitted paper. Chapters 4 to 6 describe work on OSCs, and chapters 7 and 8 on OLEDs. Chapters 4 and 5 focus on improving metal/organic interfaces to achieve higher PCE in OSCs. Chapter 4 shows that EG treated PEDOT:PSS improves hole collection at the anode/polymer interface, furthermore, it also affects the growth of the P3HT:PCBM blended film, making the phase segregation more favorable for charge collection. Chapter 5 describes the effect of a thin $\mathrm{LiF}$ layer on the hole-collection in $\mathrm{CuPc} / \mathrm{C}_{70}$-based small molecular OSCs. A thin LiF layer serves typically as an electron injection layer in OLEDs and an electron collection interlayer in the OSCs, however a few reports in OLEDs discovered that it can also assistant in hole-collection. Here we demonstrate for the first time its function in assisting hole-collection in OSCs, which is further enhanced following air-plasma treatment. Chapter 6 describes the probing of hybrid tandem cells by stacking a P3HT:PCBM-based device on top of an inorganic cell to achieve a higher open circuit voltage and power conversion efficiency. In chapter 7, the efficiency as well as the lifetime of guest (small molecular phosphorescent dye)-host (polymer)-based OLEDs is improved by modifying the electron transport. In Chapter 8, the work described in chapter 7 is continued with the OLEDs greatly improved by substituting the polymer host with a small molecular host, and the resulting high-efficiency solution- 
processed small molecule phosphorescent OLEDs are discussed. Finally, the conclusions of this dissertation are summarized in Chapter 9. 


\section{Chapter 2. Introduction to Organic Solar Cells (OSCs)}

\section{Brief history to OSCs}

In 1906 Pochettino discovered photoconductivity in solid anthracene, which was the first organic compound showing this effect [1]. This phenomenon was re-addressed by Volmer in 1913 [2]. The actual emergence of organic dyes as photoacceptors in imaging was in 1950s - 1960s [3]. These dyes were later among the first organic materials that showed photovoltaic (PV) effects. Cells made of magnesium phthalocyanines (MgPh) that produced a photovoltage of $200 \mathrm{mV}$ were fabricated by Kearns and Calvin in 1958 [4]. In 1980s, the first polymer-based solar cells were investigated [5-6]. At that time, the active layer was composed of a single layer of either a dye or a polymer, hence the power conversion efficiency (PCE) of the cell was very low $(<0.1 \%)$. In 1986 a major breakthrough in OSCs was achieved by Tang by generating a donor-acceptor heterojuction structure, which greatly assisted the charge separation and resulted in a device efficiency of $1 \%$ [7]. The concept of a heterojunction has since been widely studied in various donor-acceptor pairs, such as dye/dye, polymer/dye, polymer/polymer and polymer/fullerene. Later on, OSCs fabricated from a donor/acceptor mixture, termed bulk heterojunction, came into being. In 1991, Hiramoto demonstrated the first small

molecular bulk heterojunction [8]. And Yu et. al, fabricated the first polymer: $\mathrm{C}_{60}$ bulk heterojuction photodetector in 1994 [9]. The application of fullerene and its derivatives as acceptors reinforced the performance of the OSCs, due to their high electron affinity and electron mobility. Blends of polymer/small molecule and fullerene groups were intensively studied. The limitation of exciton diffusion and charge separation were 
overcome. For example, blends of poly(phenylenevinylene) (PPV):PCBM with 1:4 weight ratio showed a 2.4\% PCE. In 2003, Hummelen's Group first reported OSCs based on combining P3HT with PCBM at a 1:4 weight ratio with a PCE of only $0.2 \%$ [10]. This result was improved to $3.5 \%$ in the same year by Padingger's Group as they blended $\mathrm{P} 3 \mathrm{HT}$ and $\mathrm{PCBM}$ at a 1:1 weight ratio and annealed the active layer at $75^{\circ} \mathrm{C}$ for 4 minutes [11]. Thereafter, systematic studies of varying the ratio of the blend constituents, the annealing temperature and duration, and the solvent-annealing duration were carried out by various groups, including those of C. J. Brabec, D. A. Carroll, A. J. Heeger, and Y. Yang. [12-18]. As a result, the PCE of a single-unit bulk heterojunction and tandem OSCs based on P3HT:PCBM of > 5\% [12-15, 18] and 6.4\%[19], respectively, were achieved. Recently, OSCs with PCE greater than 7\% were reported; these OSCs were fabricated with synthetized materials that are not commercially available [25]. Companies like Heliatek, Konarka Technologies, and Solarmer Energy Inc, all reported cells with PCE > 8\% early 2011[26, 27]. Mitsubishi Chemical reported to have a 9.2\% PCE in April, 2011[28]. Yang and coworkers announced a 10.6\% PCE this year, which is by far the highest reported value [29]. Molecular Solar Ltd., has achieved tandem OSCs with open-circuit voltage $\left(V_{\mathrm{oc}}\right)$ exceeding $4 \mathrm{~V}$ for the first time by using a cell with only 4 junctions (sub-cells) [30]. This is considered to be a significant breakthrough in OPV performance, as this high $V_{\text {oc }}$ will be sufficient to support a wide range of consumer electronics. The bulk heterojunction is still among the most promising structures of the OSCs today. Other emerging approaches are also very promising, such as quantum dots/organic hybrid OSCs featuring multi-electron-generation upon a single incident photon, although the present PCE of this type of device is still low $[31,32]$. 


\section{Brief introduction to $\pi$ conjugated materials}

Organic materials are composed of discrete molecules held together by weak van der Waals forces. Thus, organic solids are typically soft with low melting point and poor electrical conductivity. Due to the weak bonding between the molecules, the properties of the individual molecule are largely retained in the organic materials.
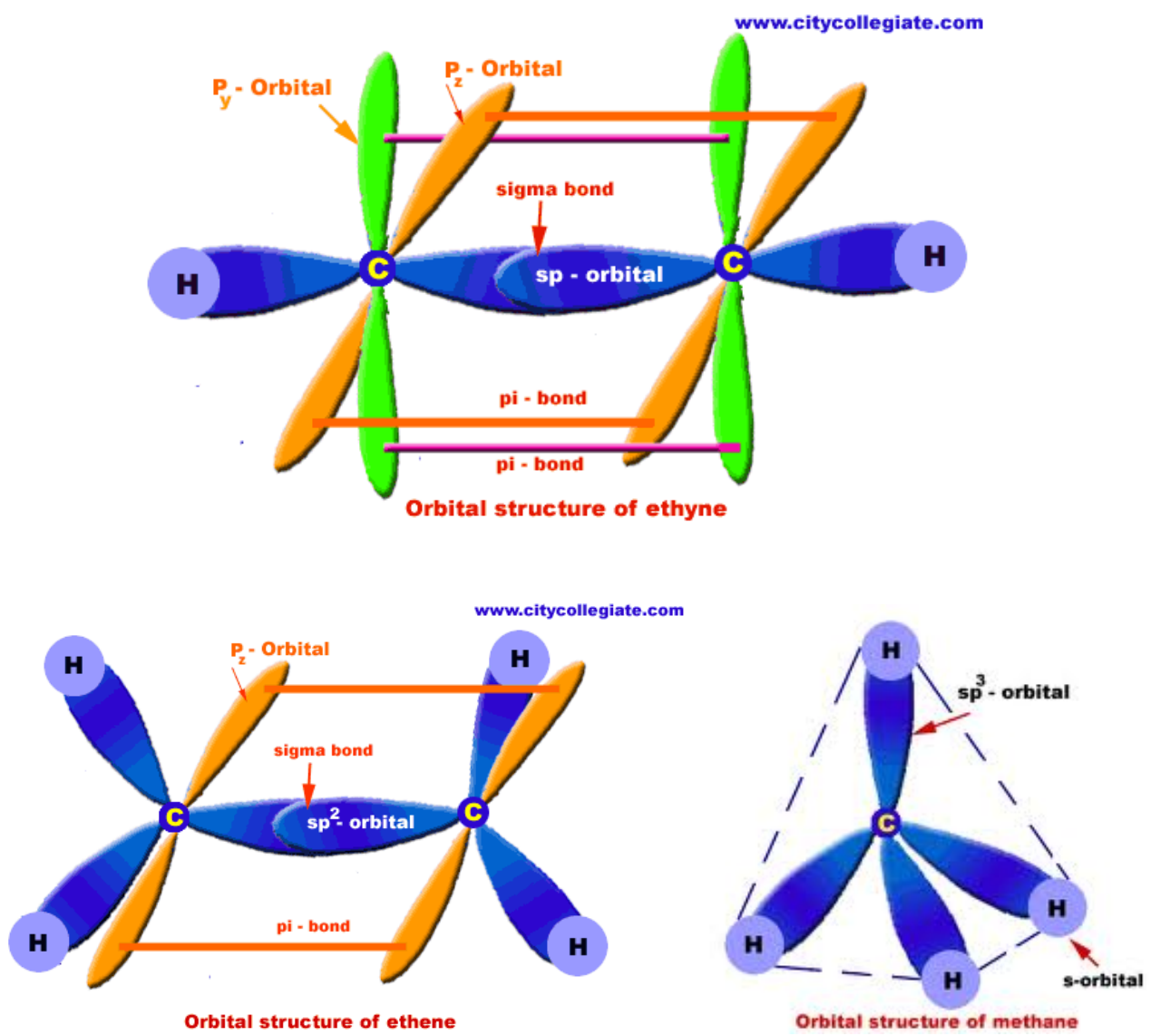

Fig. 1-1. Examples of $s p$ (in ethyne), $s p^{2}$ (in ethene) and $s p^{3}$ (in methane) hybridization.[33]

To study the electronic properties of an organic material, we should first look at the individual molecule itself. Since carbon is the main element of the organic materials, 
understanding the electronic configuration of carbon is crucial to get a general idea of the organic materials. The ground state of a single carbon atom has an electronic configuration as $1 s^{2} 2 s^{2} 2 p^{2}$. There are possibilities for the $2 s$ and $2 p$ orbitals to hybridize as sp (as in ethyne $\mathrm{C}_{2} \mathrm{H}_{2}$ ), $\mathrm{sp}^{2}$ (as in ethene $\mathrm{C}_{2} \mathrm{H}_{4}$ ) and $\mathrm{sp}^{3}$ (as in methane $\mathrm{CH}_{4}$ ), respectively, as shown in Fig. 1-1 [33]. The sp hybridization produces two hybrid orbitals at an angle of $180^{\circ}$, and the remaining $\mathrm{p}_{\mathrm{y}}$ and $\mathrm{p}_{\mathrm{z}}$ orbitals are perpendicular to the s-p orbital plane. As to $\mathrm{sp}^{2}$ hybridization, $\sigma$ bonds are formed between the carbon-carbon and carbon-hydrogen atoms, and the un-hybridized $\mathrm{p}_{\mathrm{z}}$ orbitals form a $\pi$ bond between two carbon atoms with $120^{\circ}$ bonding angles. For the $\mathrm{sp}^{3}$ hybridization, $\sigma$ bonds are formed between carbon and hydrogen atoms, with $109^{\circ}$ bonding angles.

For $\pi$ conjugated materials, which consist of alternating single and double bonds of carbon atoms, the hybrid orbital scheme provides a convenient model for understanding the molecular structure. For example, as shown in Fig. 1-2, $\mathrm{p}_{\mathrm{z}}$ orbitals 


$$
\begin{gathered}
C \quad \frac{\uparrow \downarrow}{1 s} \frac{\uparrow \downarrow}{2 s} \frac{\uparrow}{2 p_{x}} \frac{\uparrow}{2 p_{y}} \frac{}{2 p_{z}} \\
C_{s p^{2}}^{*} \frac{\uparrow \downarrow}{1 s} \frac{\uparrow}{s p^{2}} \frac{\uparrow}{s p^{2}} \frac{\uparrow}{s p^{2}} \frac{\uparrow}{p_{z}}
\end{gathered}
$$
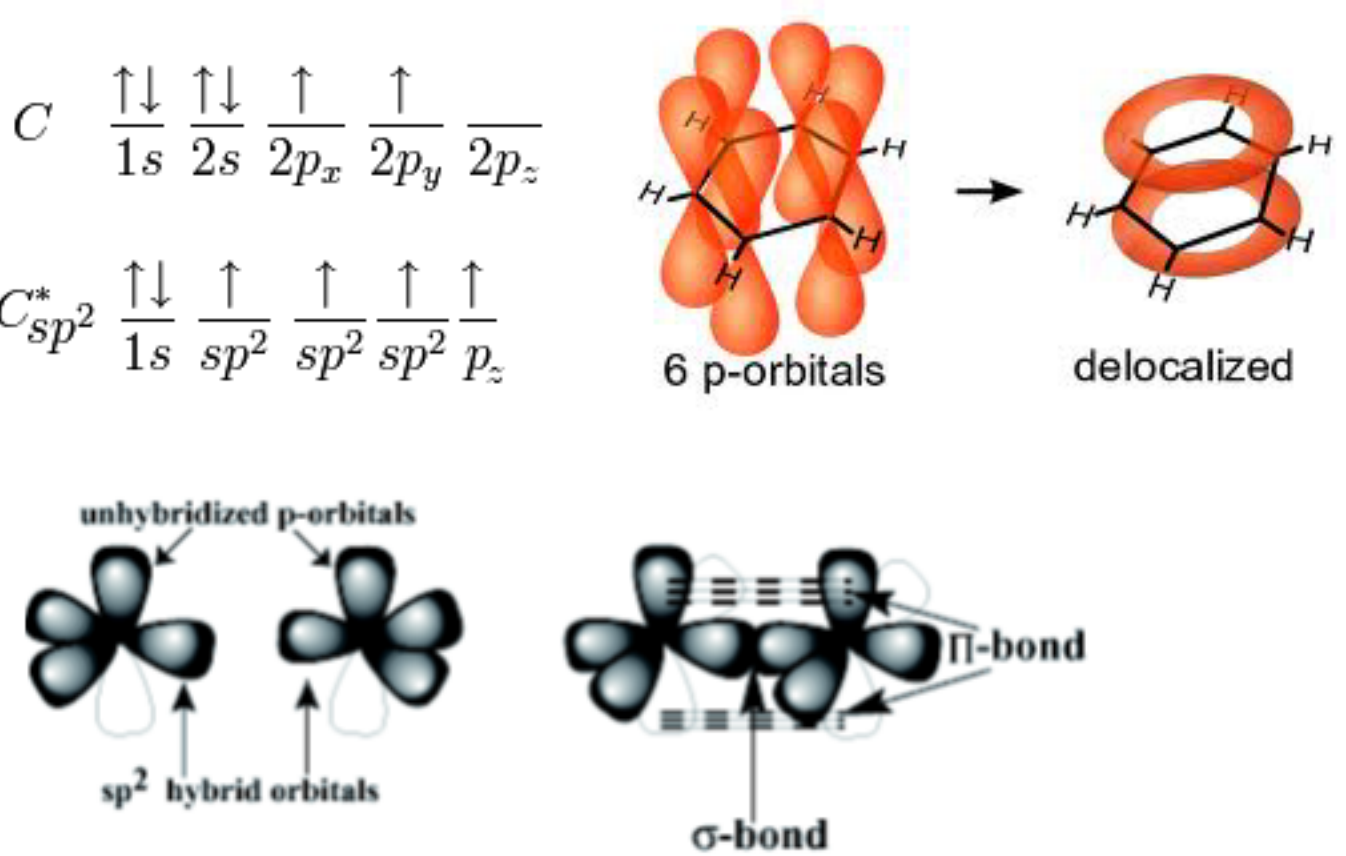

FIG. 1-2. The electronic configuration of the carbon atom's ground state, $s p^{2}$ hybridization, and the formation of $\pi$-bonds.

of each carbon atoms in the benzene ring overlap each other to form delocalized $\pi$ bonds, while the $\sigma$ bonds in the molecular plane between carbon/carbon or carbon/hydrogen are highly localized. As the delocalized electron density is present only above and below the plane of the carbon atoms in the $\pi$ bonds, it will be sufficient to focus on the properties of the $\pi$ electrons to study the electronic properties of the $\pi$ conjugated materials.

When it is extended to a macroscopic case for a many body system, the molecular orbital (MO) wavefunctions based on linear combinations of atomic orbitals (LCAO) are the most extensively used in MO theory. According to LCAO, for a molecule that has $\mathrm{N}$ carbon atoms, the wavefunction of a $\pi$-MO can be written as

$$
\psi_{\pi}=\sum_{l=1}^{N} a_{l} \phi_{l}
$$


where the $\square_{l}$ terms are atomic orbitals, and the $a_{l}$ terms are coefficients determined by minimizing the total energy of the system [34]. By the Pauli principle, each atomic orbital can accommodate two electrons of opposite spin, so the ground state wavefunction of the system is

$$
\psi_{\pi}(\text { ground })=\phi_{1} \alpha_{1} \phi_{1} \beta_{1} \ldots \phi_{N / 2} \alpha_{N / 2} \phi_{N / 2} \beta_{N / 2}
$$

where the $\square_{l}$ terms are functions of Eq. 1 and ordered according to increasing energy, $E_{l}>$ $E_{l-1} ; \alpha_{l}$ and $\beta_{l}$ denote electron spin functions for up and down orientation, respectively. When the molecule is in its ground state, the unfilled and filled MOs are called antibonding and bonding MOs, respectively [34].

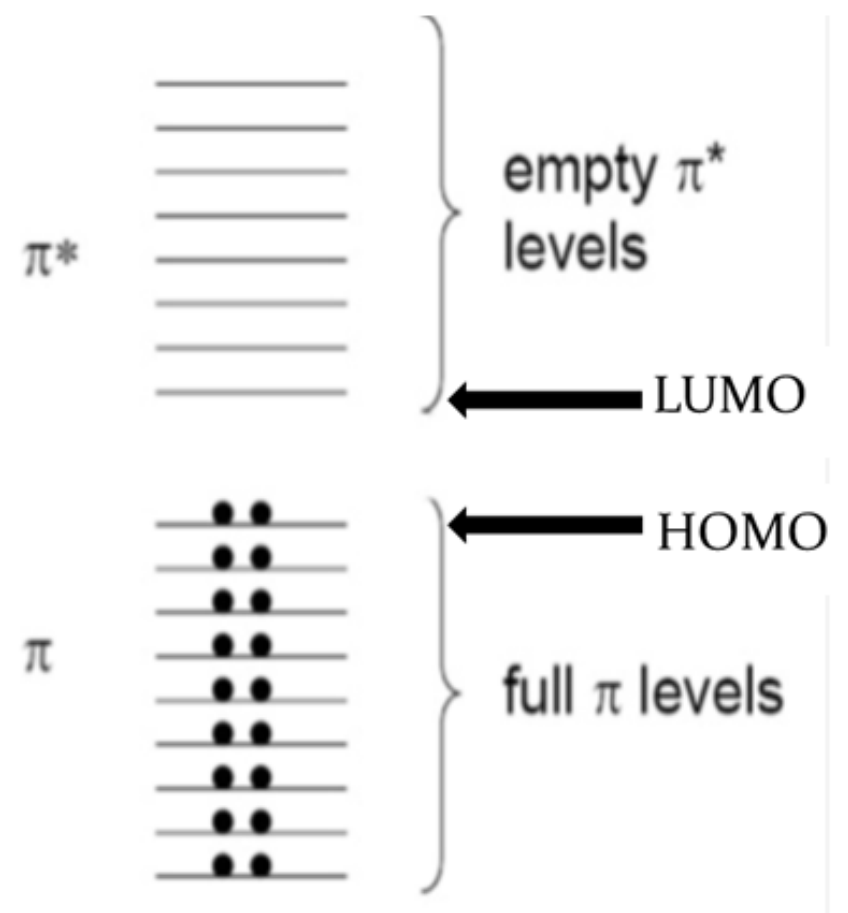

Fig. 1-3. The HOMO and LUMO levels of a molecule. 
The excited states are formed by exciting one of the bonding electrons to an unfilled anti-bonding MO. The lowest energy required for that is to excite an electron in the highest occupied molecular orbital (HOMO) to the lowest unoccupied molecular orbital

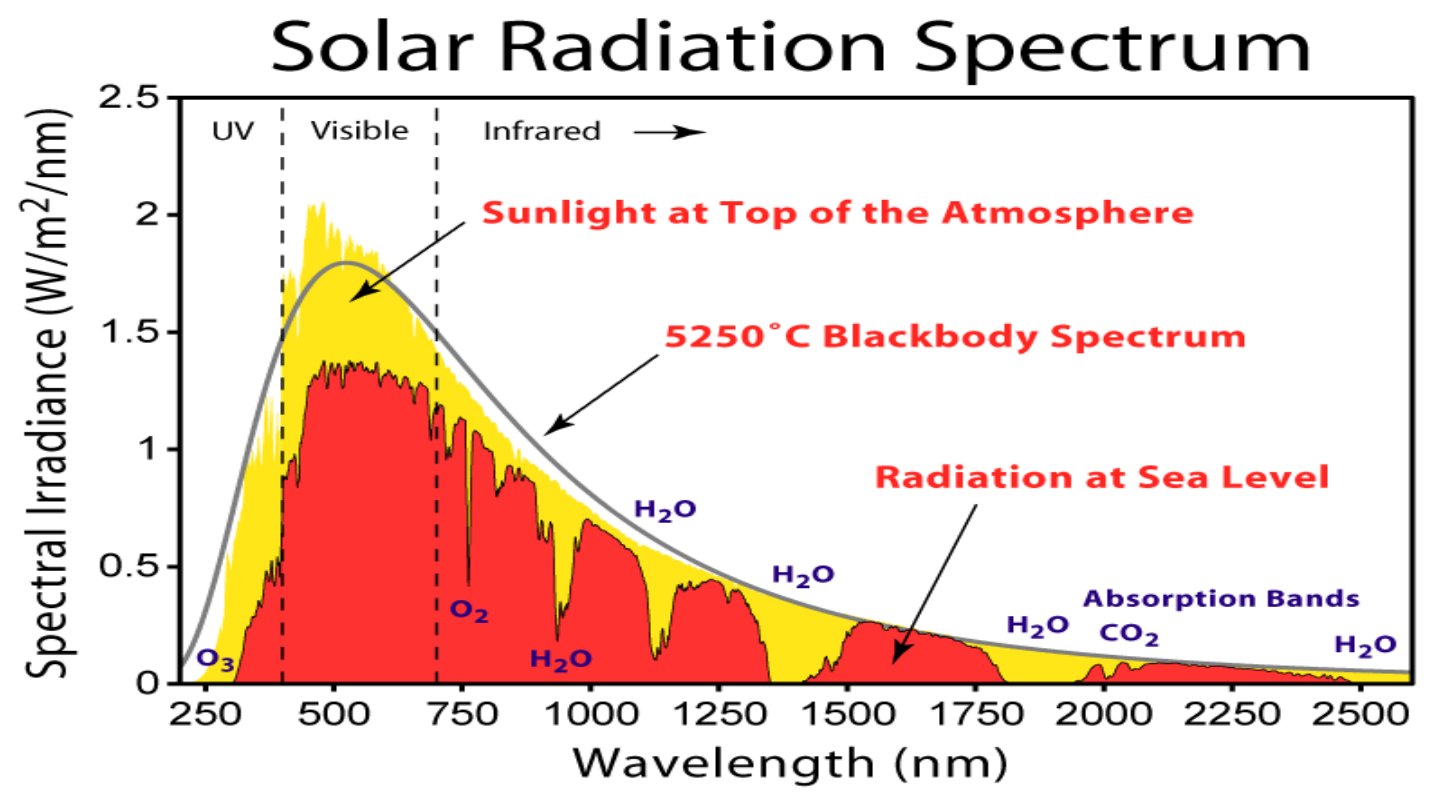

Fig. 1-4 American Society for Testing and Materials (ASTM) Terrestrial Reference Spectra for Photovoltaic Performance Evaluation (Air Mass 1.5) [35].

(LUMO). HOMO and LUMO shown in Fig. 1-3 are analogous to the valence and conduction bands of inorganic semiconductors. The energy difference between the HOMO and LUMO level is regarded as the band gap energy, $E_{\mathrm{g}}$, corresponding to the minimum photon energy $E_{\text {Photon }}$ in the optical transitions of absorption or radiative emission. The absorption of the $\pi$ conjugated materials used in OSCs should be within the solar spectrum regime, and low-band gap materials are preferred since $\sim 52 \%$ radiation energy from the sun lies in the infrared region as shown Fig. 1-4 [35]. Some $\pi$ conjugated materials, including polymers and small molecules, are shown in Fig. 1-5. 
There are greater varieties of donor materials compared to acceptor materials. In the solution processed blends, the PCBM is still the dominant acceptor material since Heeger and coworkers introduced it in 1995 [36]. It is crucial to develop new conjugated materials with higher charge carrier mobility and preferable HOMO-LUMO levels to obtain higher PCE.

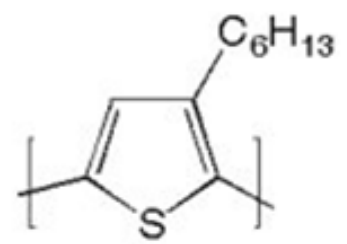

(1)

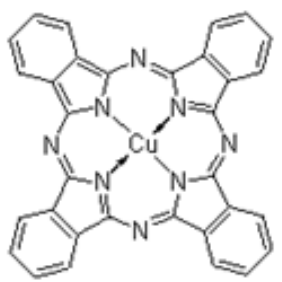

(3)
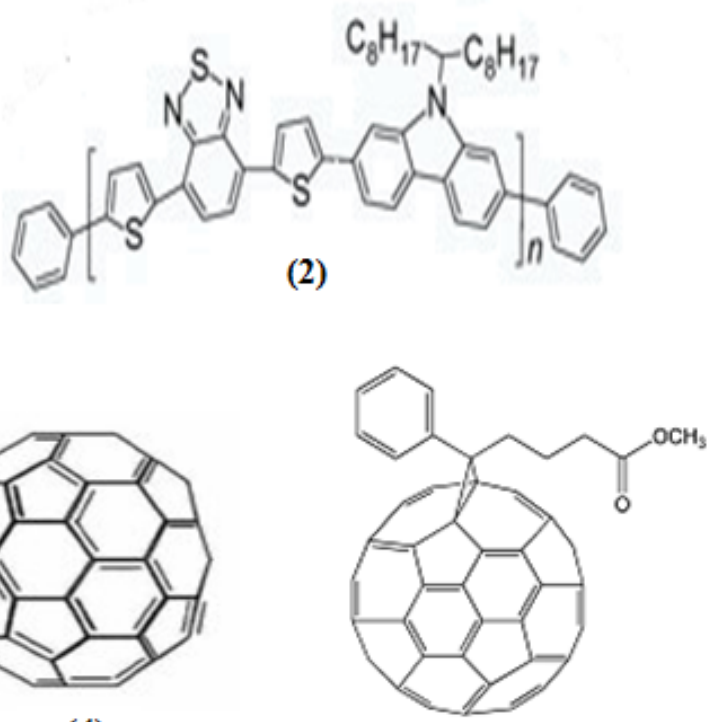

(5)

Fig. 1-5 Examples of $\pi$ conjugated materials used in OSCs (1)P3HT: Poly(3hexylthiophene-2,5-diyl); (2) PCDTBT: poly[N-900-hepta-decanyl-2,7-carbazole-alt-5,5(40,70-di-2-thienyl-20,10,30-benzothiadiazole; (3) CuPc: Copper Phthalocyanine; (4) C70: Fullerene C70; (5) PCBM:[6,6]-phenyl-C 61 -butyric acid methyl ester.

\section{Working principles and common parameters}

Working principle 


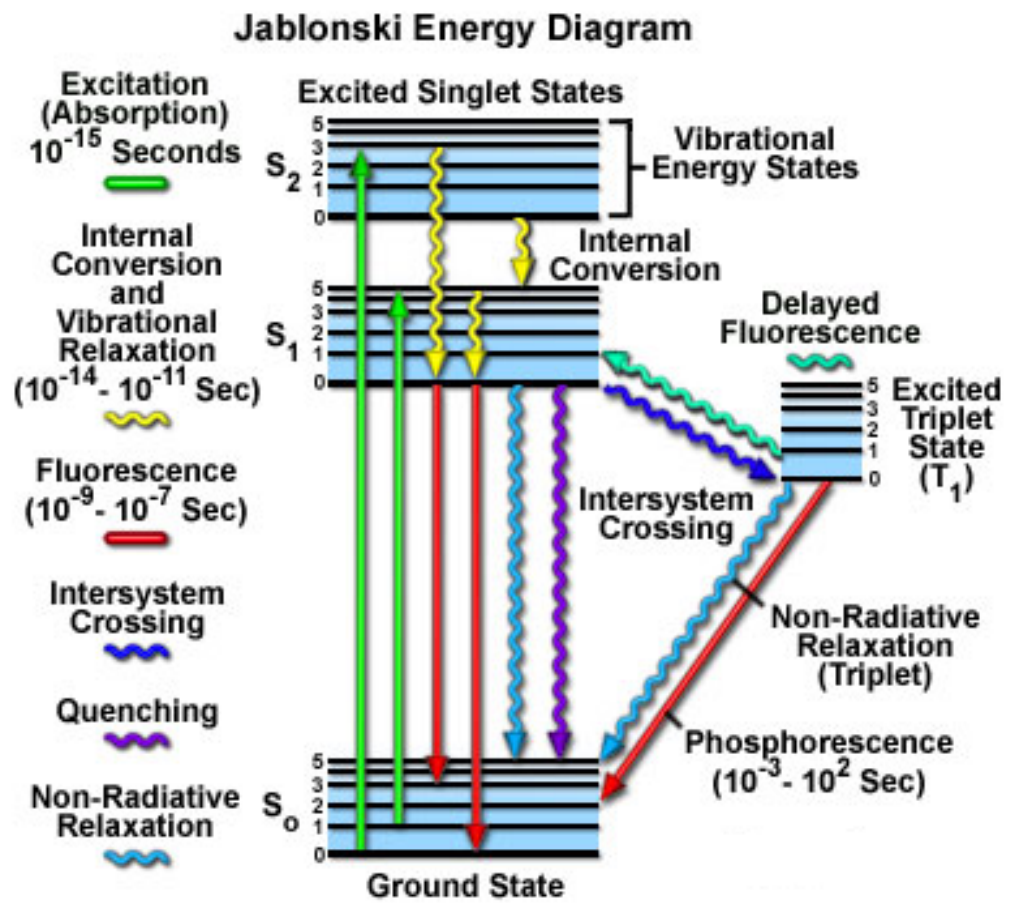

Fig. 1-6 Jablonski energy diagram [37].

As shown in Fig. 1-6 [37], absorption of light occurs in femtoseconds, the time necessary for the photon to travel a distance equivalent to its wavelength. The absorption of a photon of energy by an organic molecule occurs due to an interaction of the oscillating electric field vector of the light wave with electrons in the molecule, and can only occur with incident light of specific wavelengths. If the absorbed photon contains more energy than the optical band gap, the excess energy is usually converted into vibrational and rotational energy (thermalization). However, no absorption occurs when the photon has insufficient energy to promote a transition; this photon will be transmitted through that material. If a photon is absorbed, the excited molecule exists in the lowest excited singlet state for periods on the order of nanoseconds before finally relaxing to the ground state. During this relaxation period of the excitons (excited bound electron-hole 
pairs), several competing processes may take place: (1) fluorescence (2) intersystem crossing (3) non-radiatively decay. In OSCs, exciton dissociation is desired to generate charge carriers. So we generally use a donor-acceptor (D-A) pair to promote exciton dissociation and avoid the unwanted radiative decay or relaxation to generate heat. Even at the presence of D-A pairs, there are competing processes of charge transfer (desired) and energy transfer (not desired), as shown in Fig. 1-7 [38]. In contrast to electron transfer that produces free charge carriers, energy transfer typically produces a neutral, electronically excited state.

The actual photoelectrical processes within the OSCs under incident light are shown in Fig. 1-8, which is a simplified example for the planar heterojunction device. It is important to note that these energy diagrams are drawn for the isolated components and band bending due to Fermi level alignment is not included. When the incident photon is absorbed by the donor (or acceptor) material, the generated excitons will first diffuse to the D-A interface, and electron transfer as mentioned above will occur at the interface, namely charge transfer. The exciton diffusion length is typically at $10 \mathrm{~nm}$ level due to the short lifetime of the excitons $[39,40]$. If excitons need to cross a longer path than the exciton diffusion length, the excitons will recombine through radiative or non-radiative processes. Once the excitons reach the D-A interface, charge transfer occurs and the excitons dissociate; the probability of charge transfer approaches 100\% [39-41], as long as the energy offset between the LUMO of the donor and acceptor is no less than $0.3 \mathrm{eV}$ to provide sufficient electric field to assist in exciton dissociation. The required $\sim 0.3 \mathrm{eV}$ is believed to be 
(a) Electron Transfer

Reduction

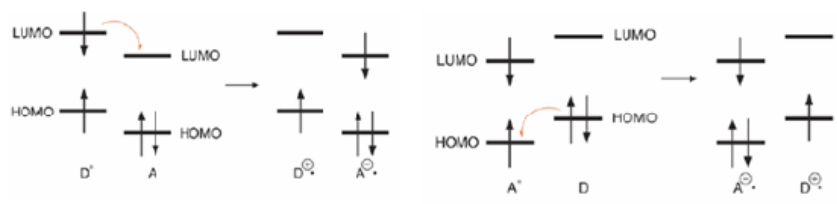

Marcus Electron Transfer Theory

Rate of photoinduced electron transfer $(k)$ is defined by $M O(A)-M O(D)$

(thermodynamic driving force, $\Delta G^{\circ}$ ) and

reorganization energy $(\lambda)$

$$
\begin{aligned}
& k=\kappa\left(\frac{k_{3} T}{h}\right) \mathrm{e}^{\left(-\Delta G^{\ddagger} / R T\right)} \\
& \Delta G^{\ddagger}=\frac{\lambda}{4}\left[1+\frac{\left(\Delta G^{\circ}\right)^{2}}{\lambda}\right]
\end{aligned}
$$

(b) Radiative (trivial) energy transfer

(no electronic interaction between $D^{*}$ and $A$ )

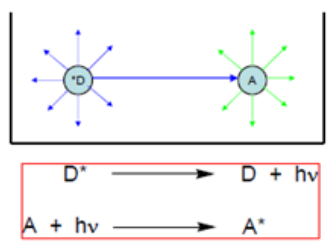

Requirements:

high PLQY of $D$ (quantum yield)

high concentration of $[A]$

large $\varepsilon_{\mathrm{A}}$ (extinction coefficient at the $\lambda_{\mathrm{em}}$ )

\section{(c) Collisional (Dexter) energy transfer}
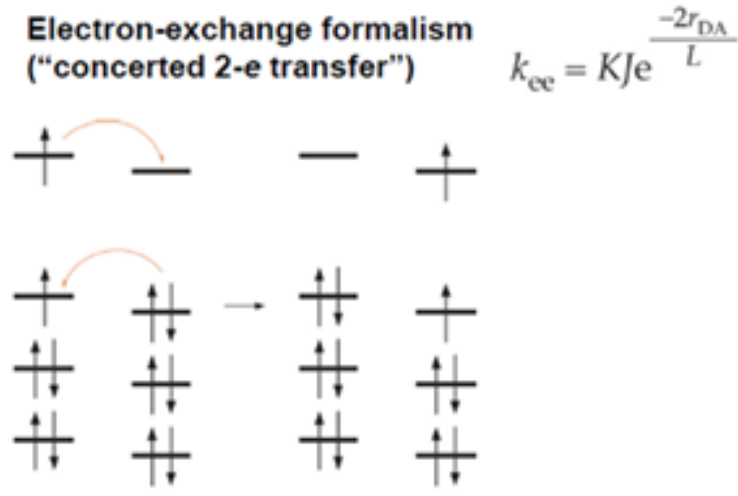

${ }^{3} \mathrm{~A}$ " $\mathrm{O} \longrightarrow \mathrm{A} \rightarrow{ }^{2} \mathrm{D}$

effective distance typically $<1 \mathrm{~nm}$ (d) Dipole-dipole coupling ('Förster energy transfer)

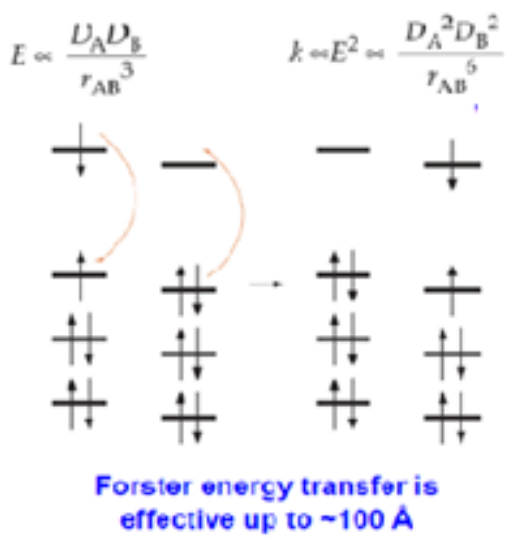

Interaction of two transition dipoles

Fig. 1-7 Possible electron transfer (a); and energy transfer (b), (c), and (d) between a donor-acceptor pair [38].

associated with the exciton binding energy [41-47]. After charge transfer, holes and electrons will be transported to the corresponding electrodes and be collected under short circuit condition. 


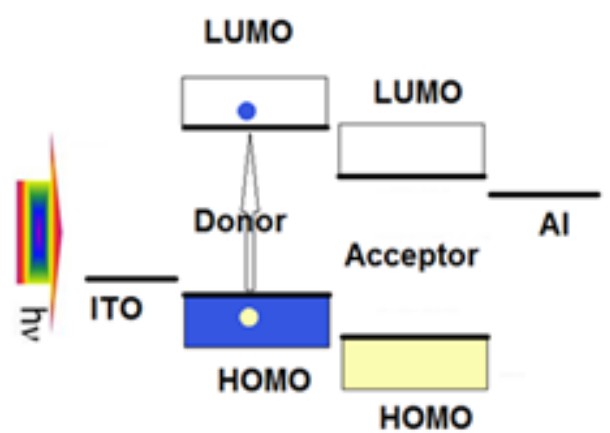

(a) Absorption

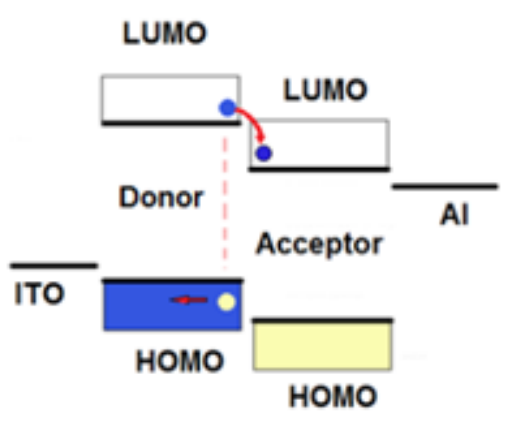

(c) Charge Transfer

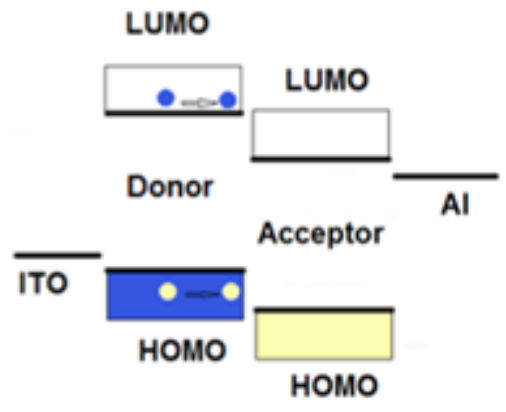

(b) Exciton Diffusion

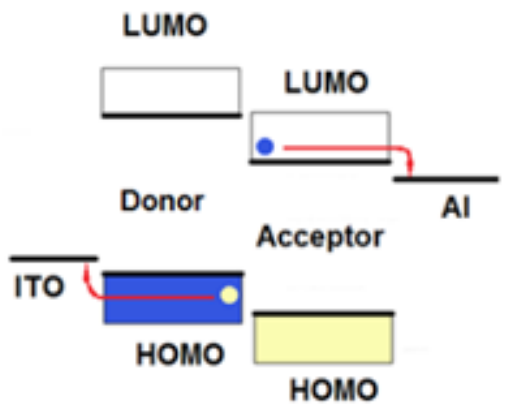

(d) Charge transport and collection

Fig. 1-8 The photoelectric processes inside a planar heterojunction.

The equivalent circuit of a solar cell fundamentally comprises a current source, a rectifying component modeled as a diode, together with a parallel resistance $\left(R_{\text {sh }}\right)$ and a series resistance $\left(R_{\mathrm{S}}\right)$, as shown in Fig. 1-9. In the ideal case, $R_{\mathrm{S}}$ vanishes and $R_{\mathrm{sh}}$ becomes enormous. Practically, the $R_{\mathrm{S}}$ value is not zero due to the resistance of the organic material, the contact resistance of the organic/electrode, and the resistance of the electrodes. $R_{\mathrm{sh}}$ is a finite number owing to leakage current and recombination within the device. 
The Equivalent Circuit Diagram J-V Curve

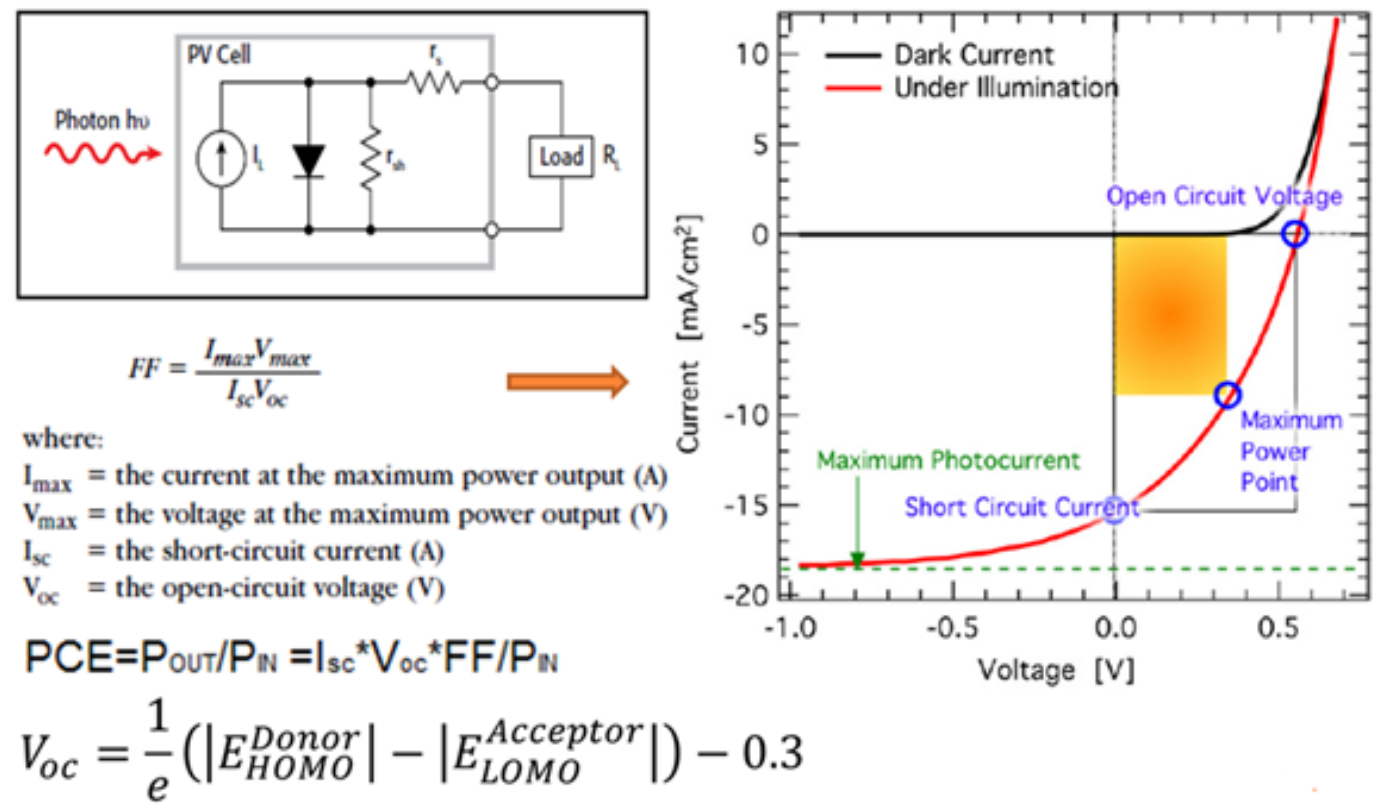

Fig. 1-9 The equivalent circuit diagram and the J-V characteristics under light and dark.

The common parameters of an OSC can be derived from $J-V$ characteristics, such as $V_{\mathrm{oc}}, J_{\mathrm{sc}}$ (short circuit current density), FF, PCE, $R_{\mathrm{s}}$ and $R_{\mathrm{sh}}$, as shown in Fig. 1-9. $V_{\mathrm{oc}}$ is the voltage across the solar cell when the cell current is zero. $J_{\mathrm{sc}}$ is the cell current density when there is no applied bias to the cell. FF describes the actual utilization of the theoretical maximum output power; it is defined as:

$F F=\frac{P_{\max }}{V_{o c} \times J_{s c}}=\frac{V_{\max } \times J_{\max }}{V_{o c} \times J_{s c}}$

where $V_{\max }$ and $J_{\max }$ are the corresponding voltage and current at the actual maximum output power $\left(P_{\max }\right)[48]$.

The PCE is the ratio of the output power and input optical power [43]. 
$P C E=\frac{V_{o c} \times J_{s c} \times F F}{\text { Input Optical Power }}$

The standard input optical power is $100 \mathrm{~mW} / \mathrm{cm}^{2}$ under simulated air Mass 1.5 (AM1.5) solar spectrum.

From the equivalent circuit shown in Fig. 1-9,

$I=-I_{\text {photocurrent }}+I_{\text {diode }}+I_{\text {shunt }}$

$=-I_{p h}+I_{0}\left(\exp \left[\frac{V+I R_{s}}{n V_{t h}}\right]-1\right)+\left(V+I R_{s}\right) / R_{s h}$

where $I_{0}$ is the reverse saturation current, $n$ is the diode ideality factor, and $V_{\text {th }}=k_{\mathrm{B}} T / \mathrm{q}$ is the thermal voltage $[49,50]$. When under dark, $I_{\mathrm{ph}} \sim 0$, typically $R_{\mathrm{sh}} \gg R_{\mathrm{s}}$ and Eq. (1.6) becomes,

$I=I_{0}\left(\exp \left[\frac{V+I R_{S}}{n V_{t h}}\right]-1\right)+V / R_{s h}$

From Eq. (1.7), we can derive

$\frac{d I}{d V}=\frac{I_{0}}{n V_{t h}} \exp \left[\frac{V+I R_{S}}{n V_{t h}}\right]+\frac{1}{R_{s h}}$

From the dark $J-V$ characteristics, $I$ approaches zero when $V=0$. Substitute $I \sim 0$ and $V=$ 0 into Eq. (1.8), we get the expression for the shunt resistance:

$\frac{1}{R_{s h}}=\left.\frac{d I}{d V}\right|_{V=0}$

That is, the inverse of the slope of the dark $I-V$ characteristics at $V=0$ is the shunt resistance [51]. 
We can also derive the expression for $R_{\mathrm{S}}$ through Eq. (1.7). When $I=0$, and assuming $V / R_{\mathrm{sh}} \sim 0$ (as $R_{\mathrm{sh}}$ is typically a large number and $V<1 \mathrm{~V}$ ), Eq. (1.7) becomes

$I_{0}\left(\exp \left[\frac{V+I R_{S}}{n V_{t h}}\right]-1\right)=0$, that is $V+I R_{S}=0 \rightarrow R_{S}=-\left.\frac{d V}{d I}\right|_{I=0}$

i.e., the inverse value of the slope at $I=0$ is indicative of the series resistance.

By fitting the dark $I-V$ curve, information about the ideality factor $n$, the reverse saturation current of the diode and the theoretical value of $V_{\mathrm{oc}}$ can also be derived. However, this method is only valid for good OSCs with low $R_{\mathrm{s}}$ and high $R_{\mathrm{sh}}$. To get more accurate parameters of OSCs, we need to fit Eq. (1.6) directly. Different approaches were made to better serve this purpose [49-56].

The origin of the $V_{\mathrm{oc}}$ of OSCs is still not fully understood. It is generally believed that the $V_{\mathrm{oc}}$ will depend on whether the contacts between the organic and both electrodes are Ohmic contacts. If the contacts are Ohmic, the $V_{\text {oc }}$ depends on the difference between the HOMO level of the donor and the LUMO level of the acceptor (termed the effective band gap), and typically expressed as

$$
\begin{aligned}
& V_{o c}=L U M O^{A}-H O M O^{D}-k T \ln \left(\frac{N_{L} N_{H}}{n p}\right) \\
& =L U M O^{A}-H O M O^{D}-0.3 \ldots 0.7 \mathrm{eV}
\end{aligned}
$$

where $N_{\mathrm{L}}$ and $N_{\mathrm{H}}$ are the density of states at the LUMO of acceptor and the HOMO of the donor, respectively [39-41]; $n$ and $p$ are the density of hole and electron, respectively. 
The $0.3-0.7 \mathrm{eV}$ is material dependent. If the contacts are not Ohmic, the $V_{\text {oc }}$ tends to approach the work function difference between the two electrodes.

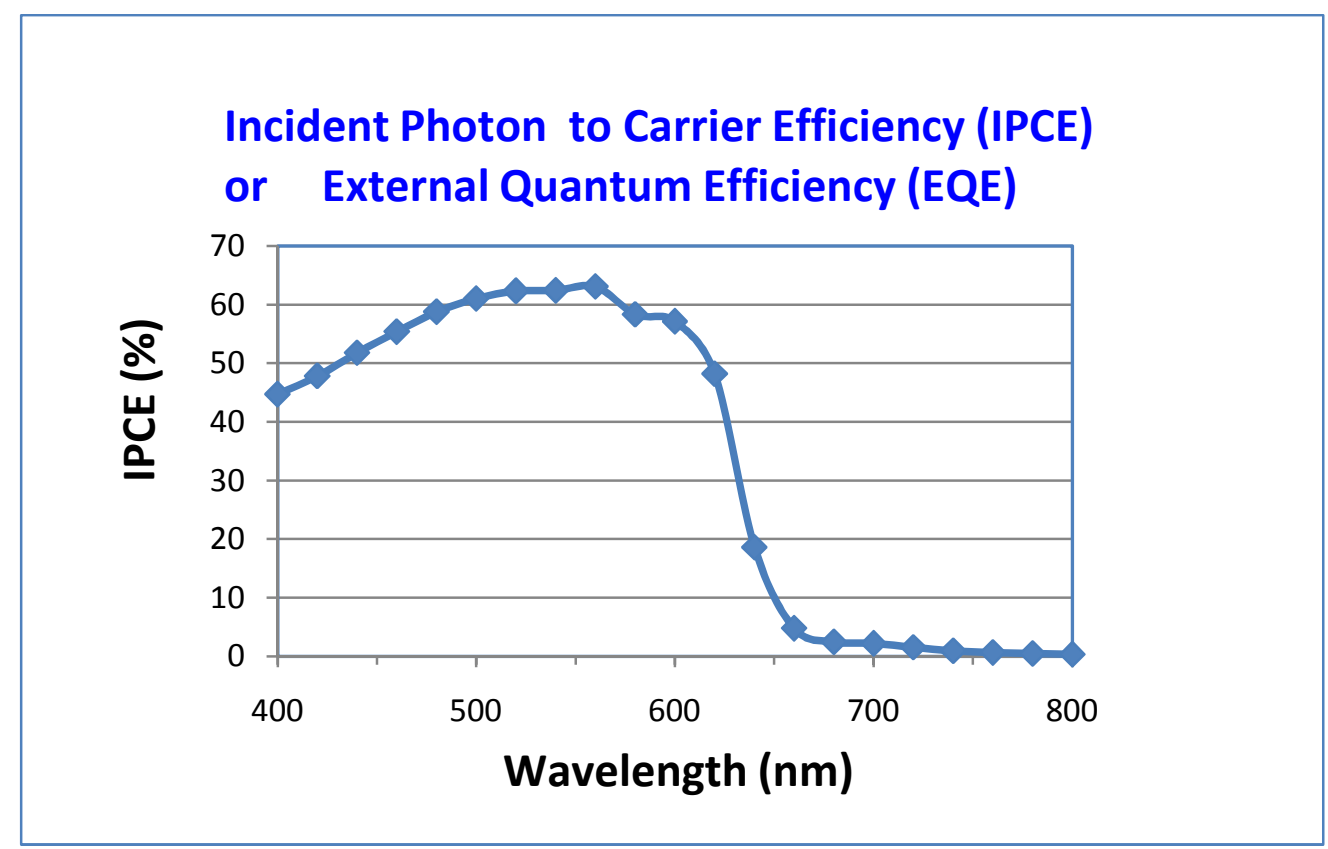

Fig. 1-10 The IPCE spectra of an inverted P3HT:PCBM solar cell.

Another important parameter is the external quantum efficiency (EQE) shown in Fig. 1-10, also called the incident photon to carrier efficiency (IPCE):

$E Q E=I P C E=\eta_{Q E}=\frac{h c I_{s c}(\lambda)}{q \lambda P(\lambda)}$

where $h$ is Plank's constant, $c$ is the speed of light, $I_{\mathrm{sc}}$ is the wavelength dependent short circuit current, $q$ is the charge of an electron, and $P$ is the wavelength dependent light intensity. Knowing EQE and the absorption, the internal quantum efficiency can be calculated. The internal quantum efficiency is defined as the number of carriers collected per number of photons absorbed by the active layer, which excludes optical losses due to reflection, transmission and absorption by non-active layers [57]. 


\section{How to improve PCE}

From Eq. (1.5), enhancement in $V_{\mathrm{oc}}, J_{\mathrm{sc}}$, and FF will lead to improved PCE. Fig. 1-11 shows a design rule for choosing proper donor LUMO level and band gap to achieve optimal PCE in Donor/PCBM-based OSCs. The donor material should preferably have a low band gap and the LUMO level should approach the LUMO of the PCBM [58, 59]. By tuning the electronic levels of the D-A system or introducing interfacial dipoles between organic and electrodes, the $V_{\mathrm{oc}}$ can be enlarged. By increasing the absorption, charge generation, charge transport and charge collection, the $J_{\mathrm{sc}}$ can be increased. There are different approaches to enhance the absorption. The plasmonic effect of metal nanoparticles was found to enhance the absorption. Optical designs such as a light concentrator, gratings, and back scattering were used to trap more light. Optimal structure design such as tandem OSCs can also improve the absorption by allowing a thicker layer and better matching to the solar spectrum. Structure designs that provide more D-A contact area will increase charge generation. Annealing the organic layer typically improves the charge carrier mobility, together with ensuring charge carrier percolating path to the electrodes by proper structure design. Modifying the organic/electrode interfaces will help charge collection. With proper structure design and favorable organic/electrode interfaces, the FF can be optimized. 


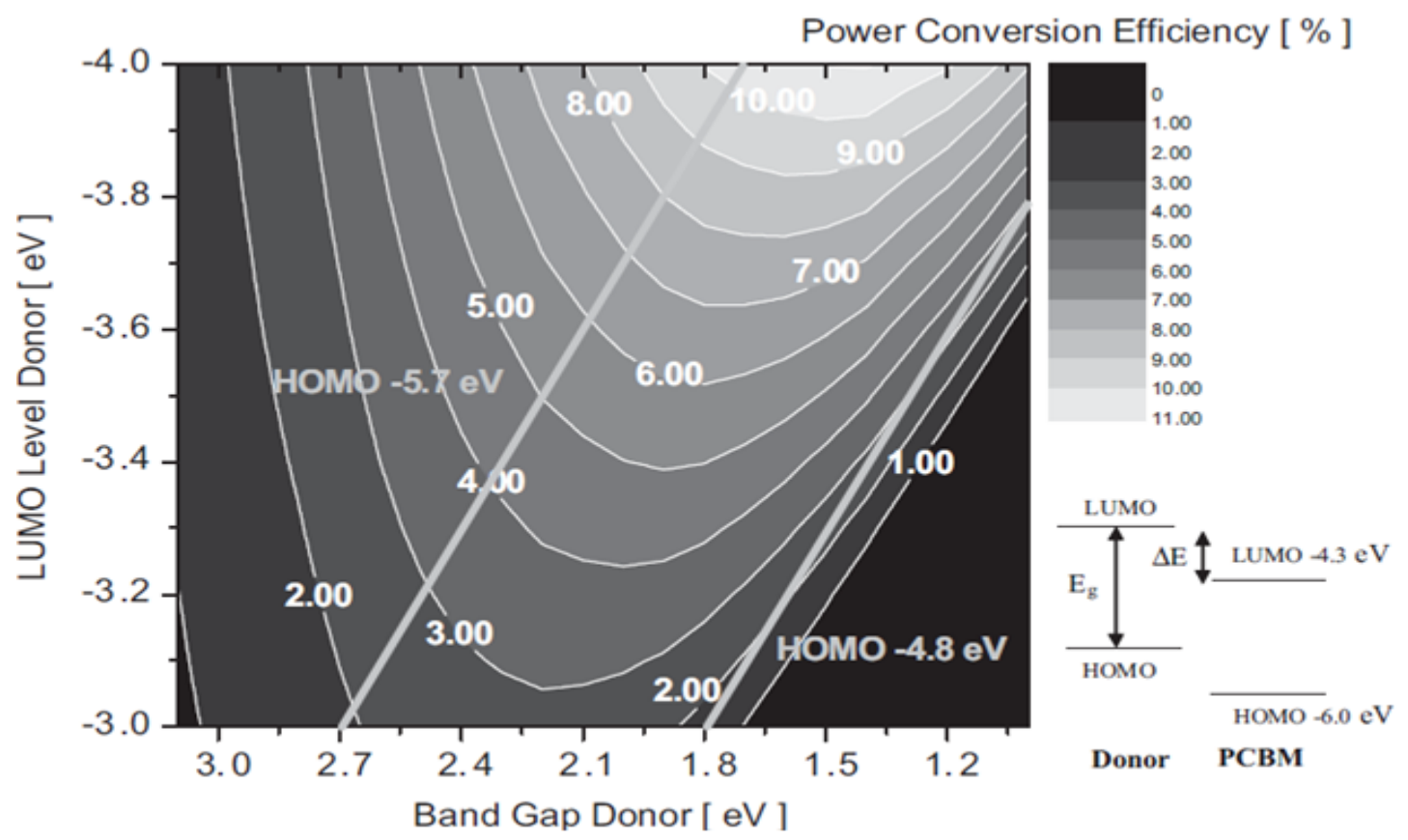

Markus C. Scharber, ${ }^{\star}$ David Mühlbacher, Markus Koppe, Patrick Denk, Christoph Waldauf,Alan J. Heeger, and Christoph J. Brabec,Adv. Mater. 2006, 18, 789 - 794

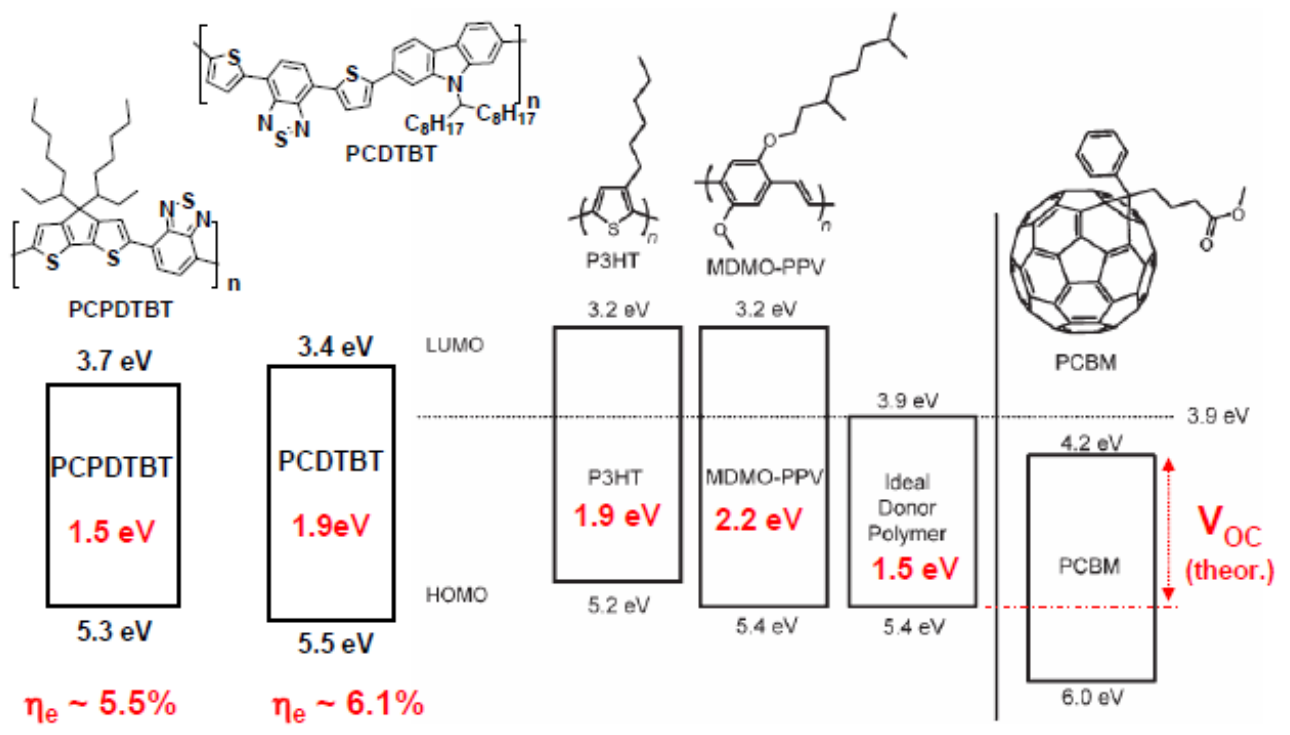

Fig. 1-11. The relation between PCE and donor LUMO level/donor band gap for cells with PCBM as the acceptor, and examples of some reported Donor/PCBM pairs.[58] 


\section{OSCs Structure}

\section{Single layer}

As the exciton binding energy in organics is often $\geq 0.3 \mathrm{eV}$, the photoinduced excitons must dissociate before free charge carriers are available. In a single layer device, the organic layer is sandwiched directly between two electrodes, thus the possible exciton dissociation sites are limited. The dissociation typically occurs at the organic /electrode interface, defects, and impurities. Moreover, the exciton diffusion length is only $\sim 10 \mathrm{~nm}$; to enable exciton diffusion to the interface, a very thin organic layer is needed. The restricted thickness of the organic layer limits the absorption of light, thus, the number of generated excitons. Due to the insufficient absorption and carrier generation, the PCE of a single layer OSC is typically well below $0.1 \%$ [3].

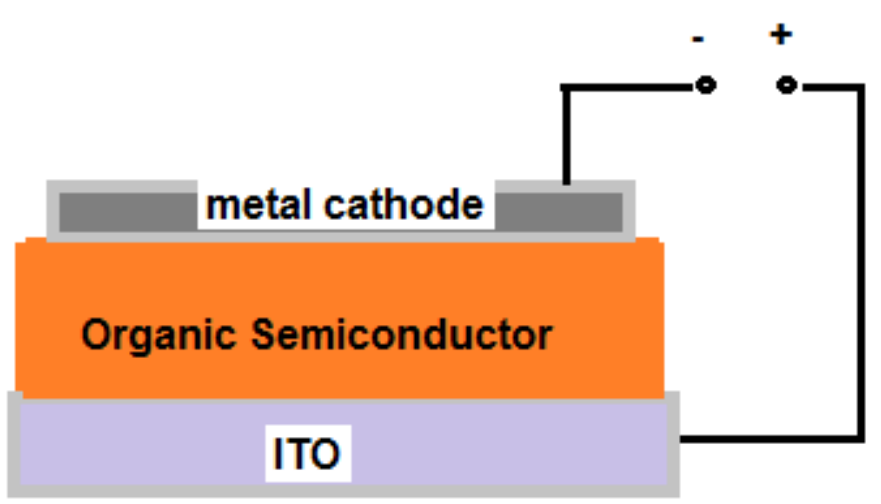

Fig. 1-12 Structure of a single layer device

\section{Planar heterojunction}

Since C. W. Tang created a donor and acceptor heterojuction structure in 1986, the charge separation is greatly improved. In this type of planar heterojunction OSCs, the active layer is sandwiched between two electrodes, and comprises two different organic 
materials with energy level offsets at the HOMO and LUMO levels. This energy offset helps exciton dissociation at the donor-acceptor interface. The probability of charge transfer at the D-A-interface approaches $100 \%$ due to the fact that the recombination process is significantly slower than the charge separation. With this structure, PCE > 1\% was realized. Nevertheless, the thickness of the organic layer is still limited by the exciton diffusion length, and the donor/acceptor layer is only a few tens of nanometers thick. By increasing the thickness to improve absorption, more excitons will be generated, however there will be excess excitons that cannot diffuse to the D-A interface. Since only the D-A interface provides effective dissociation sites, those excess excitons will not contribute to the short-circuit current $\left(I_{\mathrm{SC}}\right)$. Furthermore, a thick organic layer will hinder the charge carrier ability to reach the corresponding electrode owing to the low carrier mobility in organic materials $[3,38]$.

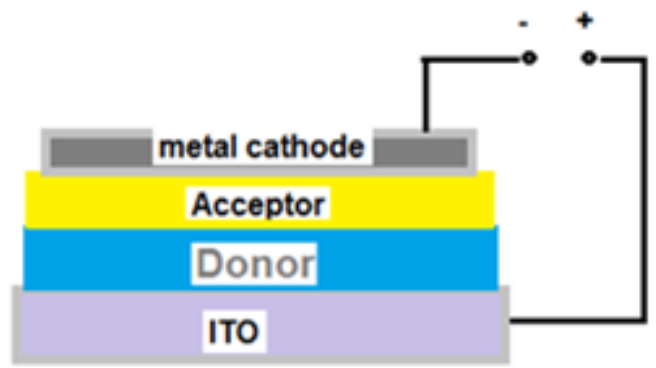

(a)

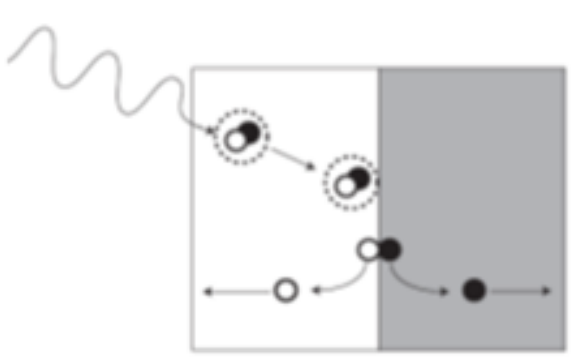

(b)F. Yang, et. al. Nature Materials 4(2005)

Fig. 1-13 Structure of planar heterojunction and the photoelectric process inside the organic. 


\section{Bulk heterojunction}

In the bulk heterojunction, the donor and acceptor materials are blended together in the active layer, so that the contact area between them is greatly enlarged [57]. Thus, the excitons may easily find their way to the D-A interface, and effectively dissociate into charge carriers. Thanks to the short diffusion path, thicker layers $(\sim 100-200 \mathrm{~nm})$ can be prepared to harvest more light. Now the main
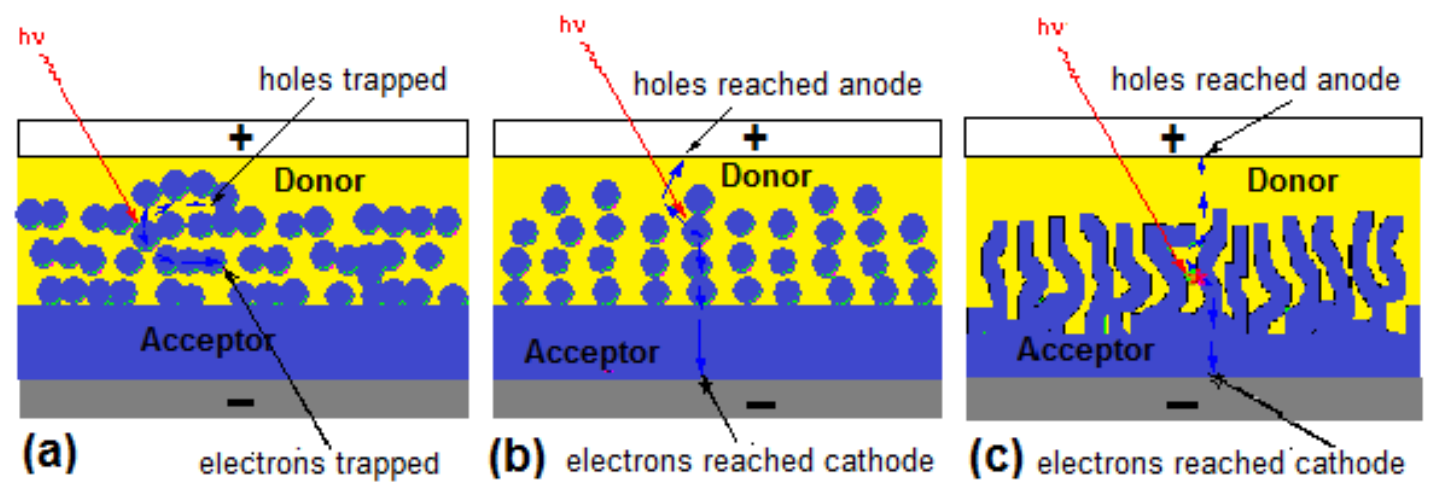

Fig. 1-14 Possible charge transport inside the bulk heterojuction.(a)Interpenetrating network with no percolating path and many traps;(b)Interpenetrating network with percolating path;(c)Segregated interpenetrating network.

challenge is the charge carrier transport inside the bulk heterojunction. Since the nanomorphology of the bulk heterojunction is randomly formed, some isolated islands of donor or acceptor may form inside the bulk as shown in Fig. 1-14(a). That is, donor materials could be surrounded by acceptor materials or the other way around. This network is not favorable for charge transport, and the generated charge carriers will eventually be trapped and result in a very low $I_{\mathrm{SC}}$. Forrest et al. proposed a concept of "percolating" in their $\mathrm{CuPc} / \mathrm{C}_{60}$-based small molecular OSCs [60-62], where the charge carriers can transport continuously from one molecule to another as long as the 
intermediate layer does not exceed exciton diffusion lengths as shown in Fig. 1-14(b). Fig. 1-14(c) exhibits an ideal phase segregated bulk heterojunction, which is difficult to realize in practice. The stability and efficiency of this type of solar cell depend greatly on the nano-morphology of the active layer. The initial formation of the phase segregation in the active layer is crucial to obtain high PCE. The performance of the cells also depends greatly on the solvent used for making the mixture solution. The segregation should provide enough interfaces for charge separation and allow paths for charge carriers to the corresponding electrodes, with sufficient donor (acceptor) material in direct contact with the anode (cathode). Under long-term operation the donor and acceptor tend to segregate and partially block available paths of the charge carriers to the contacts, which eventually greatly reduces the $J_{\mathrm{sc}}$ and FF. Hence, finding ways to control the nano-morphology of the active layer is crucial.

\section{Molecular heterojunction}

Based on the concept of the bulk heterojunction, double-cable polymer and diblock copolymers were synthetized to get more-precise control of the morphology of the active layer for achieving better cell performance [63-66]. One approach is the covalent linking of $\mathrm{C}_{60}$ to a hole-transport conjugated polymer backbone (see Fig. 1-15). Although the covalently linked polymer- $\mathrm{C}_{60}$ chains provide reasonable $J_{\mathrm{sc}}$, they tend to phase separate and cluster, which limits charge separation and collection. To get bi-continuous phase separation and large interfacial area, double-cable polymer and diblock copolymer were synthetized, as shown in Fig. 1-9. In the double-cable polymer, for example, $\mathrm{C}_{60}$ is

connected to the donor polymer backbone; it forms charge separation and ordered 
domains, which offer great potential for high PCE in the future, though many critical design parameters need to be evaluated [67]. For instance, the fullerene concentration must reach the percolation threshold to ensure efficient electron transport. The selfassembled diblock copolymers will also form ordered domains similar to the doublecable, and their HOMO and LUMO level can be tuned [68].
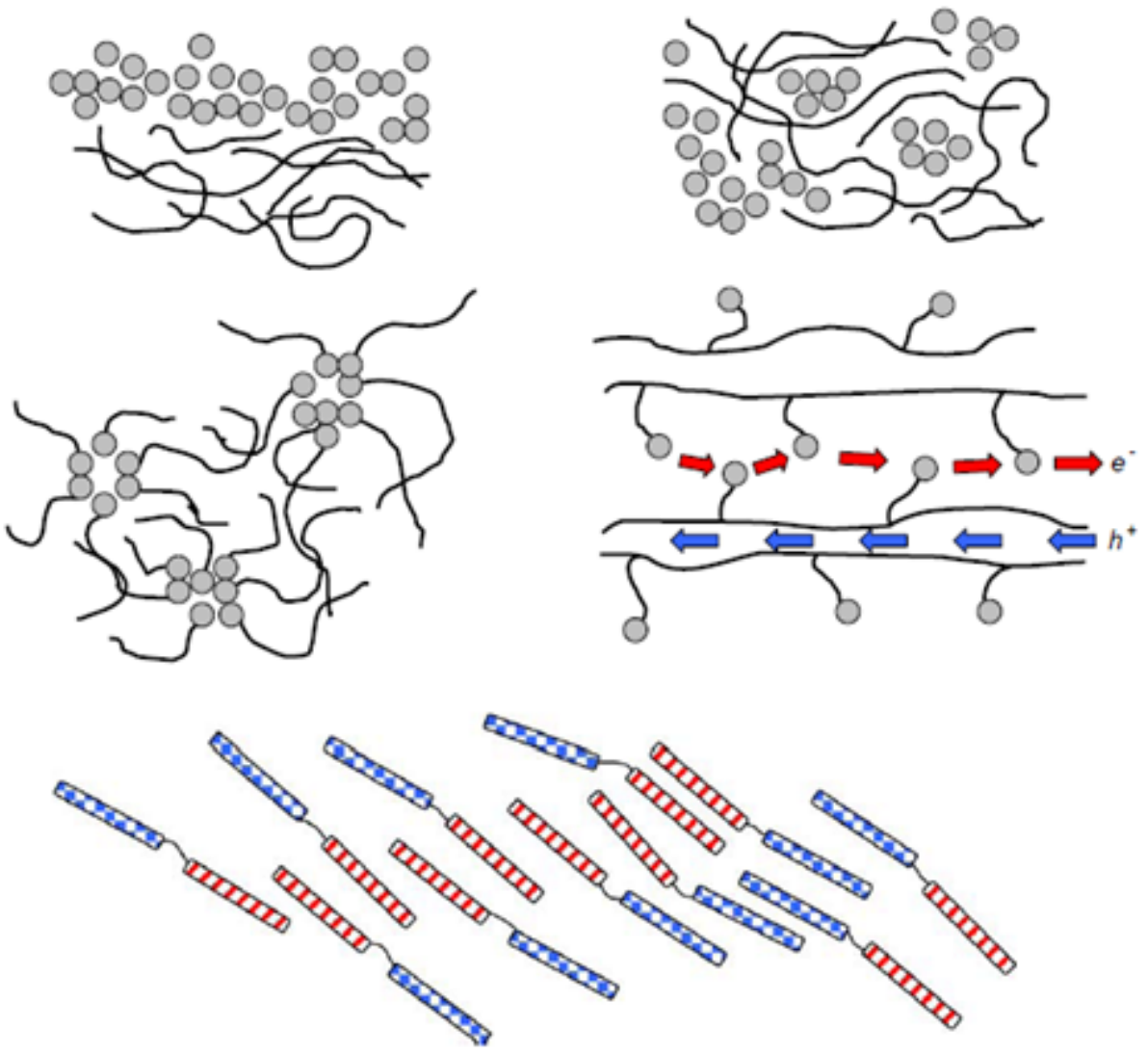

Fig. 1-15 Different morphologies of heterojunction cells. Top, left: Two-layered structure of fullerenes and polymer chains. Top, right: dispersed heterojunction. Middle, left: fullerenes with polymer chains attached. Middle, right: self-assembled layered structure of double-cable polymers. Bottom: self-assembled layered structure of diblock copolymers. The layered structure of double-cable polymers and diblock copolymers are expected to facilitate efficient electron and hole transport [68]. 


\section{Tandem OSCS}

For a single unit cell, the absorption is limited due to sub-band transmission and thermalization of hot charge carriers, which leads to the $\sim 33.7 \%$ Shockley-Queisser thermodynamic limit of the PCE. Tandem structures (shown in Fig. 1-16) can outperform this limit, reducing both types of losses [69]. De Vos proposed that by using two subcells with complementary absorption spectra the theoretical limitation increases to $42 \%$, and to $49 \%$ for 3 sub-cells [70]. A more recent paper suggested that an optimistic PCE for a single unit organic solar cell is $\sim 15.2 \%$ and for a tandem device $\sim 23.2 \%$ [71]. Since the absorption spectra of organic materials are often not sufficiently broad [69], unlike the continuum absorption of some inorganic materials, the tandem structure becomes more crucial for OSCs, where complementary absorption bands are often utilized. This approach results in reduced thermalization losses. The subcells can be connected either in series or parallel. Almost all reported tandem OSCs are of series connection as to provide a higher $V_{\mathrm{OC}}$. The intermediate layer should be an effective recombination center for holes coming from one subcell 

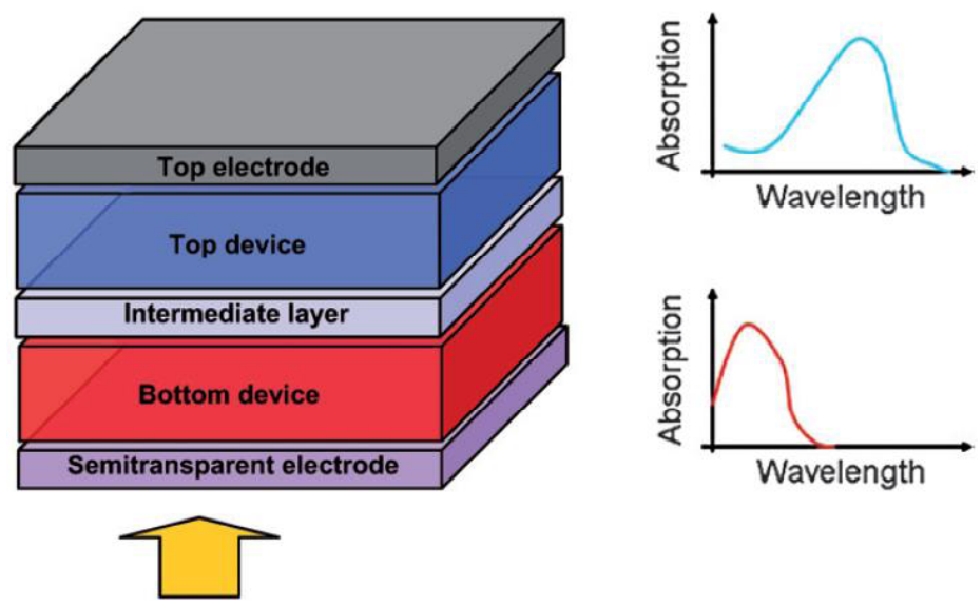

Fig. 1-16 Schematic representation of an organic tandem device comprised of two sub cells having different, complimentary absorption spectra [69].

and electrons from the other, which is achieved by aligning the quasi-Fermi levels of the donor and acceptor of the respective sub-cells.

\section{Fabrication methods}

There are two types of OPVs based on the materials used for their fabrication:-polymer OSCs and small molecular OSCs.

Due to their large molecular weight, polymer OSCs are limited to solution processing, such as spin-coating, ink-jet printing and roll to roll processing, among which spincoating is the common method in research laboratories. An illustration of spin-coating is shown in Fig. 1-18(1). This method is easy to use, and the constituents' ratio can be accurately controlled if more than one material is involved. But the formation of the films 
derived from spin-coating is affected by factors like the vapor pressure of the solvent, air flow and temperature. To ensure reproducibility, those factors must be controlled [72].

Small molecular OSCs are mainly processed by thermal evaporation, which typically includes a high vacuum chamber $\left(\sim 10^{-6}-10^{-7}\right.$ torr $)$, thermal evaporation sources, thickness monitors and substrate holders, as shown in Fig. 1-18(2). The organic material is heated by a resistance connected to a DC power supply, and the vapors pass through a shadow mask to produce a uniform layer on the substrate. The evaporation rate is normally restricted to $<0.2 \mathrm{~nm} / \mathrm{s}$ to ensure the quality of the film, while thickness can be controlled precisely at the $\sim 0.1 \mathrm{~nm}$ level. Currently, to avoid the relatively high cost of thermal evaporation, small molecules are increasingly designed for solution processing and this approach resulted in PCE of up to $~ 6.7 \%$. [73-76]
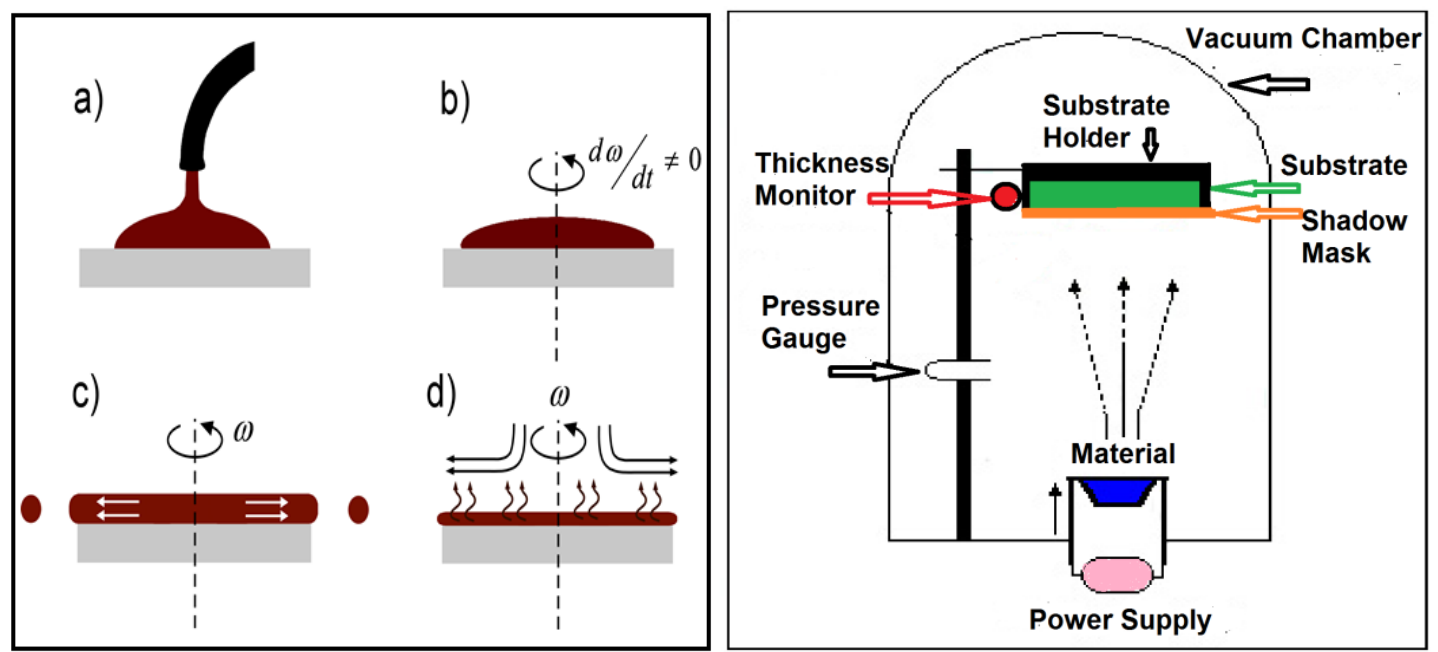

FIG. 1-18 (1) Spin-coating process; (2) Thermal evaporation system.

\section{Applications of OSCs}


Compared to inorganic solar cells, OSCs have advantages such as (1) tunable absorption with abundant materials, including synthesis of new materials; (2) compatibility with solution processing, which enables low cost and large area manufacturing; (3) flexibility and transparency of various materials; (4) easy integration with other organic electronic devices, such as OLEDs and OFETs to further minimize the size of the devices. However, the relatively low efficiency, short lifetime and reproducibility issues still limit the applications of the OSCs.

Currently, the most promising applications for OSCs, as suggested by Konarka, are (1) personal mobile phone charger; (2) small home electronics and mobile electronics attachment; (3) Building-integrated photovoltaics (BIPV), such as building's exterior wall, window, or blinder, and (4) power generation. OSCs are expected to be soon utilized for mobile electronic device charger and for military use. Nowadays, commercialized OSCs are emerging in some outdoor applications, such as building materials for windows and walls and portable electronic chargers. The first commercially available OSC products were bags integrated with Power Plastic from Konarka technologies-in 2010. Mitsubishi Chemical also plans to commercialize their $\sim 10 \%$ PCE cells as early as next year. Companies such as BASF, Solarmer Energy Inc., and Helitak $\mathrm{GmbH}$, as well as academic research groups have been developing materials and device technologies for OSCs application. We can expect a bright future for OSCs with better synthetized materials, device structures and better understanding of the device physics. 


\section{References}

[1] A. Pochettino, Acad. Lincei Rend. 15 (1906) 355.

[2] M. Volmer, Ann. Physik. 40 (1913) 775.

[3] H. Spanggaard, F. C. Krebs, Sol. Energy Mater. Sol. Cells 83 (2004) 125.

[4] D. Kearns, M. J. Calvin, Chem. Phys. 29 (1958) 950.

[5] B. R. Weinberger, M. Akhtar, S. C. Gau, Synth. Met. 4 (1982) 187.

[6] S. Glenis, G. Tourillon, F. Garnier, Thin Solid Films 139 (1986) 221.

[7] C. W. Tang, Appl. Phys. Lett. 48 (1986) 183.

[8] M. Hiramoto, H. Fukusumi, M. Yokoyama, Appl. Phys. Lett. 58 (1991) 1062.

[9]G. Yu, K. Pakbaz, A. J. Heeger, Appl. Phys. Lett., 64 (1994) 3422.

[10] D. Chirvase, Z. Chiguvare. M. Knipper, J. Parisi, V. Dyakonov, J. C. Hummelen, Synth. Met. 138 (2003) 299.

[11] F. Padinger, R. S. Rittberger, N. S. Sariciftci, Adv. Func. Mat.13 (2003) 85.

[12] R. Gaudiana, C. J. Brabec, Nat. Photon. 2 (2008) 287.

[13] M. Reyes, K. Kim, D. L. Carroll, Appl. Phys. Lett. 87 (2005) 083506.

[14] J. Y. Kim, S. H. Kim, H.-H. Lee, K. Lee, W. Ma, X. Gong, A. J. Heeger, Adv. Mater. 18 (2006) 572.

[15] J. Peet, J. Y. Kim, N. E. Coates, W. L. Ma, D. Moses, A. J. Heeger, G. C. Bazan, Nat. Mater. 6 (2007) 497.

[16] G. Li, V. Shrotriya, Y. Yao, Y. Yang, J. Appl. Phys. 94 (2005) 043704.

[17] G. Li, V. Shrotriya, J. Huang, T. Mariarty, K. Emery, Y. Yang, Nat. Mater. 4 (2005) 864. 
[18] M. A. Green, K. Emery, Y. Hishikawa, W. Warta, Prog. Photovolt. Res. Appl. 16 (2008) 61.

[19] J. Y. Kim, K. Lee, N. E. Coates, D. Moses, T.-Q. Nguyen, M. Dante, A. J. Heeger, Science 317 (2007) 222.

[20] H. Y. Chen, J. Hou, S. Zhang, Y. Liang, G. Yang, Y. Yang, L. Yu, Y. Wu, G. Li, Nat. Photon. 3 (2009) 649.

[21] Y. Y. Liang, Z. Xu, J. B. Xia, S. T. Tsai, Y. Wu, G. Li, C. Ray, L. P. Yu, Adv. Mater. 22 (2010) E135.

[22] T.Y. Chu; J. Lu; S. Beaupré; Y. Zhang; J.R. Pouliot; S. Wakim; J. Zhou; M. Leclerc; Z. Li; J. Ding; Y. Tao, J. Am. Chem. Soc. 133 (2011) 4250.

[23] H. Zhou, L. Yang, A. C. Stuart, S. C. Price, S. Liu, W. You, Angew. Chem. Int. Ed. $50(2011) 2995$.

[24] Z. He, C. Zhong, X. Huang, W.Y. Wong, H. Wu, L. Chen, S. Su, Y. Cao, Adv. Mater. 23 (2011) 4636.

[25] L. Dou, J. You, J. Yang, C.C. Chen, Y. He, S. Murase, T. Moriarty, K. Emery, G. Li, and Y. Yang, Nature Photon. 6 (2012) 180.

[26] http://content.yudu.com/A1th2v/EOAUGSEP11/resources/16.htm [27] http://www.konarka.com/index.php/company/our-history/ [28]http://techcrunch.com/2011/04/06/mitsubishi-chemical-to-commercialize-printable$\underline{\text { solar-cells-next-year/ }}$ [29] www.nrel.gov/ncpv/images/efficiency_chart.jpg [30] http://www2.warwick.ac.uk/newsandevents/pressreleases/new_record_voltage/ 
[31] J. Seo, W. J. Kim, S. J. Kim, K. Lee, A. N. Cartwright, P. N. Prasad, Appl. Phys. Lett. 94 (2009) 133302.

[32] Y. Zhou, F. S. Riehle, Y. Yuan, H.-F. Schleiermacher, M. Niggemann, Appl. Phys. Lett. 96 (2010) 013304.

[33] http://www.citycollegiate.com/hybridization2.html

[34] Electronic processes in organic crystals and polymers, 2nd ed., edited by M. Pope and C. E. Swenberg (Oxford University Press, New York, 1999)

[35] http://en.wikipedia.org/wiki/Sunlight

[36] G. Yu, J. Gao, J. C. Hummelen, F. Wudl, A. J. Heeger, Science 270 (1995) 1789.

[37] http://www.olympusmicro.com/primer/java/jablonski/jabintro/

[38] Organic materials for solar cells, Dimitrii Perepichka.

[39] P. Peumans, A. Yakimov, S. R. Forrest, J. Appl. Phys. 93 (2003) 3693.

[40] L.-M. Chen, Z. Hong, G. Li, Y. Yang, Adv. Mater. 21 (2009) 1434.

[41] M. Riede, T. Mueller, W. Tress, R. Schueppel, K. Leo, Nanotechnology 19 (2008) 424001.

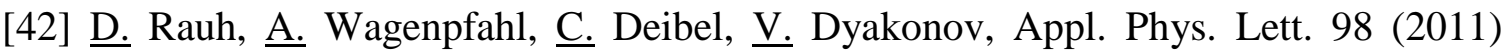
133301.

[43] W"urfel, Physics of Solar Cells: From Principles to New Concepts (Weinheim: Wiley-VCH) (2004)

[44] L. J. A. Koster, V. D. Mihailetchi, R. Ramaker, P. W. M. Blom, Appl. Phys. Lett. 86 (2005) 123509.

[45] M. F. Lo, T. W. Ng, T. Z. Liu, V. A. L. Roy, S. L. Lai, M. K. Fung, C. S. Lee, S. T. Lee, Appl. Phys. Lett. 96 (2010) 113303. 
[46] C. J. Brabec, A. Cravino, D. Meissner, N. S. Sariciftci, T. Fromherz, M. T. Rispens, L. Sanchez, J. C. Hummelen, Adv. Funct. Mater. 11 (2001) 5.

[47] K. Vandewal, K. Tvingstedt, A. Gadisa, O. Inganäs, J. V. Manca, Nat. Mater. 8 (2009) 904.

[48] H. Hoppe, N. S. Sariciftci, J. Mater. Res.19 (2004) 7.

[49] K. Bouzidi, M. Chaggar, A. Bouhemadou, Sol. Energy Mater. Sol. Cells 91 (2007) 1647.

[50] A. Jain, A. Kapoor, Sol. Energy Mater. Sol. Cells 85 (2005) 391.

[51] M. Chegaar, G. Azzouzi, P. Mialhe, Solid State Electron. 50 (2006) 1234.

[52] N. Nehaoua, Y. Chergui, D. E. Mekki, Vacuum, 84 (2009) 326.

[53] P. Schilinsky, C. Waldauf, J. Hauch, C. J. Brabec, J. Appl. Phys. 95 (2004) 2816.

[54] J. C. Nolasco, R. Cabré, J. Ferré-Borrull, L. F. Marsal, M. Estrada, J. Pallarès, J. Appl. Phys. 107 (2010) 044505.

[55] N. Li, B. E. Lassiter, R. R. Lunt, G. Wei, S. R. Forrest, Appl. Phys. Lett. 94 (2009) 023307.

[56] J. D. Servaites, M. A. Ratner, T. J. Marks, Appl. Phys. Lett. 95 (2009) 163302.

[57] T. L. Benanti, D. Venkataraman, Photosynth. Res. 87 (2006) 73.

[58] M. C. Scharber, D. Mühlbacher, M. Koppe, P. Denk, C. Waldauf, A. J. Heeger, C. J. Brabec, Adv. Mater. 18 (2006) 789.

[59] G. Dennler, M. C. Scharber, T. Ameri, P. Denk, K. Forberich, C. Waldauf, C. J. Brabec, Adv. Mater. 20 (2008) 579.

[60] J. Xue, B. P. Rand, S. Uchida, S. R. Forrest, J. Appl. Phys. 98 (2005) 124903. 
[61] J. Xue, B. P. Rand, S. Uchida, S. R. Forrest, Adv. Mater. 17 (2005) 66.

[62] J. Xue, S. Uchida, B. P. Rand, S. R. Forrest, Appl. Phys. Lett. 85 (2004) 5757.

[63] A. Cravino, N. S. Sariciftci, J. Mater. Chem. 12 (2002) 1931.

[64] A. Cravino, N. S. Sariciftci, Nat. Mater. 6 (2003) 360.

[65] F. Zhang, M. Svensson, M. R. Andersson, M. Maggini, S. Bucella, E. Menna, O. Inganas, Adv.Mater. 13 (2001) 1871.

[66] A. M. Ramos, M. T. Rispens, J. K. J. van Duren, J. C. Hummelen, R. A. J. Janssen, J. Am. Chem.Soc. 123 (2001) 6714.

[67] A. Cravino, G. Zerza, M. Maggini, S. Bucella, M. Svensson, M. R. Andersson, H. Neugebauer, C. J. Brabec, N. S. Sariciftci, Monatsh. Chem. 134 (2003) 519.

[68] F. C. Krebs, M. Jorgensen, Polym. Bull. 50 (2003) 359.

[69] T. Ameri, G. Dennler, C. Lungenschmied, C. J. Brabec, Energy Environ. Sci. 2 (2009) 347.

[70] A. De Vos, J. Phys. D: Appl. Phys. 13 (1980) 839.

[71] B. Minnaert, M. Burgelman. Prog. Photovolt: Res. Appl. 15 (2007) 741.

[72] F. C. Krebs, Sol. Energy Mater. Sol. Cells 93 (2009) 394.

[73] X. D. Dang, A. B. Tamayo, J. Seo, C. V. Hoven, B. Walker, and T. Q. Nguyen, Adv. Funct. Mater. 20 (2010) 3314.

[74] Y. Liu, X. Wan, F. Wang, J. Zhou, G. Long, J. Tian, J. You, Y. Yang, Y. Chen, Adv. Energy Mater. 1 (2011) 771.

[75] X. Xiao, G. Wei , S. Wang, J. D. Zimmerman , C. K. Renshaw , M. E. Thompson , and S. R. Forrest, Adv. Mater. 24 (2012) 1956. 
[76] Y. Sun, G. C.Welch,W. L. Leong, C. J. Takacs, G. C. Bazan, and A. J. Heeger, Nature Mater. 11 (2012) 44. 


\section{Chapter 3. Introduction to Organic Light-Emitting Diodes (OLEDs)}

\section{Brief history of OLED technology}

The first electroluminescence (EL) in organic materials was discovered in the early 1950s and after that research on organic electroluminescent materials and devices expanded [1-13]. Initially, the electrical conductivity of organic materials used was very poor and the device structure of organic light-emitting diodes (OLEDs) was very simple, consisting of only a single organic layer between two electrodes, the anode and the cathode. Due to these limiting factors, the efficiency of the early OLEDs was quiet low, i.e., $<0.1 \%$ [14]. The chemical structure of anthracene, which is the lighting-emitting material of Ref. 14, is shown in Fig. 2-1.

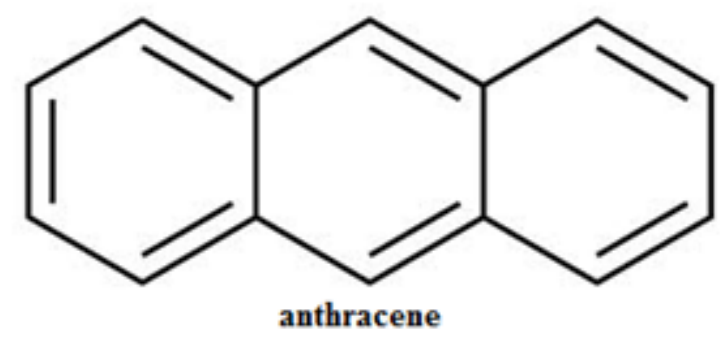

Fig. 2-1. Chemical structure of anthracene [14].

The first important breakthrough in OLED technology was in the 1980s. Tang and Van Slyke reported the first thin film organic heterostructure small molecule OLEDs (SMOLEDs) in 1987 [15]. Those OLEDs were fabricated from thin amorphous and polycrystalline layers deposited by vacuum thermal evaporation (VTE). They contained a novel two-layer structure with a separate thin hole transport layer (N,N'-diphenyl-N,N'- 
bis (3-methylphenyl) 1,1'-biphenyl-4, 4' diamine (TPD)) and a thin electron transport layer/light emitting layer (tris(8-hydroxyquinoline) aluminum $\left.\left(\mathrm{Alq}_{3}\right)\right)$, so the charge carrier recombination and light emission occurred, away from the quenching metal cathode. The reduction in thickness of the organic layers to $\sim 100 \mathrm{~nm}$ drastically reduced the required operation voltage $V$, and a brightness exceeding $1000 \mathrm{Cd} / \mathrm{m}^{2}$ at $V \sim 10 \mathrm{~V}$ was achieved for the first time. The quantum efficiency of those OLEDs was improved to $1 \%$, approximately $\sim 100$ fold compared to the early OLEDs [14-15]. The device structure and chemical structures of the materials used are shown in Fig. 2-2 [15].
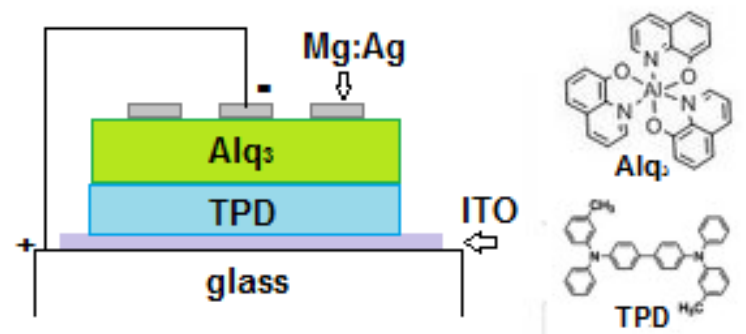

Fig. 2-2. Device structure of the first heterojunction OLEDs and molecular structures of TPD and $\mathrm{Alq}_{3}$.

The largely improved OLED efficiency attracted worldwide industry and academia attention, and stimulated explosive development of this field. In following designs, additional functional organic layers were introduced (see in Fig. 2-3) to improve the performance of the OLEDs. And more and more advanced SMOLEDs with higher efficiency were reported. The state-of-art fluorescent OLEDs reach a power efficiency of 20-30 lm/W and phosphorescent OLEDs (PHOLEDs) $>100 \mathrm{~lm} / \mathrm{W}$ (PHOLEDs, see the discussion below). However, the complex multilayer SMOLEDs present some 
disadvantages, mainly due to the VTE fabrication method. First, VTE requires high vacuum, which limits the size of the device. Second, making multi-dopant OLEDs, such as white OLEDs (WOLEDs), requires precise control of the doping concentration of each dopant in the emitting layer (EML) to obtain the desired emission [16,17], which dramatically increases the fabrication complexity. All these issues usually lead to a higher cost and limited device size; for example, the price of the first commercially available OLED TV, i.e., the 11-inch diagonal Sony XEL-1, was $\sim \$ 2900$ (the price of at least a 50-inch LCD HDTV).

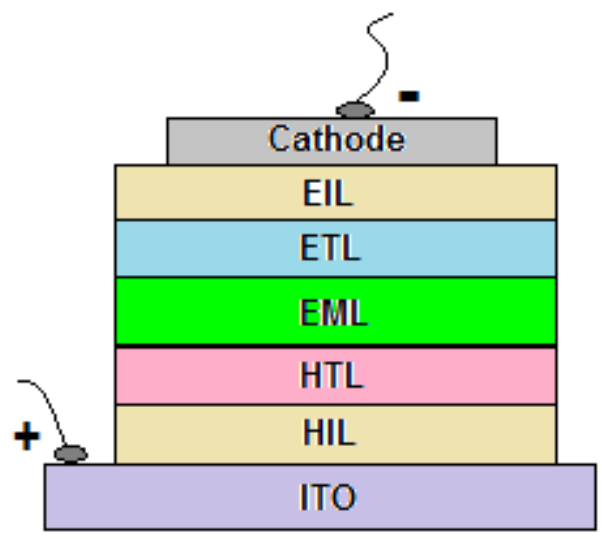

Fig. 2-3. Device structure of multilayered SMOLEDs.

In the 1970s, in parallel with the development of small molecule OLEDs conjugated polymers were also used, mostly due to their unique properties, such as light weight, mechanical flexibility, processability, tunable bandgap and conductivity. Polymers are too large for thermal evaporation, so unlike small molecules, they are fabricated by solution-processing methods, such as spin-coating and ink-jet printing. The first low- $V$ green polymer light-emitting diodes (PLEDs) was reported by J. H. Burroughes et al. in 1990 using a 100-nm thick films of poly(p-phenylene vinylene) (PPV) [18]. Because 
PPV preferentially conducts holes rather than electrons, the electron injection in these original PPV-based devices was strongly limited, therefore the quantum efficiency was very poor, only $\sim 0.05 \%$. Adopting the idea of heterostructure, which was successfully demonstrated in SMOLEDs, in 1992 a polymeric heterostructure was developed using an electron transport layer of 2-(4-biphenylyl)-5-(4-tert-butylphenyl)-1,3,4-oxadiazole (PBD) dispersed in an insulating polymer, poly(methyl methacrylate) (PMMA) [19]. This design improved the quantum efficiency of the PPV device to $0.8 \%$, roughly the same as the efficiency of undoped $\mathrm{Alq}_{3}$ devices.

Due to the requirement of orthogonal organic solvents (if the solvents are not orthogonal, the solvent used for one layer can redissolve or otherwise damage the previous layers), PLEDs usually have fewer organic layers than SMOLEDs [20]. The limited number of layers in PLEDs typically results in less efficient devices in comparison to the most advanced SMOLEDs. On the other hand, solution-processed PLEDs is potentially of low cost with the advantage of large area manufacturability [17, 21].

\section{Basic OLED Photophysics and Operation}

During operation of OLEDs a positive $V$ is applied to the anode, resulting in hole $\left(\mathrm{h}^{+}\right)$ injection to the HOMO level of the adjacent organic layer, usually a hole transport layer (HTL), and the electron ( $\mathrm{e}^{-}$) injection from the cathode to the LUMO level of the adjacent organic layer, usually an electron transport layer (ETL). Injected $\mathrm{h}^{+}$and $\mathrm{e}^{-}$drift toward each other in the organic layers by the external electric field, and some of them 
recombine-to form the excited states, i.e., excitons. The radiative decay of the excitons generates the light.

As is well known, both $\mathrm{e}^{-}$and $\mathrm{h}^{+}$are fermions with spin $S=1 / 2$. Statistically, $25 \%$ of the excitons are in singlet states, called singlet excitons (SEs), and the rest $75 \%$ are in triplet states, termed as triplet excitons (TEs) [22-23]. Because of the weak spin-orbit coupling (SOC) effects, the intersystem crossing (ISC) time( 10 ns) between these two states is significantly longer than relaxation times of internal conversion (IC, a process of internal

relaxation that occurs within the same spin manifold), which is $\sim 10^{-12} \mathrm{~s}$ [24]. The ground state of organic materials is in the singlet configuration $S_{0}$, therefore only the efficient and fast decaying singlet emission $\left(S_{1} \rightarrow S_{0}\right.$, fluorescence), with lifetime $\tau$ of the order of one ns, is quantum mechanically allowed [25-27]. On the other hand, since the probability for the radiative $T_{1} \rightarrow S_{0}$ transition (phosphorescence) is very small, the deactivation of the $T_{1}$ state occurs normally non-radiatively at ambient temperature. Therefore, $75 \%$ excitons are lost for the emission, whose energy is transferred into heat. So for the fluorescent OLEDs, only the SEs emit light, which results in a theoretical upper limit of $25 \%$ on the internal quantum efficiency $\eta_{\text {int }}$ (defined as the ratio of the total number of photons generated within the structure to the number of electrons injected [2829]), leading to a relatively low efficiency for the fluorescent OLEDs.

\section{Phosphorescent OLEDs (PHOLEDs)}

The foregoing $25 \%$ limit was overcome by the groundbreaking work of Forrest and his group on phosphorescent OLEDs (PHOLEDs) in the late 1990s and early 2000s, where 
both the SEs and TEs are used in generating light [30-32]. The phosphorescent organic molecules are mostly organo-transition metal complexes, which usually contain a heavy metal atom at the center of the molecule, for example platinum or iridium. Molecular structures of 3 widely-used phosphorescent materials: (a) $\mathrm{Pt}(\mathrm{II})$ octaethylporphine (PtOEP), (b) Tris(2-phenylpyridine) iridium(III) (Ir(ppy) 3 ) and (c) Bis(3,5-difluoro-2-(2pyridyl)phenyl-(2-carboxypyridyl) iridium(III) (FIrpic) are shown in Fig. 2-4 [30-32]. These transition metal ions induce significant SOC effect, which enables the radiative path from $T_{1}$ to $S_{0}$. Moreover, a very efficient ISC from the populated SEs to the emitting $T_{1}$ state is induced by SOC, so that efficient phosphorescence with a quantum yield $\square_{\mathrm{PL}}$ of almost $100 \%$ can occur even at ambient temperature [33-39]. This process is called triplet harvesting, as shown in Fig. 2-5. That is, all four possible spin orientations of the excitons (SEs and TEs) can be harvested and populate the lowest $T_{1}$ state, therefore a $\eta_{\text {int }}$ $=100 \%$ in principle can be achieved, which largely improves the efficiency of OLEDs (peak power efficiency is already over $100 \mathrm{~lm} / \mathrm{W}$ ), rendering OLEDs as the nextgeneration technology for both flat-panel displays and solid state lighting more and more competitive.

In the organo-transition metal complexes, the actual molecular orbitals (MOs) could be very complicated, but only a small numbers of frontier orbitals are often expected to be mainly responsible for the electronic and photophysical properties. Fig. 2-6 represents MOs for the well-studied green phosphorescent material: $\operatorname{Ir}(\mathrm{ppy})_{3}$, which is in a quasioctahedral geometry with three chelating ligands that each of them has one $\pi$ and $\pi^{*}$ orbitals in the relevant energy range. Moreover, three d-orbitals from 


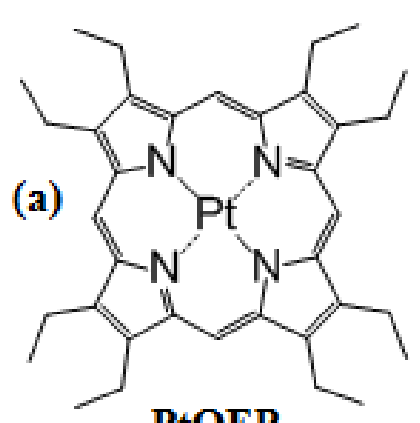

PtOEP (b)

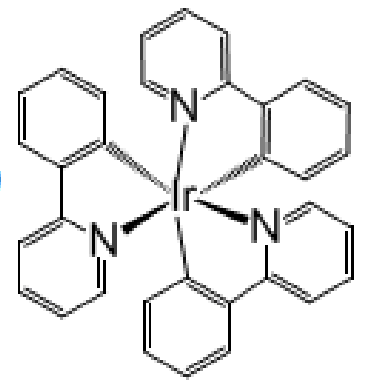

$\operatorname{Ir}($ ppy) 3 (c)

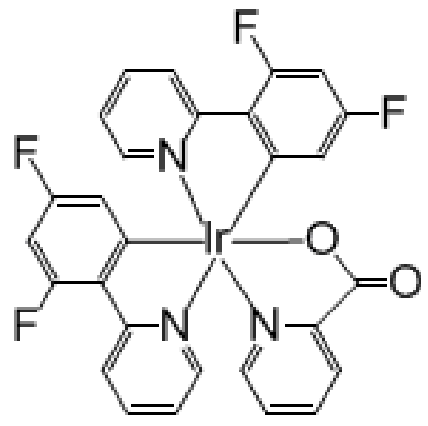

FIrpic

Fig. 2-4. Molecular structures of 3 widely-used phosphorescent materials: (a) PtOEP (b) $\operatorname{Ir}(\text { ppy })_{3}($ c) FIrpic.

the center metal ion, iridium, are also shown. Mostly the excited $d^{*}$ orbitals have a very large energy separation from the $\pi^{*}$ MOs and therefore it is further assumed that these orbitals do not interfere with each other [29].

To reduce the rate constants $k^{\mathrm{nr}}$ of nonradiative deactivation processes of the $T_{1}$ state it is also crucial to obtain high emission quantum yields. For intermolecular quenching of the emission, the quencher can be either the same or different species. If the quenching is from the same species, it usually occurs at higher dopant concentrations via annihilation of excited emitters in close proximity (e.g. triplet-triplet-annihilation (TTA) [40-43]) or via energy transfer according to the Forster and/or the Dexter mechanism [24] from excited to non-excited molecules. Annihilation and energy transfer effects can usually be avoided by using low dopant concentrations or by effectively shielding the emitter molecules. This can, for example, be reached by using bulky [44-45] or dendrimeric ligands [46-48]. 


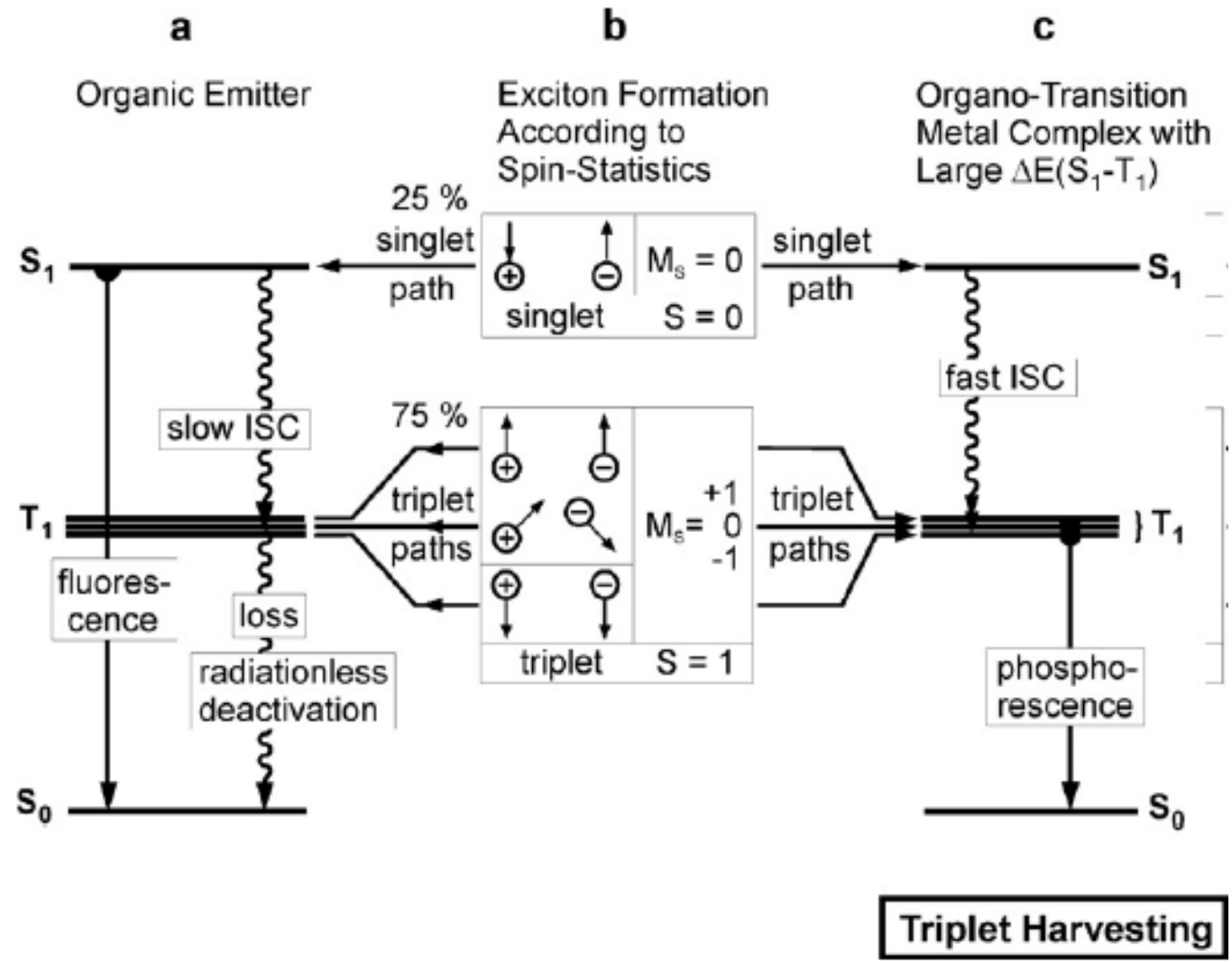

Fig. 2-5. The diagram displays electroluminescence excitation processes for organic and organo-transition metal emitters, and explains the effects of triplet and singlet harvesting. (a) In organic molecules, only singlets emit light (fluorescence), while the triplet excitation energy is transferred into heat. (b) Due to spin-statistics, electron-hole recombination leads to $25 \%$ singlet and $75 \%$ triplet state population. (c) Organometallic compounds with transition metal centers show a fast intersystem crossing (ISC) from the singlet state $S_{1}$ to the lowest triplet state $T_{1}$. Thus, this triplet state harvests singlet and triplet excitation energy and can efficiently emit [29].

The luminescence also can be quenched by different species, e.g. impurities, such as molecular oxygen. Because the emission decay time for any phosphorescent material is 
usually significantly longer than fluorescent emitters, this quenching process is frequently very effective. For molecular oxygen, it is believed that the energy of the excited emitter is transferred to triplet oxygen $\left({ }^{3} \mathrm{O}_{2}\right.$, ground state) with subsequent conversion to the excited singlet oxygen $\left({ }^{1} \mathrm{O}_{2}\right.$, excited state) [49-51]. On the other hand, the compounds which exhibit extremely high oxygen quenching rates can be used in oxygen sensor applications with a high sensitivity [52-54].

In contrast to intermolecular quenching, intramolecular quenching is an intrinsic property and frequently ascribed to two mechanisms:

1. Thermal population of metal-centered states

The quantum yield of phosphorescence of many transition metal compounds is strongly or even totally quenched at ambient temperature, however, it is significantly higher at low temperature. In many cases, this phenomenon can be ascribed to the thermal population of metal-centered states of $d d^{*}$ character, so-called ligand-field (LF) states [33, 55-59]. This quenching is particularly effective for the blue light emitting materials. The $E_{\mathrm{T} 1}$ of blue materials is higher which is supported by the higher photon energy $E_{\mathrm{photon}}$ of blue emission, which means the activation energy for the population of $d d^{*}$ states from the emitting $T_{1}$ is significantly smaller. Consequently, the quenching via this mechanism is quite efficient. Very useful approaches to avoid the thermal population of the $d d^{*}$ states are realized by "pushing" them to higher energies and making them thermally inaccessible at ambient temperature [60-68].

2. Quenching of the excited state by vibrational coupling to the ground state Nonradiative processes from excited $T_{1}$ state to the $S_{0}$ state can be effective via an involvement of vibrational modes of the ground $S_{0}$ state, which is often termed 
vibrational quenching [69-72]. And the famous energy gap law predicts an exponential increase of $k^{\mathrm{nr}}$ with decreasing energy gap between the excited state and the ground state [73-81]. The $k^{\mathrm{nr}}$ value is found to decrease with increasing $E_{0}$, thus, red emitting compounds with emitting states that are geometrically distorted with respect to the ground state are especially sensitive to emission quenching via this mechanism [82].

\section{References}

[1] A. Bernanose, M. Comte, P. Vouaux, J. Chim. Phys. 50 (1953) 64.

[2] A. Bernanose, P. Vouaux, J. Chim. Phys. 50 (1953) 261.

[3] A. Bernanose, J. Chim. Phys. 52 (1955) 396.

[4] A. Bernanose, P. Vouaux, J. Chim. Phys. 52 (1955) 509.

[5] H. Kallmann, M. Pope, J. Chem. Phys. 32 (1960) 300.

[6] H. Kallmann, M. Pope, Nature 186 (1960) 4718.

[7] P. Mark, W. Helfrich, J. Appl. Phys. 33 (1962) 205.

[8] M. Pope, H. P. Kallmann, P. Magnante, J. Chem. Phys. 38 (1963) 2042.

[9] W. Helfrich, W. Schneider, Phys. Rev. Lett. 14 (1965) 229.

[10] R. Partridge, Polymer 24 (1983) 733.

[11] R. Partridge, Polymer 24 (1983) 739.

[12] R. Partridge, Polymer 24 (1983) 748.

[13] R. Partridge, Polymer 24 (1983) 755.

[14] P. S. Vincett, W. A. Barlow, R. A. Hann, G. G. Roberts, Thin Solid Films 94 (1982) 171.

[15] C. W. Tang, S. A. Vanslyke, Appl. Phys. Lett. 51 (1987) 913. 
[16] B. W. D’Andrade, M. E. Thompson, S. R. Forrest, Adv. Mater. 14 (2002) 147.

[17] M. C. Gather, A. Köhnen, K. Meerholz, Adv. Mater. 23 (2011) 2.

[18] J. H. Burroughes, D. D. C. Bradley, A. R. Brown, R. N. Marks, K. MacKay, R. H. Friend, P. L. Burns, A. B. Holmes, Nature 347 (1990) 539.

[19] A. R. Brown, D. D. C. Bradley, J. H. Burroughes, R. H. Friend, N. C. Greenham, P.

L. Burn, A. B. Holmes, A. Kraft, Appl. Phys. Lett. 61 (1992) 2793.

[20] S. R. Forrest, Nature 428 (2004) 911.

[21] J. Huang, G. Li, E. Wu, Q. Xu, Y. Yang, Adv. Mater. 18 (2006) 114.

[22] A. R. Brown, K. Pichler, N. C. Greenham, D. D. C. Bradley, R. H. Friend, A. B. Holmes, Chem. Phys. Lett. 210 (1993) 61.

[23] M. A. Baldo, D. F. O'Brien, M. E. Thompson, S. R. Forrest, Phys. Rev. B 60 (1999) 14422.

[24] N. J. Turro, Modern Molecular Photochemistry, Benjamin Inc., Menlo Park, 1978.

[25] S. Kalinin, M. Speckbacher, H. Langhals, L. B.-A. Johansson, Phys. Chem. Chem. Phys. 3 (2001) 172.

[26] H. Langhals, J. Karolin, L.B.-A. Johansson, J. Chem. Soc., Faraday Trans. 94 (1998) 2919.

[27] M. Montalti, A. Credi, L. Prodi, M. T. Gandolfi, Handbook of Photochemistry, 3rd ed., CRC Tayler \& Francis, Boca Raton, 2006.

[28] S. R. Forrest, D. D. C. Bradley, M. E. Thompson, Adv. Mater. 15 (2003) 1043. 
[29] H. Yersin, A. F. Rausch, R. Czerwieniec, T. Hofbeck, T. Fischer, Coordin. Chem. Rev. 255 (2011) 2622.

[30] M. A. Baldo, D. F. O'Brien, Y. You, A. Shoustikov, S. Sibley, M. E. Thompson, S. R. Forrest, Nature 395 (1998) 151.

[31] M. A. Baldo, S. Lamansky, P. E. Burrows, M. E. Thompson, S. R. Forrest, Appl. Phys. Lett. 75 (1999) 4.

[32] C. Adachi, M. A. Baldo, M. E. Thompson, S. R. Forrest, J. Appl. Phys. 90 (2001) 5048.

[33] T. Sajoto, P. I. Djurovich, A. B. Tamayo, J. Oxgaard, W. A. Goddard III, M. E. Thompson, J. Am. Chem. Soc. 131 (2009) 9813.

[34] K. Goushi, Y. Kawamura, H. Sasabe, C. Adachi, Jpn. J. Appl. Phys. 43 (2004) L937.

[35] T. Hofbeck, H. Yersin, Inorg. Chem. 49 (2010) 9290.

[36] H. Yersin, W. J. Finkenzeller, Highly Efficient OLEDs with Phosphorescent Materials, Wiley-VCH, Weinheim, 2008, p. 1.

[37] A. F. Rausch, H. H. H. Homeier, P. I. Djurovich, M. E. Thompson, H. Yersin, Proc. SPIE 6655 (2007) 66550F.

[38] A. F Rausch, H. H. H. Homeier, H. Yersin, Top. Organomet. Chem. 29 (2010) 193.

[39] S. P. McGlynn, T. Azumi, M. Kinoshita, Molecular Spectroscopy of the Triplet State, Prentice-Hall, Eaglewood Cliff, 1969. 
[40] S. Reineke, K. Walzer, K. Leo, Phys. Rev. B 75 (2007) 125328.

[41] N.C. Giebink, S. R. Forrest, Phys. Rev. B 77 (2008) 235215.

[42] S. Reineke, G. Schwartz, K. Walzer, K. Leo, Appl. Phys. Lett. 91 (2007) 123508.

[43] M. A. Baldo, C. Adachi, S. R. Forrest, Phys. Rev. B 62 (2000) 10967.

[44] W. B. Connick, D. Geiger, R. Eisenberg, Inorg. Chem. 38 (1999) 3264.

[45] C. S. K. Mak, W. K. Chan, T. Fischer, H. Yersin, US Patent Application 61/264,731.

[46] S.-C. Lo, R. E. Harding, C. P. Shipley, S. G. Stevenson, P. L. Burn, I. D. W. Samuel, J. Am. Chem. Soc. 131 (2009) 16681.

[47] S.-C. Lo, R. N. Bera, R. E. Harding, P. L. Burn, I. D. W. Samuel, Adv. Funct. Mater. 18 (2008) 3080 .

[48] J. M. Lupton, I. D. W. Samuel, R. Beavington, P. L. Burn, H. Bassler, Adv. Mater. 13 (2001) 258.

[49] J. N. Demas, E. W. Harris, R. P. McBride, J. Am. Chem. Soc. 99 (1977) 3547.

[50] P. I. Djurovich, D. Murphy, M. E. Thompson, B. Hernandez, R. Gao, P. L. Hunt, M. Selke, Dalton Trans. (2007) 3763.

[51] C. Schweitzer, R. Schmidt, Chem. Rev. 103 (2003) 1685.

[52] C. S. K. Mak, D. Pentlehner, M. Stich, O. S. Wolfbeis, W. K. Chan, H. Yersin, Chem. Mater. 21 (2009) 2173.

[53] D. B. Papkovsky, G. V. Ponomarev, W. Trettnak, P. O’Leary, Anal. Chem. 67 (1995) 4112.

[54] S. Ji, W. Wu, Y. Wu, T. Zhao, F. Zhuo, Y. Yang, X. Zhang, X. Liang, W. Wu, L. Chi, Z. Wang, J. Zhao, Analyst 134 (2009) 958. 
[55] A. Islam, N. Ikeda, K. Nozaki, Y. Okamoto, B. Gholamkhass, A. Yoshimura, T. Ohno, Coord. Chem. Rev. 171 (1998) 355.

[56] F. Barigelletti, D. Sandrini, M. Maestri, V. Balzani, A. von Zelewsky, L. Chassot, P. Jolliet, U. Maeder, Inorg. Chem. 27 (1988) 3644.

[57] T.J. Meyer, Pure Appl. Chem. 58 (1986) 1193.

[58] J. van Houten, R. J. Watts, Inorg. Chem. 17 (1978) 3381.

[59] J. V. Caspar, T. J. Meyer, J. Am. Chem. Soc. 105 (1983) 5583.

[60] T. Sajoto, P. I. Djurovich, A. Tamayo, M. Yousufuddin, R. Bau, M. E. Thompson, R. J. Holmes, S. R. Forrest, Inorg. Chem. 44 (2005) 7992.

[61] S. Haneder, E. Da Como, J. Feldmann, J. M. Lupton, C. Lennartz, P. Erk, E. Fuchs, O. Molt, I. Munster, C. Schildknecht, G. Wagenblast, Adv. Mater. 20 (2008) 3325.

[62] C.-F. Chang, Y.-M. Cheng, Y. Chi, Y.-C. Chiu, C.-C. Lin, G.-H. Lee, P.-T. Chou, C.-C. Chen, C.-H. Chang, C.-C. Wu, Angew. Chem. Int. Ed. 47 (2008) 4542.

[63] J. A. G. Williams, A. Beeby, E. S. Davies, J. A. Weinstein, C. Wilson, Inorg. Chem. 42 (2003) 8609.

[64] S. J. Farley, D. L. Rochester, A. L. Thompson, J. A. K. Howard, J. A. G. Williams, Inorg. Chem. 44 (2005) 9690.

[65] A. F. Rausch, L. Murphy, J. A. G. Williams, H. Yersin, Inorg. Chem. 48 (2009) 11407.

[66] C. S. Chin, M.-S. Eum, S. Y. Kim, C. Kim, S. K. Kang, Eur. J. Inorg. Chem. (2007) 372.

[67] M.-S. Eum, C. S. Chin, S. Y. Kim, C. Kim, S. K. Kang, N. H. Hat, J. H. Seo, G. Y. Kim, Y. K. Kim, Inorg. Chem. 47 (2008) 6289. 
[68] D. Di Censeo, S. Fantacci, F. De Angelis, C. Klein, N. Evans, K. Kalyanasundaram,

H. J. Bolink, M. Gratzel, M. K. Nazeeruddin, Inorg. Chem. 47 (2008) 980.

[69] G. W. Robinson, R. P. Frosch, J. Chem. Phys. 38 (1963) 1187.

[70] R. Englman, J. Jortner, Mol. Phys. 18 (1970) 145.

[71] W. Siebrand, J. Chem. Phys. 46 (1967) 440.

[72] K.F. Freed, J. Jortner, J. Chem. Phys. 52 (1970) 6272.

[73] W. Siebrand, J. Chem. Phys. 47 (1967) 2411.

[74] H. J. Griesser, U. P. Wild, Chem. Phys. 52 (1980) 117.

[75] A. Maciejewski, A. Safarzadeh-Amiri, R. E. Verrall, R. P. Steer, Chem. Phys. 87 (1984) 295.

[76] J. S. Wilson, N. Chawdhury, M. R. A. Al-Mandhary, M. Younus, M. S. Khan, P. R. Raithby, A. Kohler, R. H. Friend, J. Am. Chem. Soc. 123 (2001) 9412.

[77] D. J. Stufkens, A. Vl`cek Jr., Coord. Chem. Rev. 177 (1998) 127.

[78] C. E. Whittle, J. A. Weinstein, M. W. George, K. S. Schanze, Inorg. Chem. 40 (2001) 4053.

[79] J. V. Caspar, E. M. Kober, B. P. Sullivan, T. J. Meyer, J. Am. Chem. Soc. 104 (1982) 630.

[80] L. A. Worl, R. Duesing, P. Chen, L. Della Ciana, T. J. Meyer, J. Chem. Soc., Dalton Trans. (1991) 849.

[81] E. M. Kober, J. V. Caspar, R. S. Lumpkin, T. J. Meyer, J. Phys. Chem. 90 (1986) 3722.

[82] J. A. Treadway, B. Loeb, R. Lopez, P. A. Anderson, F. R. Keene, T. J. Meyer, Inorg. Chem. 35 (1996) 2242. 


\title{
Chapter 4. Simple routes for improving polythiophene:fullerene-based organic solar cells
}

\author{
A paper published in Organic Electronics
}

Teng Xiao, Weipan Cui, James W. Anderegg, Joseph Shinar and Ruth Shinar

\begin{abstract}
Improved power conversion efficiency (PCE), by up to $27 \%$, of organic solar cells based on poly(3,4-ethylenedioxy-thiophene):poly(styrenesulfonate) (PEDOT:PSS) /poly(3-hexylthiophene):[6,6]-phenyl-C60-butyric acid methyl ester (P3HT:PCBM) were obtained via simple modifications, widely applicable, in the fabrication of the spin-coated PEDOT:PSS layer. These included (i) further diluting the original PEDOT:PSS solution with deionized water, (ii) mixing the original PEDOT:PSS solution with ethylene glycol (EG), and (iii) spin coating EG over a PEDOT:PSS layer fabricated using the original solution. The optimal dilutions spin coating rates, and durations were determined. Approach (iii) resulted in the best cell with a PCE of $4.7 \%$ as compared to $3.7 \%$ for the untreated PEDOT:PSS. To evaluate the origin of the improvements we monitored the PEDOT:PSS conductivity, external quantum efficiency of the devices, and their I-V curves that indicated an increase of $\sim 16 \%$ in the short-circuit current $I_{\mathrm{SC}}$. Other characteristics included the PEDOT:PSS layer thickness, its transmittance, P3HT:PCBM absorption spectra, its morphology, and surface chemical composition. The results indicate that in addition to the enhanced PEDOT:PSS conductivity (following some of the treatments) that improves charge extraction, enhanced PEDOT:PSS transmission and
\end{abstract}


especially, enhanced P3HT:PCBM absorption contribute to improved solar cell performance, the latter by increasing $I_{\mathrm{SC}}$. While the various treatments in the optimized devices had a minor effect on the PEDOT:PSS thickness, its morphology, and consequently that of the active layer, were affected. The surface roughness of the active layer increased significantly and, importantly, in devices with PEDOT:PSS/EG/P3HT:PCBM, PCBM aggregates were observed near the cathode. Such aggregates may also result in increased absorption and improved charge extraction.

\section{Introduction}

The development of organic solar cells is a fast-growing field as such devices have the advantage of being flexible, simple to fabricate, and potentially low cost [1-4]. Solar cells with a poly(3-hexylthiophene):[6,6]-phenyl-C60-butyric acid methyl ester (P3HT:PCBM) active layer have been studied extensively with reports of typical power conversion efficiency (PCE) of $\sim 3 \%$ to $\sim 5 \%$ and fill factors (FF) of $\sim 50 \%$ to $\sim 70 \%$ [411]. The PCE and FF depend on the starting materials, fabrication conditions and treatments at various stages of device fabrication. As an example, a PCE of $4.4 \%$ was obtained by varying the annealing conditions of the active layer $[7,8]$. The PCE was improved to $5.3 \%$ by replacing the PEDOT:PSS layer with $\mathrm{NiO}_{2}$ [9]. A PCE of 5\% was obtained for a single cell with $\mathrm{TiO}_{\mathrm{x}}$ as an optical spacer, and a two-unit tandem structure with $6.5 \%$ PCE was obtained by applying the $\mathrm{TiO}_{\mathrm{x}}$ layer as an electron transport and collecting layer for the first unit and as a stable foundation to fabricate the second unit [10-12]. To obtain a good short-circuit current $\left(I_{\mathrm{SC}}\right)$, the active layer needs to have strong absorption of the solar spectrum, efficient exciton diffusion, good charge transfer, and sufficient charge extraction at the electrodes [13]. To achieve a high open-circuit voltage 
$\left(V_{\mathrm{OC}}\right)$, the offset between the highest occupied molecular orbital (HOMO) of the donor material and the lowest unoccupied molecular orbital (LUMO) of the acceptor material should be high, and ohmic contacts between the electrodes and the organics are required [13-16]. To get a high FF, the series resistance of the device should be low and the shunt resistance should be high. The polymer/electrode interfaces and the active layer properties play an important role in determining these parameters [17-19].

It is well known that the conductivity of PEDOT:PSS films is enhanced by over 100fold by addition of organic materials, such as dimethyl sulfoxide (DMSO), N,Ndimethylformamide, tetrahydrofuran, sorbitol (with baking), glycerol, or ethylene glycol (EG) to the aqueous PEDOT:PSS solution [20-30]. Depending on the additive, the enhancement was related to the dielectric constant of the additive and to retention of some of the solvents used in the film [26], to reorientation of PEDOT chains with heat treatment [29], and to washing away of PSS [27]. For diethylene glycol addition, it was suggested that the particle size of the PEDOT:PSS reduces as the insulating, inter-particle excess PSS layer becomes very thin [28]. It was also shown that not only dilution of the PEDOT:PSS solution with EG enhances the conductivity, but also immersing the untreated PEDOT:PSS in EG solution for a few minutes [21]. It was reported that EG affects the solubility of the PEDOT:PSS film in water, suggesting, together with other measurements, that EG affects the conformation of the polymer chains with the surface becoming more hydrophobic. The conformational change of the PEDOT chains was attributed to the interaction between the dipole of one of the polar groups (only additives with two or more polar groups were found to enhance conductivity) of the organic additive and the dipoles or positive charges on the PEDOT [21]. It was also reported that 
the size of the PEDOT:PSS particles was increased by adding DMSO [23]. The increased conductivity was linked to the increased particles' size, due to reduced particle boundaries. Hence, there are still different fundamental explanations for the enhanced PEDOT:PSS conductivity upon addition of polar solvents.

Additives to PEDOT:PSS that enhance performance of solar cells were also evaluated. In addition to the effect of DMSO [23], for example, the substitution of ITO by PEDOT:PSS and PEDOT:PSS doped with glycerol or sorbitol was studied [22]. Glycerol and the surfactant ethylene glycol butyl ether at specific concentrations were also mixed with PEDOT:PSS for improved ink-printed solar cells [24]. The authors suggested that these additives may also affect the morphology of the ink-jet printed PEDOT:PSS, with a strong ionic interaction between the glycerol and the PEDOT, including with the addition of low-levels of the surfactant to enhance the conductivity. Improved device performance was attributed to surface morphology and enhanced conductivity that increase charge collection [24].

As every step in the fabrication of the solar cells affects device performance, this paper describes a systematic study of the effect of treatments of the PEDOT:PSS layer on the performance of the common P3HT:PCBM-based solar cells. Morphology variations of P3HT:PCBM were observed, with increased roughness, when PEDOT:PSS was treated in different ways. The treatments included (i) dilution of the as-received PEDOT:PSS solution with deionized (DI) water or (ii) with EG, and (iii) spin coating EG over the PEDOT:PSS layer. Among the various treatments that included optimization of the dilution and spin coating rate and duration, treatment (iii), namely the EG-treated PEDOT:PSS layer (following the fabrication of the latter from the original aqueous 
solution) exhibited the largest change in the P3HT:PCBM morphology, which is probably responsible for the observed largest improvement in the, $I_{\mathrm{SC}}, \mathrm{FF}$, and PCE. Importantly, small aggregates of PCBM, whose size depended on the anneal period of the EG-treated PEDOT:PSS layer, were observed at the surface of the active layer. These aggregates at the active layer/cathode interface may improve charge extraction and light absorption, and hence $I_{\mathrm{SC}}, \mathrm{FF}$, and PCE. Importantly, the conductivity of PEDOT:PSS exhibited a relatively minor contribution to the enhanced performance.

\section{Experimental procedures}

\section{Materials}

P3HT (P\#200) was obtained from Rieke Metals and PCBM from nano-C; both materials were used without further purification. A solution of a 1:1 weight ratio of P3HT:PCBM in 1,2-dichlorobenzene, with a concentration of $30 \mathrm{mg} / \mathrm{mL}$ was used. The P3HT solution was filtered using a $0.22 \mathrm{~lm}$ Millex PTFE Filter before it was mixed with PCBM. The mixture was then stirred for $24 \mathrm{~h}$ before spin-coating. PEDOT:PSS was a CleviosTM P VP AI 4083 obtained from H.C. Starck. The PEDOT:PSS ratio was 1:6 by weight and the solid content 1.3-1.7\%. EG was obtained from Fisher Scientific.

\section{Procedures}

The PEDOT:PSS layers ( 40 nm thick) were baked for $\sim 1 \mathrm{~h}$ at $120 \square \mathrm{C}$ under ambient conditions; they were then transferred into an argon-filled dual-sided MBraun glovebox. The oxygen level in the glovebox was $\sim 30 \mathrm{ppm}$ and that of water $<0.1 \mathrm{ppm}$. Three different treatments of the PEDOT:PSS were evaluated in an attempt to improve the device performance. These treatments were: (i), diluting PEDOT:PSS with DI water (ii) mixing PEDOT:PSS with EG, and (iii) spin-coating EG following fabrication of the 
PEDOT:PSS layer. Each treatment was optimized by varying the spin-coating speed and duration as well as the dilution ratio as detailed above. The P3HT:PCBM solution was spin-coated on top of the PEDOT:PSS layer at the optimized $600 \mathrm{rpm}$ rate for $60 \mathrm{~s}$, and immediately placed under a petri dish for $2 \mathrm{~h}$ before baking at $110 \square \mathrm{C}$ for $12 \mathrm{~min}$. The $\mathrm{Ca}(25 \mathrm{~nm}) / \mathrm{Al}(100 \mathrm{~nm})$ were deposited on the P3HT:PCBM layer by low vacuum $\left(\sim 10^{-6}\right.$ mbar) thermal evaporation. The active layers in all devices were fabricated under the same experimental conditions.

\section{Measurements}

The thickness of PEDOT:PSS layers was estimated with an Atomic Force Microscopy (AFM) by using a sharp blade to generate $\sim 9 \mu \mathrm{m}$ wide cuts in the layer. In all cases a thickness of $\sim 40 \mathrm{~nm}$ resulted in devices with the best performance, regardless of the treatment. $I-V$ curves were obtained using a $100 \mathrm{~mW} / \mathrm{cm}^{2} \mathrm{ELH}$ bulb. The EQE was measured at $0 \mathrm{~V}$. AFM measurements were performed using a Digital Instruments system. SEM and Auger were measured with JEOL JAMP 7830F.

\section{Results and discussion}

Devices with an untreated PEDOT:PSS layer were optimized by varying the spincoating rate, in the range of $1000-4000 \mathrm{rpm}$, and the spin duration, in the range of $60-$ 120 s. The optimized condition for the untreated (prepared from the original solution) PEDOT:PSS was 3000 rpm for 60 s. Devices in which the PEDOT:PSS solution was further diluted with DI water (treatment (i)) were optimized by varying the volume ratio of PEDOT:PSS to water from 1:5 to $4: 1$, in combination with varying the spin-coating speed from 500 to $3000 \mathrm{rpm}$ for each dilution. Optimized layers, as evaluated by the

performance of the solar cells, were obtained for a volume ratio of 3:7 that was used to 
fabricate the PEDOT:PSS layers at $600 \mathrm{rpm}$ for $60 \mathrm{~s}$. Similarly to the dilution of the PEDOT:PSS with DI water, the volume ratio of the PEDOT:PSS to EG (treatment(ii)) varied from 10:3 to 3:7, and the spin-coating speed from 500 to $3000 \mathrm{rpm}$. The optimized condition for the EG-mixed PEDOT:PSS was obtained by using a 1:1 volume ratio and spin coating at $1000 \mathrm{rpm}$ for $60 \mathrm{~s}$. The performance of solar cells with the latter was similar to those based on the DI water dilution.

EG-treated devices were prepared also by spin-coating EG on top of the PEDOT:PSS layer (treatment (iii)). Different spin-coating speeds for both, the PEDOT:PSS layer and the EG, ranging from 500 to $3000 \mathrm{rpm}$, were tested. The best device was obtained by spin-coating the EG at $2000 \mathrm{rpm}$ for $60 \mathrm{~s}$ on top of an untreated PEDOT:PSS layer prepared by spin-coating at $2000 \mathrm{rpm}$ for $60 \mathrm{~s}$.

All PEDOT:PSS layers were annealed at $120 \square \mathrm{C}$ for $\sim 1 \mathrm{~h}$. Following the application of the P3HT:PCBM, the samples were annealed at $110 \square \mathrm{C}$ for $12 \mathrm{~min}$.

Fig. 3-1 shows the I-V curves of different, optimized P3HT:PCBM-based devices with PEDOT:PSS layers that underwent the different treatments, and Table 3-1 summarizes the values of VOC, ISC, FF and PCE for each device, including for devices prepared by spin coating EG at different rates for $60 \mathrm{~s}$. As clearly seen, the 


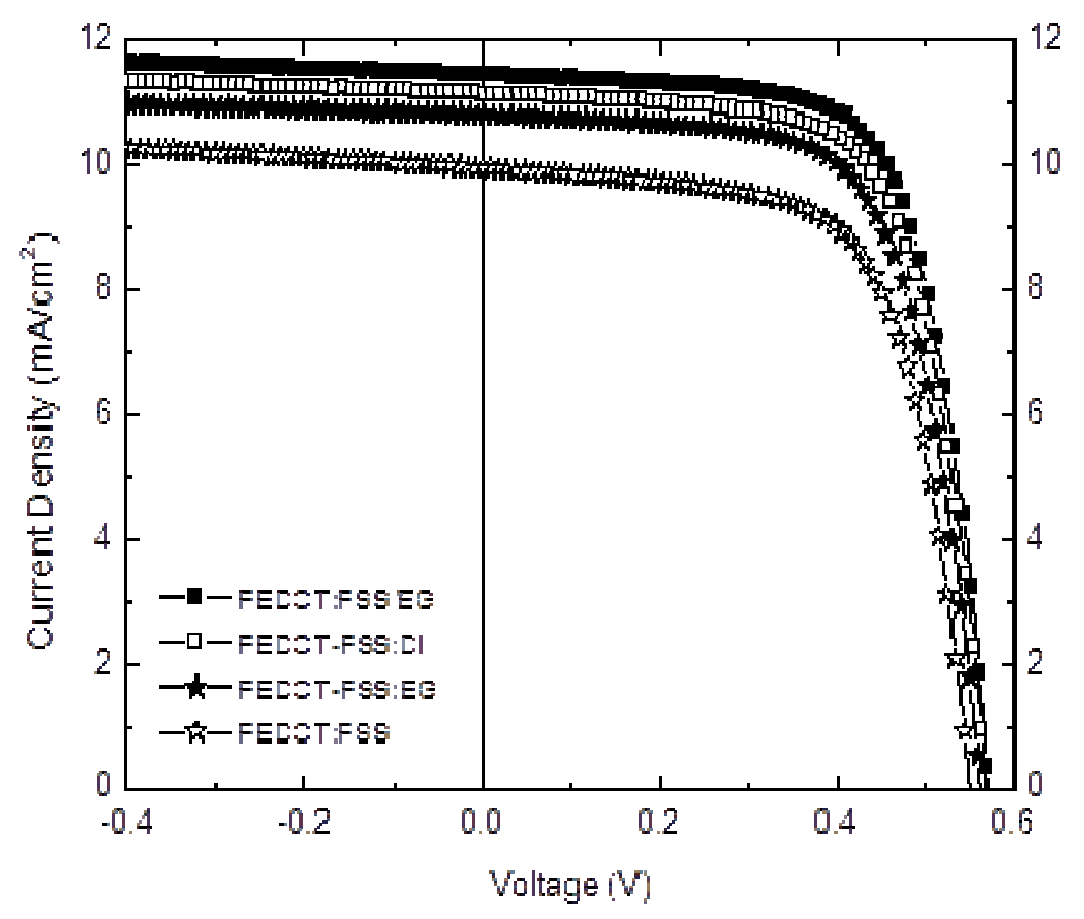

Fig. 3-1. I-V Curves of optimized (see text) P3HT:PCBM-based solar cells, with the PEDOT:PSS layer generated by spin coating the original solution (open stars), the original solution diluted with EG (solid stars) or with DI water (open squares), and by spin coating EG on the untreated PEDOT:PSS layer (solid squares).

treatments improved the cells' performance, in particular ISC increased by up to $16 \%$ from 9.94 to $11.5 \mathrm{~mA} / \mathrm{cm} 2$ and PCE by up to $~ 27 \%$ from $3.7 \%$ to $4.7 \%$ for the device with the EG-treated PEDOT:PSS in comparison to the untreated one. $V_{\mathrm{OC}}$ was unchanged at $0.55-0.57 \mathrm{~V}$.

To elucidate the origin of the observed improvement in the device performance, various parameters described next were measured. The thickness of the PEDOT:PSS films, which may affect absorption, was measured by making fine cuts ( $\sim \mu$ m wide) on them with a sharp blade, and using scanning AFM with a scan size of $20 \mu \mathrm{m}$ across the 
Table 3-1. Device characteristics of solar cells prepared with different treatments of the PEDOT:PSS layer. The data in the top three rows indicate EG solution spin coated over the PEDOT:PSS layer at various rates for $60 \mathrm{~s}$.

\begin{tabular}{|c|c|c|c|c|}
\hline Treatment & $V_{\mathrm{OC}}(\mathrm{V})$ & $I_{\mathrm{SC}}\left(\mathrm{mA} / \mathrm{cm}^{2}\right)$ & $\mathrm{FF}(\%)$ & PCE (\%) \\
\hline EG $1000 \mathrm{rpm}$ & 0.571 & 10.7 & 71.8 & 4.39 \\
\hline EG $2000 \mathrm{rpm}$ & 0.573 & 11.5 & 71.3 & 4.70 \\
\hline EG $3000 \mathrm{rpm}$ & 0.566 & 11.2 & 70.3 & 4.46 \\
\hline $\begin{array}{l}\text { PEDOT- } \\
\text { PSS:DI (3:7 } \\
\text { volume ratio) }\end{array}$ & 0.571 & 11.2 & 69.5 & 4.44 \\
\hline $\begin{array}{l}\text { PEDOT- } \\
\text { PSS:EG:(1:1 } \\
\text { volume ratio) }\end{array}$ & 0.563 & 10.8 & 69.3 & 4.21 \\
\hline $\begin{array}{l}\text { Untreated } \\
\text { PEDOT-PSS }\end{array}$ & 0.551 & 9.94 & 67.6 & 3.70 \\
\hline
\end{tabular}

cuts to measure the films' thickness. The AFM results showed that the typical thickness of the optimized PEDOT:PSS layers of both treated and untreated samples is $\sim 40 \mathrm{~nm}$. This situation excludes a change in the PEDOT:PSS layer thickness as a major contributor to the observed enhancement.

The conductivity of the different PEDOT:PSS layers, which affects charge extraction and therefore, $I_{\mathrm{SC}}$ and FF, was also measured. The conductivity of the layer in the best performing devices, i.e., where EG was spin-coated on top of the PEDOT:PSS, was $\sim 0.1$ 
S/cm. It was $\sim 10$-fold larger than that of the untreated PEDOT:PSS film, but $\sim 10$-fold smaller than that of the PEDOT:PSS layer prepared from the mixed solution of PEDOT:PSS and EG. The conductivity of the layer prepared from the solution diluted with DI water was comparable to that of the untreated film. Hence, the improved performance of the devices is not directly related to the enhanced conductivity. That is, the $I_{\mathrm{SC}}$ of the cell with the PEDOT:PSS layer with the highest conductivity (prepared from a mixture of PEDOT:PSS with EG) was inferior to that of the other devices with the treated PEDOT:PSS layer. And, the $I_{\mathrm{SC}}$ of the cell with the PEDOT:PSS layer prepared from further diluting the original solution with DI water was larger that of the device with the untreated layer, though their conductivities were comparable. Hence, and as shown below, other factors besides the conductivity play an important role in improving the performance of the solar cells.

Fig. 3-2 shows the external quantum efficiency (EQE) spectra of the four devices of Fig. 3-1. As seen, the EQE increased with PEDOT:PSS treatments, with a trend comparable to that shown in Fig. 1, as expected. The highest EQE, peaking at $~ 540 \mathrm{~nm}$, was $\sim 62 \%$; it was observed for the device in which EG was spin coated at $2000 \mathrm{rpm}$ for $60 \mathrm{~s}$ on top of the PEDOT:PSS prepared from the original solution at $2000 \mathrm{rpm}$ for $60 \mathrm{~s}$. The corresponding EQE for the optimized untreated device was $\sim 50 \%$. 
61

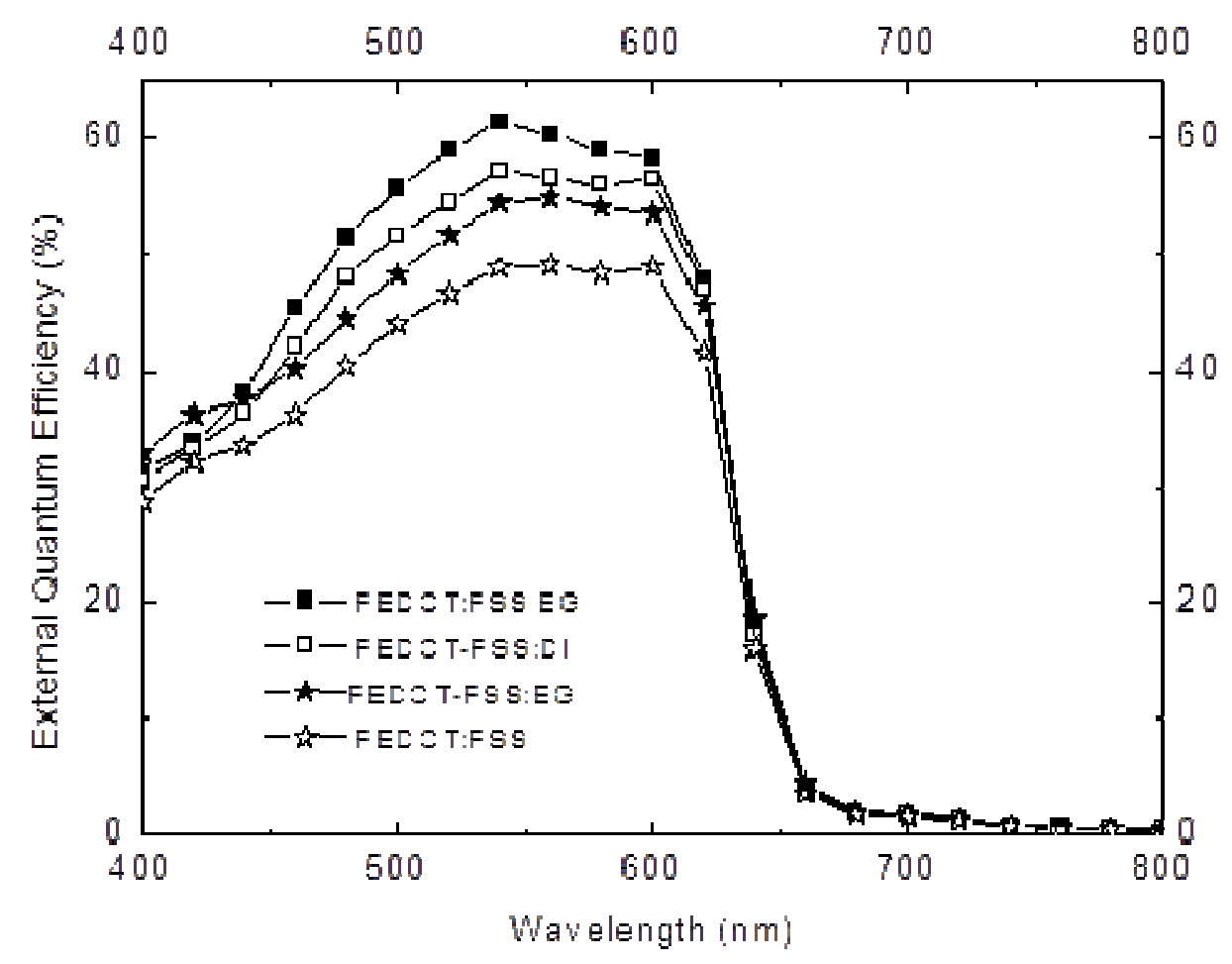

Fig. 3-2. External quantum efficiency vs wavelength for optimized devices with differently treated PEDOT:PSS layers, i.e., untreated - prepared using the original PEDOT:PSS solution - (open stars), prepared by EG dilution of the original PEDOT:PSS solution (solid stars), prepared by DI water dilution (open squares), and EG-treated following PEDOT:PSS fabrication (solid squares). See text for details.

In view of the above results, specifically the significant, reproducible increase in $I_{\mathrm{SC}}$ and EQE following modification of the PEDOT:PSS, the transmission of the different PEDOT:PSS layers and the absorption spectra of the different PEDOT:PSS/P3HT:PCBM structures were measured (Fig. 3-3). As seen in Fig. 3-3, the transmission of the DI water and EG-treated PEDOT:PSS in the range 500-700 nm (which covers the main absorption region of the P3HT:PCBM) is slightly larger than that of the untreated layer. Similarly, the absorption spectra of PEDOT:PSS/ 


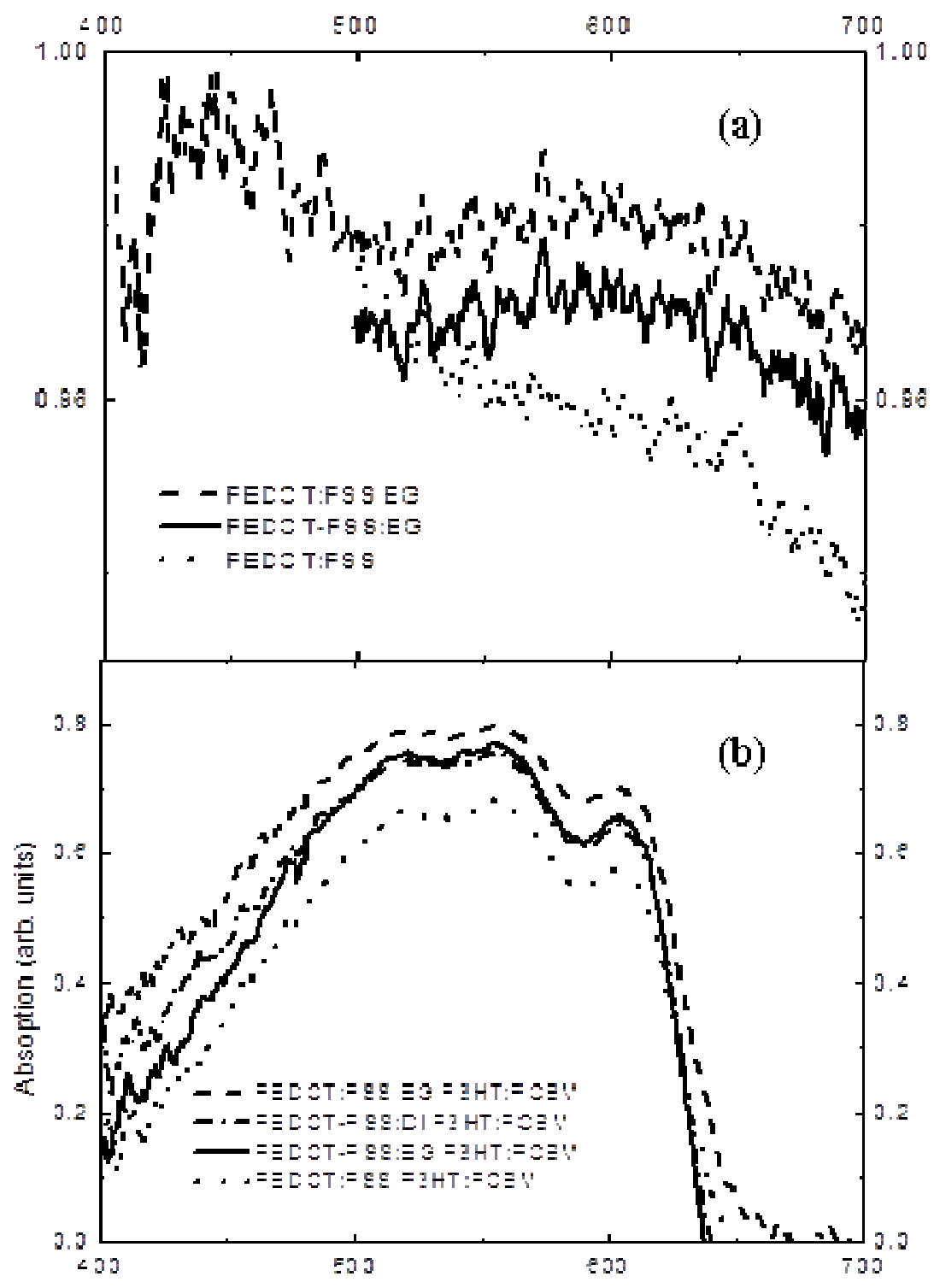

Fig. 3-3. (a) The transmission spectra of the PEDOT:PSS layer following different treatments. The PEDOT:PSS transmission at wavelengths $<500 \mathrm{~nm}$ is comparable for all films and for clarity is shown only for one case. (b) The corresponding absorption spectra of the PEDOT:PSS/P3HT:PCBM structures: an untreated PEDOT:PSS film (dotted line), PEDOT:PSS film prepared from a volume dilution ratio of 3:7 PEDOTPSS:DI water (solid line), PEDOT:PSS film prepared from a 1:1 PEDOT-PSS:EG 
volume ratio dilution (dashed-dotted line), and PEDOT:PSS film with post-fabrication EG spin coating (dashed line).

P3HT:PCBM in the 400-700 $\mathrm{nm}$ range show that the absorption increases with the PEDOT:PSS treatments, with the largest absorption observed for the PEDOT:PSS over which EG was spin-coated.

To identify potential device characteristics those are responsible for the enhanced absorption and hence increased $I_{\mathrm{SC}}$ and $\mathrm{EQE}$, the surface morphology of the PEDOT: PSS and P3HT:PCBM layers as well as the surface chemical composition of the P3HT:PCBM were monitored using AFM, SEM, and Auger electron spectroscopy.

The roughness of the PEDOT:PSS layer, as measured by AFM (Fig. 3-4) increased slightly from $2.8 \mathrm{~nm}$ RMS in the untreated layer and $2.7 \mathrm{~nm}$ RMS in the DI water-diluted solution to $3.4 \mathrm{~nm}$ in the PEDOT:PSS/EG film. Also, as seen, following the
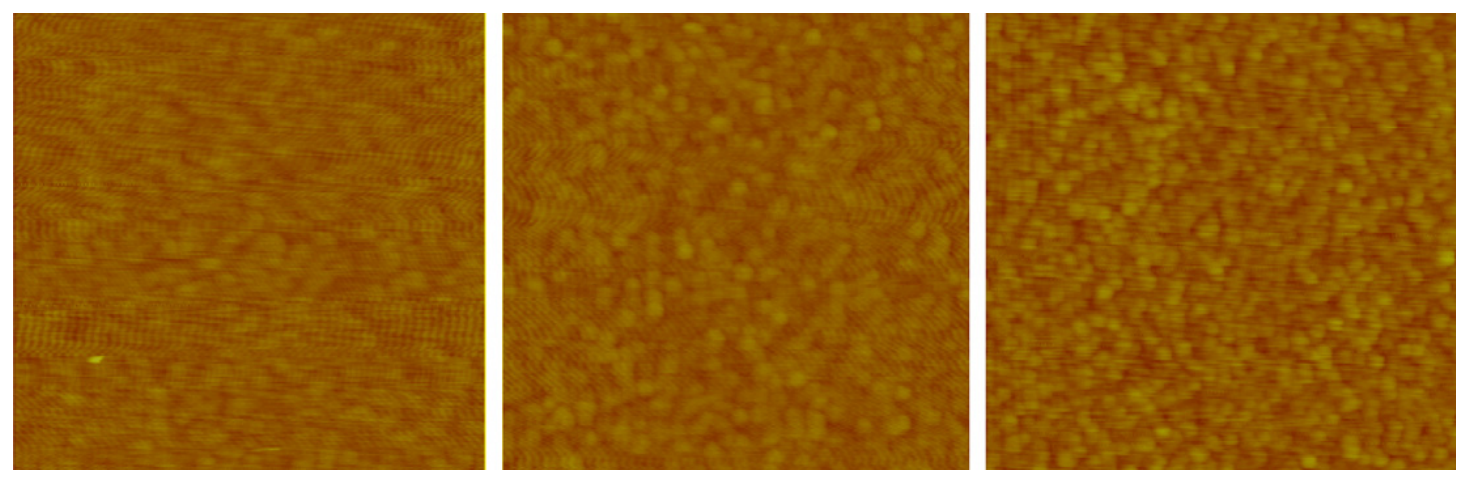

Fig. 3-4. AFM images of the morphology of PEDOT:PSS films differently treated: leftuntreated, original PEDOT:PSS; center-additional dilution of 3:7 PEDOT-PSS: DI water volume ratio; right-EG-treated PEDOT:PSS following the fabrication of the latter. The full scale in each image is $5 \mu \mathrm{m}$. 
treatments, a more condensed packing of particles was observed. Specifically, the particles appeared smaller for the DI water- and EG-treated samples, in particular for the latter. The smaller particle size is in accordance to previous reports suggesting that the reduced size is due to removal of excess inter-particle PSS [21]. The slightly increased roughness of the PEDOT:PSS layer, and most importantly, the significantly increased "graininess" from untreated to DI water-diluted to EG-coated PEDOT:PSS likely increase the contact area between the PEDOT:PSS and the active layer, improving hole extraction to the anode.

Significant morphology variations were observed in the P3HT:PCBM layers spincoated on the differently-treated PEDOT:PSS layers, as seen in the AFM and SEM images of Figs. 3-5 and 3-6. The RMS surface roughness of P3HT:PCBM with the untreated PEDOT:PSS layer was $13.3 \mathrm{~nm}$, that of the active layer with the PEDOT:PSS layer spun from DI water-diluted PEDOT:PSS (treatment (i)) was $28.5 \mathrm{~nm}$, and the RMS of the active layer with the PEDOT:PSS layer on top of which EG was spin-coated (treatment (iii)) was $34.5 \mathrm{~nm}$. Since all the P3HT:PCBM layers were prepared under the same experimental conditions, these changes in the surface roughness are obviously due to the various treatments and resulting graininess of the PEDOT:PSS layers. Rough surfaces may increase scattering of the incident light back into the active layer and hence lead to increased absorption. In addition, the larger roughness also enlarges the contact area between the active layer and the cathode, which may lead to better electron extraction. 

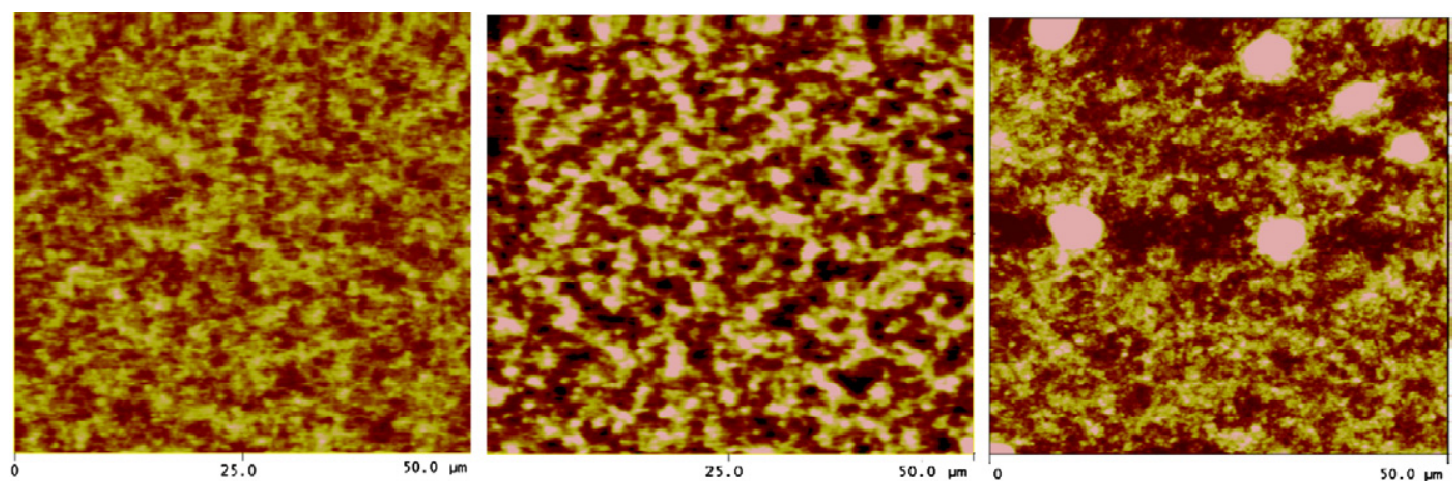

Fig. 3-5. Morphology AFM images of the P3HT:PCBM layers on top of the different PEDOT:PSS layers (full scale $50 \mu \mathrm{m}$ ). Left: untreated PEDOT:PSS; center: DI water diluted PEDOT:PSS; right: PEDOT:PSS layer with EG spun on top.

As seen in Figs. 3-5 and 3-6, small aggregates, $\sim 3 \mu \mathrm{m}$ wide, were distributed across the surface of the P3HT:PCBM layer spin-coated on the EG-treated PEDOT:PSS layer. The dimensions of these aggregates, which are largely at the active layer/cathode interface, increased with anneal duration; this behavior is currently being investigated. We note that these features were not present if PEDOT:PSS annealing was performed for less than 30 $\min$.

Auger surface mapping (Fig. 3-6) revealed a higher carbon (but no sulfur) concentration in those aggregates, which indicates that the aggregates were predominantly of PCBM. Increased PCBM level near the cathode following annealing of PEDOT:PSS/P3HT:PCBM is a known phenomenon, which facilitates electron extraction, improving the efficiency of the solar cells [31-33]. Similarly, the PCBM aggregates may result in an improved FF, since more of the acceptor molecules contact the metal cathode, 

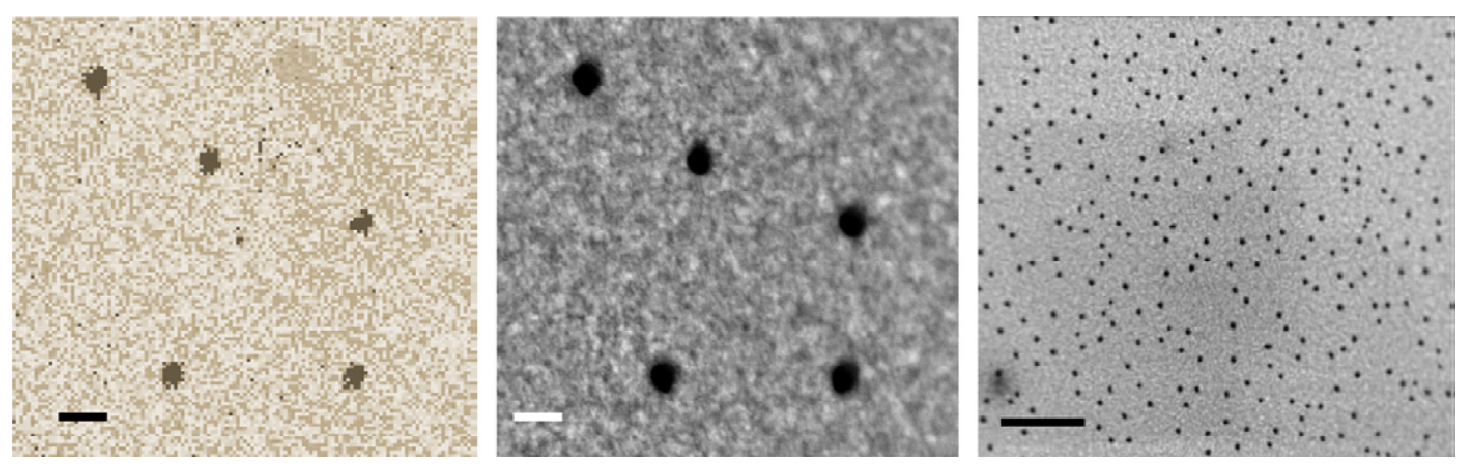

Fig. 3-6. Left: Auger carbon mapping of the surface of P3HT:PCBM spin-coated on top of the EG-treated PEDOT:PSS post-fabrication of the latter; the darker color indicates a higher concentration, center: the corresponding SEM image with $10 \square m$ scale bar, and right: SEM image--with $100 \square m$ scale bar showing the distribution of the aggregates.

resulting in more efficient charge collection. Moreover, the aggregates may also lead to light scattering into the active layer, and thus increased path of the light and consequently, its absorption.

\section{Conclusions}

Various treatments of the PEDOT:PSS layer in ITO/PEDOT:PSS/P3HT:PCBM/ Ca/Al solar cells resulted in improved overall device performance. In particular, the use of a PEDOT:PSS film with spin coated EG on it post-fabrication resulted in an increase in the P3HT:PCBM absorption, and hence, an increase of $\sim 16 \%$ in $I_{\mathrm{SC}}$ and a $\sim 27 \%$ increase in PCE, from $3.7 \%$ in the cell with the untreated PEDOT:PSS to $4.7 \%$ in the former. The FF increased to $71-72 \%$ (from $\sim 68 \%$ in the untreated cell). Dilution of PEDOT:PSS with DI water, and not only with organic solvents, also improved device performance. Based on the above results, it appears that the improved devices result mostly from an increased surface roughness of the $\mathrm{P} 3 \mathrm{HT}: \mathrm{PCBM}$ associated with the treatment and consequently 
graininess of the PEDOT:PSS layers. The increased roughness generates a better contact with the metal electrode, which, possibly, together with the observed PCBM aggregates near the cathode improves charge extraction. The improved PEDOT:PSS transmission and PEDOT:PSS/P3HT:PCBM absorption, together with the improved PEDOT:PSS conductivity in some of the cases, improved the $I_{\mathrm{SC}}$ and the overall cell performance. This improvement is possibly also due to improved light scattering by the rougher surfaces that results in enhanced absorption in the active layer. The results do not indicate that a change in the thickness of the PEDOT:PSS films is a major contributor to the observed improvements, as optimized spin-coating conditions were employed in each case (untreated and treated PEDOT:PSS) and the optimized thicknesses of the different layers were comparable. Similarly, changes in the PEDOT:PSS conductivity did not correlate with the improved performance. The simple routes that led to the significantly increased PCE are expected to be applicable to other organic-based solar cells.

\section{Acknowledgements}

This work was partially supported by the Iowa Power Fund and the Director for Energy Research, Office of Basic Energy Sciences, USDOE. Ames Laboratory is operated by Iowa State University for the US Department of Energy (USDOE) under Contract No. DE-AC 02-07CH11358.

\section{References}

[1] B. A. Gregga, M. C. Hanna, J. Appl. Phys. 93 (2003) 3605.

[2] H. Hoppea, N.S. Sariciftci, J. Mater. Res. 19 (2004) 1924.

[3] T. L. Benanti, D. Venkataraman, Photosynth. Res. 87 (2006) 73.

[4] C. J. Brabec, Sol. Energy Mater. Sol. Cells 83 (2004) 273. 
[5] M. Reyes-Reyes, K. Kim, D.L. Carroll, Appl. Phys. Lett. 87 (2005) 083506.

[6] J. D. Servaites, S. Yeganeh, T. J. Marks, M. A. Ratner, Adv. Funct. Mater. 20 (2010) 97.

[7] G. Li, V. Shrotriya, J. Huang, Y. Yao, Tom Moriarty, K. Emery, Y. Yang, Nat. Mater. $4(2005) 864$.

[8] G. Li, V. Shrotriya, Y. Yao, Y. Yang, J. Appl. Phys. 98 (2005) 043704-1.

[9] M. D. Irwin, D. B. Buchholz, A. W. Hains, R. P. H. Chang, T. J. Marks, Proc. Nat. Acad. Sci. USA 105 (2008) 2783.

[10] J. Y. Kim, S. H. Kim, H.-H. Lee, K. Lee, W. Ma, X. Gong, A. J. Heeger, Adv. Mater. 18 (2006) 572.

[11] A. Roy, S. H. Park, S. Cowan, M. H. Tong, S. Cho, K. Lee, A. J. Heeger, Appl. Phys. Lett. 95 (2009) 013302-1.

[12] J. Y. Kim, K. Lee, N. E. Coates, D. Moses, T.-Q. Nguyen, M. Dante, A. J. Heeger, Science 317 (2007) 222.

[13] A. Moliton, J.-M. Nunzi, Polym. Int. 55 (2006) 583.

[14] Y. Shen, A. R. Hosseini, M. H. Wong, G. G. Malliaras, ChemPhysChem 5 (2004) 16.

[15] M. D. Perez, C. Borek, S. R. Forrest, M. E. Thompson, J. Am. Chem. Soc. 131 (2009) 9281.

[16] B. P. Rand, D. P. Burk, S. R. Forrest, Phys. Rev. B 75 (2007) 115327-1.

[17] J. D. Servaites, M. A. Ratner, T. J. Marks, Appl. Phys. Lett. 95 (2009) 163302-1.

[18] D. Gupta, M. Bag, K. S. Narayan, Appl. Phys. Lett. 92 (2008) 093301.

[19] M.-S. Kim, B.-G. Kim, J.-S. Kim, ACS Appl. Mater. Interfaces 1 (2009) 1264. 
[20] S. Timpanaro, M. Kemerink, F. J. Touwslager, M. M. De Kok, S. Schrader, Chem. Phys. Lett. 394 (2004) 339.

[21] J. Ouyang, Q. Xua, C.-W. Chua, Y. Yang, G. Li, J. Shinar, Polymer 45 (2004) 8443.

[22] F. Zhang, M. Johansson, M. R. Andersson, J. C. Hummelen, O. Inganas, Adv. Mater. $14(2002) 662$.

[23] S.-I. Na, S.-S. Kim, J. Jo, D.-Y. Kim, Adv. Mater. 20 (2008) 4061.

[24] S. H. Eom, S. Senthilarasu, P. Uthirakumar, S. Ch. Yoon, J. Lim, C. Lee, H. S. Lim, J. Lee, S.-H. Lee, Org. Electron. 10 (2009) 536.

[25] T. Ameri, G. Dennler, C. Waldauf, H. Azimi, A. Seemann, K. Forberich, J. Hauch, M. Scharber, K. Hingerl, C. J. Brabec, Adv. Funct. Mater. 20 (2010) 1592.

[26] J. Y. Kim, J. H. Jung, D. E. Lee, J. Joo, Synth. Met. 126 (2002) 311.

[27] S. K. M. Jönsson, J. Birgerson, X. Crispin, G. Greczynski, W. Osikowicz, A. W. D. van der Gon, W. R. Salaneck, M. Fahlman, Synth. Met. 139 (2003) 1.

[28] X. Crispin, S. Marciniak, W. Osikowicz, G. Zotti, A. W. Denier van der Gon, F. Louwet, M. Fahlman, L. Groenendaal, F. de Schryver, W. R. Salaneck, J. Polym. Sci. Pol. Phys. 41 (2003) 2561.

[29] L. A. A. Pettersson, S. Ghosh, O. Inganäs, Org. Electron. 3 (2002) 143.

[30] W. H. Kim, A. J. Mäkinen, N. Nikolov, R. Shashidhar, H. Kim, Z. H. Kafafi, Appl. Phys. Lett. 80 (2002) 3844.

[31] M. Campoy-Quiles, T. Ferenczi, T. Agostinelli, P. G. Etchegoin, Y. Kim, T. D. Anthopoulos, P. N. Stavrinou, D. D. C. Bradley, J. Nelson, Nat. Mater. 7 (2008) 158.

[32] S. S. Van Bavel, E. Sourty, G. De With, J. Loos, Nano Lett. 9 (2009) 507. 
[33] A. J. Parnell, A. D. F. Dunbar, A. J. Pearson, P. A. Staniec, A. J. C. Dennison, H.

Hamamatsu, M. W. A. Skoda, D. G. Lidzey, R. A. L. Jones, Adv. Mater. 22 (2010) 2444. 


\title{
Chapter 5. Thin air-plasma-treated alkali fluoride layers for improved hole extraction in copper phthalocyanine $/ \mathrm{C}_{70}$-based solar cells
}

A paper published in Journal of Photonics for Energy

Teng Xiao, Weipan Cui, Min Cai, Rui Liu, James W. Anderegg, Joseph Shinar and Ruth Shinar

\begin{abstract}
Alkali fluorides, mostly $\mathrm{LiF}$ and $\mathrm{CsF}$, are well-known to improve electron injection/extraction in organic light-emitting diodes (OLEDs)/organic solar cells (OSCs). They are also utilized, though to a lesser extent, for hole injection in OLEDs. Here we demonstrate a new role for such fluorides in enhancing OSCs' hole extraction. We show that an ultrathin air-plasma-treated alkali fluoride layer between the ITO anode and the active layer in copper phthalocyanine $(\mathrm{CuPc}) / \mathrm{C}_{70}$-based OSCs increases the short circuit current by up to $\sim 17 \%$ for cells with $\mathrm{LiF}$ and $\sim 7 \%$ for cells with $\mathrm{NaF}$ or CsF. The effects of the fluoride layer thickness and treatment duration were evaluated, as were OSCs with oxidized and plasma-treated $\mathrm{Li}$ and UV-ozone treated LiF. Measurements included current-voltage, absorption, external quantum efficiency (EQE), atomic force microscopy, and X-ray photoelectron spectroscopy, which showed the presence of alkali atoms, F, and $\mathrm{O}$ at the treated ITO/fluoride surface. The EQE of optimized devices with LiF increased at wavelengths $>560 \mathrm{~nm}$, exceeding the absorption increase. Overall the results indicate that the improved performance is due largely to enhanced hole extraction, possibly
\end{abstract}


related to improved energy-level alignment at the fluorinated ITO/CuPc interface, reduced OSC series resistance, and in the case of $\mathrm{LiF}$, improved absorption.

\section{Introduction}

Organic solar cells (OSCs) are promising to become a low-cost and environmentally friendly alternative for inorganic solar cells (SCs) [1-2]. They can be deposited on flexible substrates such as plastic and are potentially printable [3-4]. Small molecule OSCs have the advantage of simple layer-by-layer deposition, which is a problem with polymer SCs due to the difficulty of finding orthogonal solvents suitable for the different layers [5-6].

As is well known, one of the outstanding challenges of OSCs is to enhance extraction of photogenerated charge carriers. As cell performance depends greatly on the interfaces between the various layers [7-9], it is essential to minimize the energy barrier between the electrodes and the organic layers to achieve a nearly Ohmic contact. Different interfacial layers between the electrodes and the organic layers have been used to improve charge collection and reduce surface recombination. For example, poly $(3,4-$ ethylenedioxy thiophene): poly(styrenesulfonate) (PEDOT:PSS) [10], $\mathrm{MoO}_{3}$ [11], $\mathrm{V}_{2} \mathrm{O}_{5}$ [12], and $\mathrm{NiO}_{\mathrm{x}}$ [13]were used for efficient hole collection in OSCs. LiF [14], CsF [15], $\mathrm{Cs}_{2} \mathrm{CO}_{3}$ [16] and $\mathrm{TiO}_{\mathrm{x}}$ [17] interlayers deposited between the organic layers and the cathode were found to assist in electron collection, increasing the power conversion efficiency (PCE) [9-10].

In organic light emitting diodes (OLEDs), $\mathrm{LiF}$ and $\mathrm{CsF}$ have been widely used to enhance electron injection at the metal cathode [18-21]. It was reported that they either 
dope the preceding organic layer [22-23], form dipole layers at the interface [24], or, in some cases, react with the preceding organic layer [25]. It was also reported that $\mathrm{LiF} / \mathrm{Al}$ yields a lower workfunction electrode [19, 26-27]. A recent electron paramagnetic resonance study of OLEDs showed that the doping effect by Li was strongly dependent on the organic material adjacent to the $\mathrm{LiF}$ [28]. Similar behavior was found in OSCs [29].

While it is well established that in typical OLEDs LiF serves as an efficient electron injection layer, studies on $\mathrm{ITO} / \mathrm{LiF}$ demonstrated improved hole injection in OLEDs as well [30]. This improvement was attributed to an increased ITO/LiF work function to $w_{f}$ $\sim 5.2 \mathrm{eV}$ with $1 \mathrm{~nm} \mathrm{LiF}$, from $w_{f} \sim 4.8 \mathrm{eV}$ of the ITO [31]. The $w_{f}$ further increased with LiF film thickness to $5.6 \mathrm{eV}$ for $5 \mathrm{~nm} \mathrm{LiF}$ on ITO. NaF (on ITO) was also reported to assist in hole injection in OLEDs following UV-ozone treatment, also as a result of an increased $w_{f}$ to $5.2 \mathrm{eV}$ [32]. The formation of $\mathrm{Na}-\mathrm{O}$ bonds was proposed to be responsible for this increased $w_{f}$. Recently, an increase in the workfunction of chlorinated ITO was reported [33-34]. This increase was associated with a layer of surface In-Cl dipoles [33]. Hence, alkali fluorides, like oxides, are also likely to increase the composite ITO workfunction for better alignment with the highest occupied molecular orbital (HOMO) of the adjacent organic active layer, copper phthalocyanine $(\mathrm{CuPc})$ in this study.

This work shows for the first time enhanced hole extraction in OSCs induced by ultrathin air-plasma treated alkali fluoride layers deposited on the ITO anodes. The structure of the devices was ITO/LiF, NaF or $\mathrm{CsF}(x \mathrm{~nm}) / \mathrm{CuPc}(15 \mathrm{~nm}) / \mathrm{C}_{70}(30$ or 27 $\mathrm{nm}) /$ Bphen $(3.5 \mathrm{~nm}) / \mathrm{Al}(120 \mathrm{~nm})$ (Bphen is 4,7-diphenyl-1,10-phenanthroline; the thin Bphen layer acts as an exciton-blocking layer) [35]. We demonstrate that $\mathrm{LiF}$, and to a 
lesser extent $\mathrm{NaF}$ and $\mathrm{CsF}$, enhance hole collection following air-plasma treatment. We investigated the effect of the duration of the air-plasma treatment, including the effect of the layers on the subsequent growth of the $\mathrm{CuPc}$ and $\mathrm{C}_{70}$ layers. Reference measurements with UV-ozone-treated $\mathrm{LiF}$ and differently-treated $\mathrm{Li}$ layers on the ITO were also performed. As expected. these measurements exclude the effect of Li diffusion into the active layer in enhancing device performance, and prove that pristine $\mathrm{Li}-\mathrm{O}$ bonds do not improve the short circuit current $J_{S C}$ to the same degree as the treated LiF layer. $J-V$ characteristics, XPS, absorption, and external quantum efficiency (EQE) spectra, as well as atomic force microscopy (AFM) were employed to elucidate the observed OSC performance enhancement. The treated fluorides are believed to reduce the energy barrier for hole extraction, which leads to a higher $J_{\mathrm{SC}}$ and PCE. Importantly, the plasma treatment of the alkali fluorides was essential for improving the Ohmic contact, lowering the high series resistance $R_{\mathrm{S}}$ observed in devices with the as-deposited fluorides.

\section{Experimental procedures}

Devices studied were of the structure ITO/LiF, NaF or $\mathrm{CsF}(x \mathrm{~nm}) / \mathrm{CuPc}(15 \mathrm{~nm}) / \mathrm{C}_{70}$ (30 or $27 \mathrm{~nm}) / \mathrm{Bphen}(3.5 \mathrm{~nm}) / \mathrm{Al}(120 \mathrm{~nm})$. These thicknesses of $\mathrm{CuPc}, \mathrm{C}_{70}$, and Bphen layers were found to be the optimal. The active area of all cells was $0.11 \mathrm{~cm}^{2}$. The ITOcoated glass substrates were purchased from Colorado Concept Coatings. Prior to cell fabrication, they were cleaned sequentially with surfactant, deionized water, acetone, and isopropanol, and blown dry with nitrogen after the cleaning process. In all cases the ITO was air-plasma treated for $20 \mathrm{~min}$; changing the duration had only a minor effect on cell performance. The alkali fluoride layers were deposited on the ITO by thermal vacuum 
$\left(\sim 10^{-6}\right.$ mbar $)$ evaporation inside a glovebox and then air-plasma-treated. Next, the organic layers were thermally evaporated.

The effect of the interfacial layers was studied systematically. The thickness of the fluoride layers varied from 0 to $4 \mathrm{~nm}$, by a $1 \mathrm{~nm}$ step. Air-plasma treatment (Harrick PDC-32G Plasma Cleaner/sterilizer; $18 \mathrm{~W}$ ) was performed on these layers for durations of $0,10,20$, and 30 minutes. The deposition rate of $\mathrm{CuPc}$ and $\mathrm{C}_{70} \mathrm{was} \sim 0.1 \mathrm{~nm} / \mathrm{s}$, and of BPhen $\sim 0.15 \mathrm{~nm} / \mathrm{s}$. CuPc (dye content 97\%), Bphen ( $\geq 99 \%), \mathrm{LiF}(99.995 \%), \mathrm{NaF}$ (99.99\%), and CsF (99.9\%) were all purchased from Sigma-Aldrich. $\mathrm{C}_{70}(>99 \%)$ was purchased from Nano-C. All materials were used without further purification.

The effects of treating $\mathrm{LiF}$ in a UV ozone oven or replacing $\mathrm{LiF}$ by a $1 \mathrm{~nm} \mathrm{Li}$ layer were also studied. Three different treatments of the latter were tested: $(i)$ an untreated thin Li layer on which $\mathrm{CuPc}$ was deposited without breaking the vacuum, (ii) an air-oxidized Li layer, and (iii) an air-oxidized layer that was subsequently air-plasma treated for 20 $\min$.

$J-V$ characteristics of the OSCs were obtained using a $100 \mathrm{~mW} / \mathrm{cm}^{2} \mathrm{ELH}$ bulb for illumination. The EQE was measured at $0 \mathrm{~V}$. Absorption spectra were taken with an Ocean Optics spectrometer. XPS data were obtained using a Physical Electronics 5500 multi-technique system, and AFM images were acquired with a Digital Instruments system. We note that all the experiments were performed multiple times to ensure the validity of the conclusions.

\section{Results and discussion}

Effect of LiF thickness 
LiF, as the other alkali fluorides, is an insulator with a high bandgap [36]. This attribute, as expected, is in accordance with our results that show that for untreated 1 to 4 $\mathrm{nm} \mathrm{LiF}$, the series resistance $R_{\mathrm{s}}$ of the OSCs increases from $\sim 78$ to $331 \Omega$. However, as discussed later, the $R_{\mathrm{s}}$ values decrease to $\sim 71-83 \Omega$ following air-plasma treatment of the LiF.

LUMO

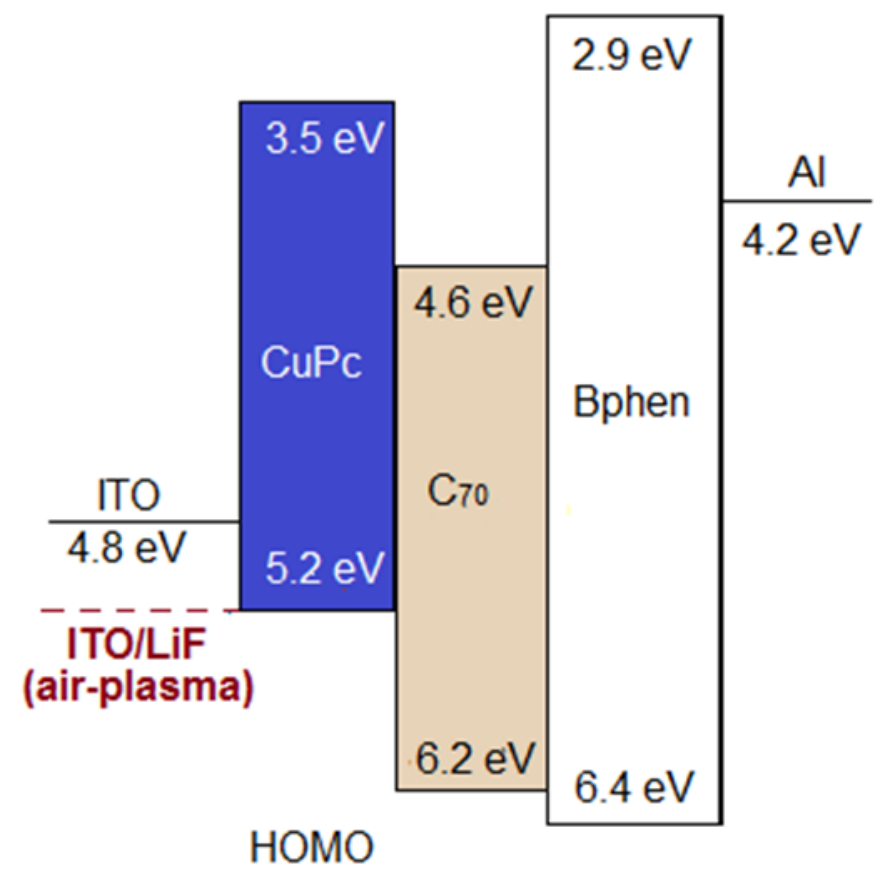

Fig. 4-1. Schematic energy band diagram of ITO/LiF/CuPc/C $70 / B P h e n / A l$. The ITO/1 nm LiF workfunction is believed to align with the HOMO level of CuPc upon air-plasma treatment for 10-20 $\min$ ( see text).

The energy level diagram of the devices is shown in Fig. $4-1$. The $w_{f}$ of ITO is $\sim 4.8$ $\mathrm{eV}$, which was found to be suitable for hole extraction from $\mathrm{CuPc}$ [37]. It was reported that $w_{f}$ of $\mathrm{ITO} / \mathrm{LiF}(1 \mathrm{~nm})$ increases to $\sim 5.2 \mathrm{eV}[31]$, which matches well the $\sim 5.2 \mathrm{eV}$ level of the $\mathrm{HOMO}$ of $\mathrm{CuPc}$. For $3 \mathrm{~nm} \mathrm{LiF}$, however, $w_{f}$ further increases to $5.5 \mathrm{eV}$ [31]. 
These reported values are also consistent with our results of cell characteristics, shown in Table 4-1. The Table shows the values of $J_{\mathrm{SC}}$, the open-circuit voltage $\left(V_{\mathrm{OC}}\right)$, the fill factor $(\mathrm{FF})$, and PCE of the different devices. As seen, LiF improves $J_{\mathrm{SC}}$ even before airplasma treatment. This can be explained by a reduced barrier height associated with the presence of surface dipoles. However, without plasma treatment the performance of the OSC deteriorates when the LiF layer is $>2 \mathrm{~nm}$ thick. This is not surprising based on the increased $R_{s}$.

Table 4-1 Device properties of ITO/LiF $(x \mathrm{~nm}) / \mathrm{CuPc}(15 \mathrm{~nm}) / C_{70}(30 \mathrm{~nm}) /$ Bphen $(3.5$ $n m) / A l$, where $x=0,1,2,3$, and $4 \mathrm{~nm}$, with and without plasma treatment.

\begin{tabular}{|c|c|c|c|c|c|}
\hline $\begin{array}{c}\text { LiF } \\
\text { thickness }\end{array}$ & Plasma etching period & Voc & $J s c$ & $F F$ & PCE \\
$(\mathrm{nm})$ & $(\mathrm{min})$ & $(\mathrm{V})$ & $\left(\mathrm{mA} / \mathrm{cm}^{2}\right)$ & $(\%)$ & $(\%)$ \\
\hline 1 & 0 & 0.46 & 6.02 & 59.2 & 1.65 \\
\hline 2 & 0 & 0.48 & 6.19 & 55.7 & 1.64 \\
\hline 3 & 0 & 0.47 & 6.23 & 54.2 & 1.59 \\
\hline 4 & 0 & 0.48 & 6.15 & 46.4 & 1.36 \\
\hline $0 *$ & 0 & 0.45 & 6.15 & 59.1 & 1.64 \\
\hline $\mathbf{1}$ & 20 & $\mathbf{0 . 4 5}$ & $\mathbf{7 . 2 2}$ & $\mathbf{5 8 . 6}$ & $\mathbf{1 . 9 0}$ \\
\hline 2 & 20 & 0.45 & 7.18 & 58.0 & 1.86 \\
\hline 3 & 20 & 0.45 & 7.11 & 56.4 & 1.78 \\
\hline 4 & 20 & & & & \\
\hline & 20.44 & 7.21 & 52.1 & 1.64 \\
\hline & 20 & & & & \\
\hline & 20 & & & & \\
\hline
\end{tabular}

* Reference device; in all cases the ITO was plasma-treated. 
Following air-plasma treatment $J_{\mathrm{SC}}$ and PCE for 1-2 $\mathrm{nm}$ thick LiF layers improved beyond the enhancement with the untreated LiF, which, as mentioned, is related to the reduced $R_{s}$, but possibly only when $w_{f}$ does not significantly exceed $\sim 5.2 \mathrm{eV}$. For the 1 $\mathrm{nm}$ LiF layer, $J_{\mathrm{SC}}$ increased by $>17 \%$ and PCE increased from $\sim 1.6 \%$ to $1.9 \%$ following 20 min of air-plasma treatment. As shown below, this increase is largely associated with improved hole extraction, which is likely related to closer energy level alignment between the ITO/treated $\mathrm{LiF}$ anode and $\mathrm{CuPc}$, and hence a better Ohmic contact.

Fig. 4-2 shows the $J-V$ curves of the cells without $\mathrm{LiF}$ and with $1 \mathrm{~nm} \mathrm{LiF}$ plasmatreated for 10, 20, and $30 \mathrm{~min}$. As seen, the plasma duration is important, with the 20 min

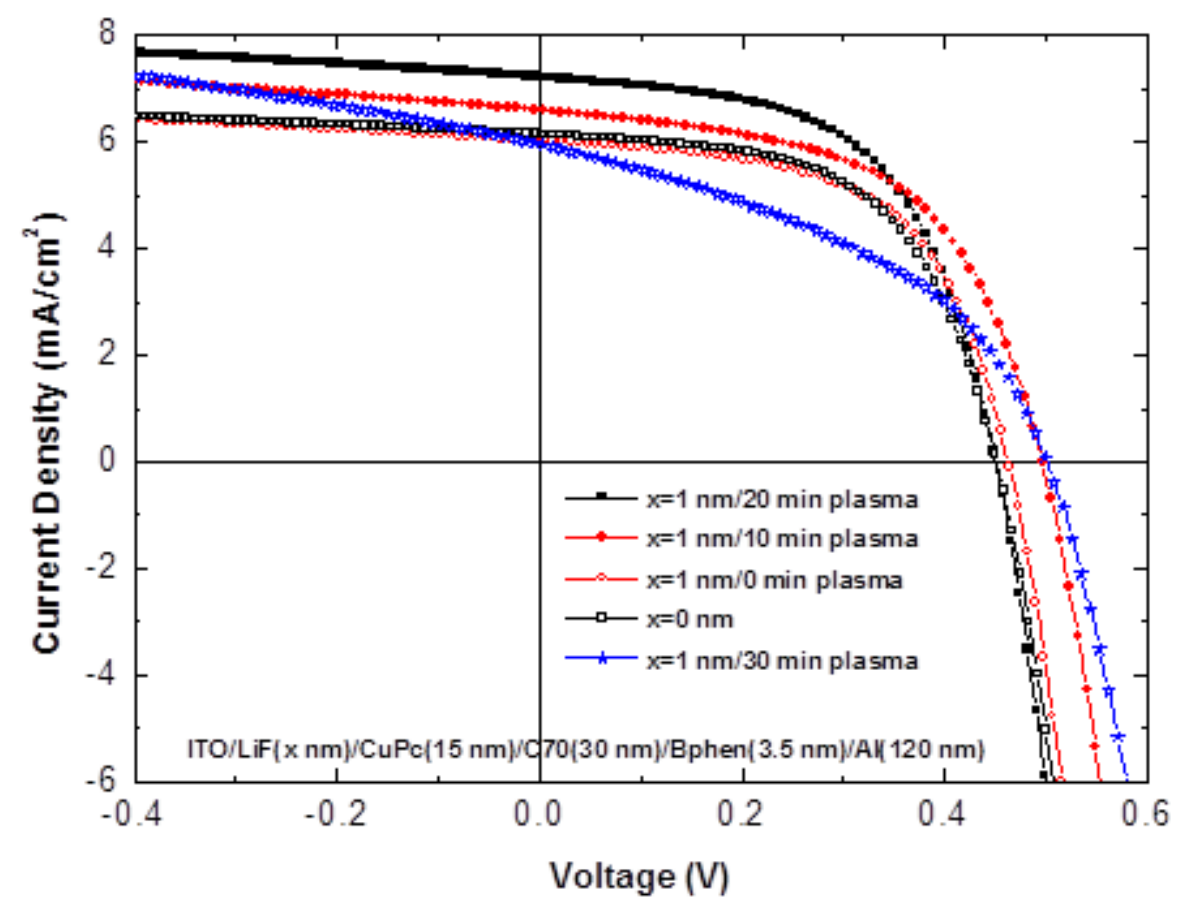

Fig. 4-2. J-V characteristics of ITO/x nm LiF/15 nm CuPc/30 nm $C_{70} / 3.5 \mathrm{~nm}$ BPhen/Al devices, with LiF air-plasma treatment periods of 10, 20, or 30 min. The J-V curve for a device with $x=0 \mathrm{~nm}$ is also shown as a reference. 
treatment resulting in the highest $J_{\mathrm{SC}}$. This optimal $20 \mathrm{~min}$ period is probably related to optimal Li-F and Li-O levels at the ITO surface, which would affect the energy level alignment. XPS data, discussed in detail in Section 3.3, indeed indicated the presence of $\mathrm{Li}, \mathrm{F}$, and $\mathrm{O}$ in the ITO/ultrathin films following plasma etching.

To verify that the air-plasma-treated $\mathrm{LiF}$ is responsible for the improved device performance, we additionally studied the effect of UV-ozone treatment of ITO/LiF, which did improve $J_{\mathrm{SC}}$, but only by $\sim 6 \%$, i.e., much less than the air-plasma treatment. We also evaluated the possibility that the OSCs' performance is affected by the diffusion of $\mathrm{Li}$ atoms into the organic layer or improved by the presence of only Li-O bonds. Devices with a $1 \mathrm{~nm}$ metallic Li layer resulted in non-performing OSCs, indicating that if Li diffusion occurs it is, as expected, detrimental. An air-oxidized Li layer, however, did yield an operable OSC, but a poor one, with $V_{\mathrm{OC}}=0.22 \mathrm{~V}, J_{\mathrm{SC}}=2.24 \mathrm{~mA} / \mathrm{cm}^{2}$, and $\mathrm{FF}=$ 24.4\%. But when this oxidized Li layer was air-plasma treated for $20 \mathrm{~min}$, the cell performance improved strongly, and $J_{\mathrm{SC}}$ reached a value higher by $\sim 5 \%$ than that of the "standard" ITO/CuPc/C $70 / \mathrm{Bphen} / \mathrm{Al}$ cell. Hence, these experiments exclude a contribution of Li diffusion to the enhanced OSC performance, but support a contribution of $\mathrm{Li}-\mathrm{O}$ bonds to the enhancement. Alkali oxides are known to reduce $w_{f}$ at metal cathodes [38], but their effect on ITO/LiF is not clear. The air plasma increases the level of Li-O bonds, indicating that an optimized level of such bonds is needed to yield the observed improvement in performance. Moreover, as the devices with treated LiF were superior to those with $\mathrm{Li}-\mathrm{O}$ only, it is clear that $\mathrm{F}$ or $\mathrm{LiF}$ is the key to improving the performance. 
Absorption and EQE

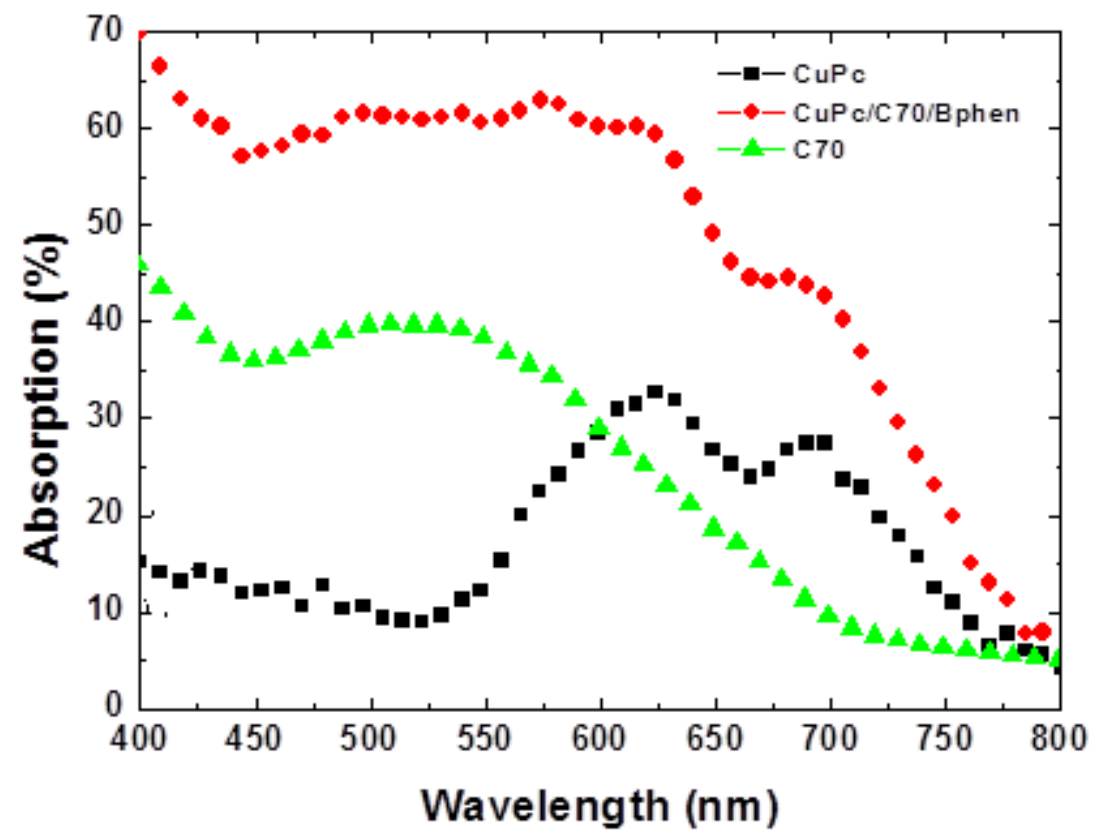

Fig. 4-3. Absorption spectra of $15 \mathrm{~nm} \mathrm{CuPc,} 30 \mathrm{~nm} C_{70}$ and $15 \mathrm{~nm} \mathrm{CuPc/30} \mathrm{nm}$ $C_{70} / 3.5 \mathrm{~nm}$ BPhen films.

Fig. 4-3 shows the absorption spectra of $\mathrm{CuPc}$ films, $\mathrm{C}_{70}$ films, and the $\mathrm{CuPc} / \mathrm{C}_{70} / \mathrm{Bphen}$ structure. Fig. 4-4(a) compares the absorption spectra of the complete devices with and without the $1 \mathrm{~nm}$ treated $\mathrm{LiF}$ layer. The absorption of the devices was obtained by subtracting the specular reflection due mostly to the Al cathode from the incident light. As seen, the absorption of the device pixel with the $1 \mathrm{~nm}$ treated $\mathrm{LiF}$ is stronger at $\sim 650-750 \mathrm{~nm}$ in comparison to that of the device pixel fabricated directly on the ITO-coated glass.

Fig. 4-4(b) shows the EQE spectra of the two devices. As seen, the EQE of the device with the treated $\mathrm{LiF}$ increased in the $\sim 550$ to $750 \mathrm{~nm}$ range relative to the device with no LiF. Comparison with Fig. 4-4(a) shows that the increase in the EQE is stronger than the 
increase in the absorption, which was largely unchanged at $\sim 550-650 \mathrm{~nm}$. The latter wavelength range corresponds to an absorption band of the $\mathrm{CuPc}$

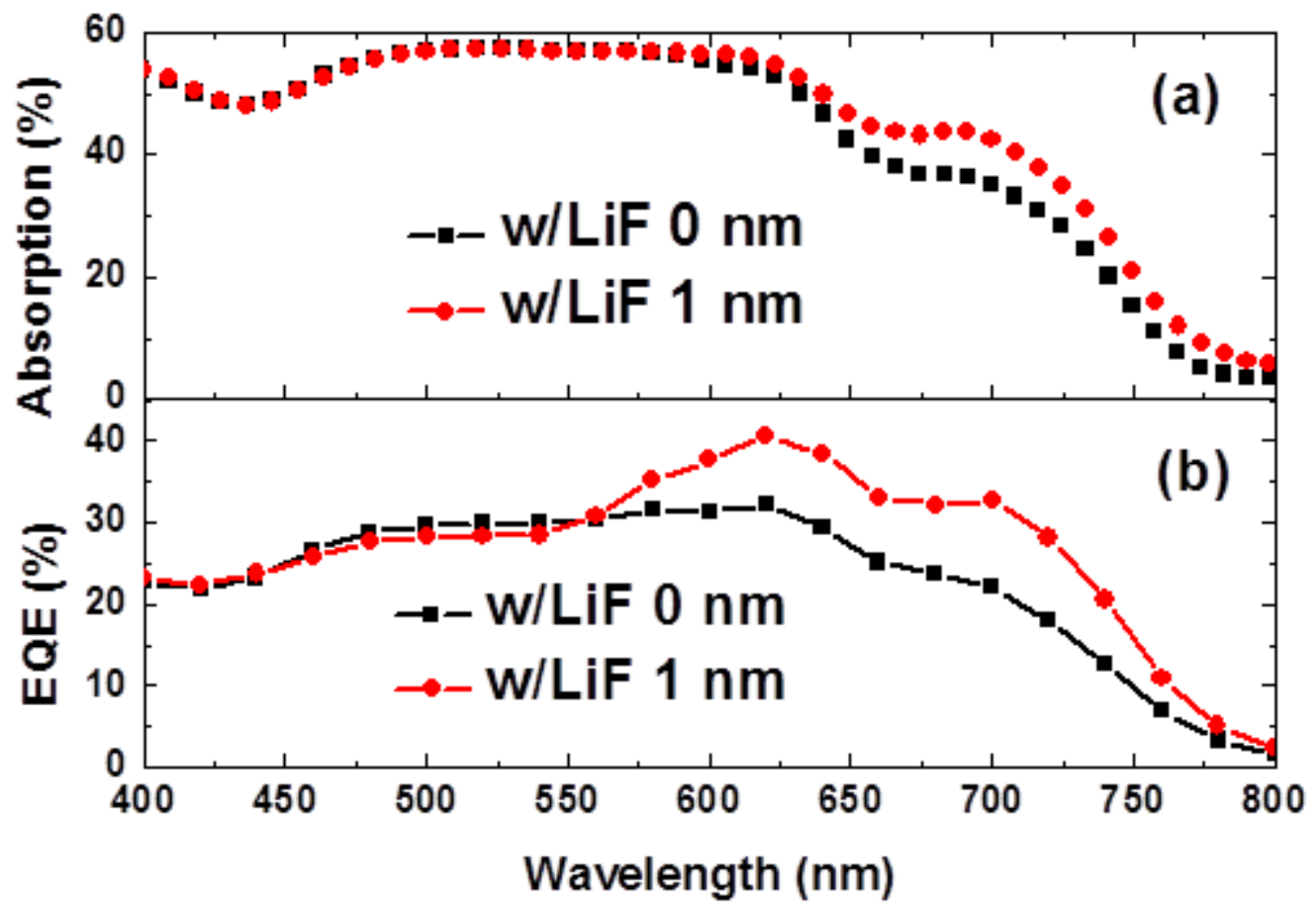

Fig. 4-4. Comparison of (a) absorption spectra and (b) EQE of the devices with and without the $1 \mathrm{~nm}$ plasma-treated LiF film.

layer (see Fig. 4-3), which is deposited directly on the ITO/LiF surface. This result together with the EQE spectra indicates that in the presence of the treated LiF layer some of the charges otherwise lost to recombination at the ITO/CuPc interface are now collected by the anode. The increased absorption at $\sim 700 \mathrm{~nm}$ is believed to contribute to the increased EQE as well, though to a lesser extent.

XPS results

The presence of $\mathrm{Li}, \mathrm{F}$, and $\mathrm{O}$ on the $\mathrm{ITO} / 1 \mathrm{~nm}$ plasma-treated $\mathrm{LiF}$ surfaces was confirmed by XPS. However, as expected, the ITO constituents are also observed for 
such thin films, even before treatment. Fig. 4-5(a) shows the XPS spectra of ITO/LiF (1 $\mathrm{nm}$ ) before and following 20 min of air-plasma treatment. As seen, the $\mathrm{F} 1 \mathrm{~s}$ binding energy shifted from $685.5 \mathrm{eV}$ to $685.25 \mathrm{eV}$. The former corresponds to the $\mathrm{F} 1 \mathrm{~s}$ bond in $\mathrm{LiF}(685.5 \mathrm{eV})$ [39-40], while the latter is very close to the $\mathrm{F} 1 \mathrm{~s}$ value in $\mathrm{InF}_{3}(685.2 \mathrm{eV})$ [41]. Similar to a conclusion regarding chlorinated ITO [33], the large difference in the electronegativity of In (1.78) and F (3.98) suggests the presence of an In-F surface dipole layer, which increases $w_{f}$.
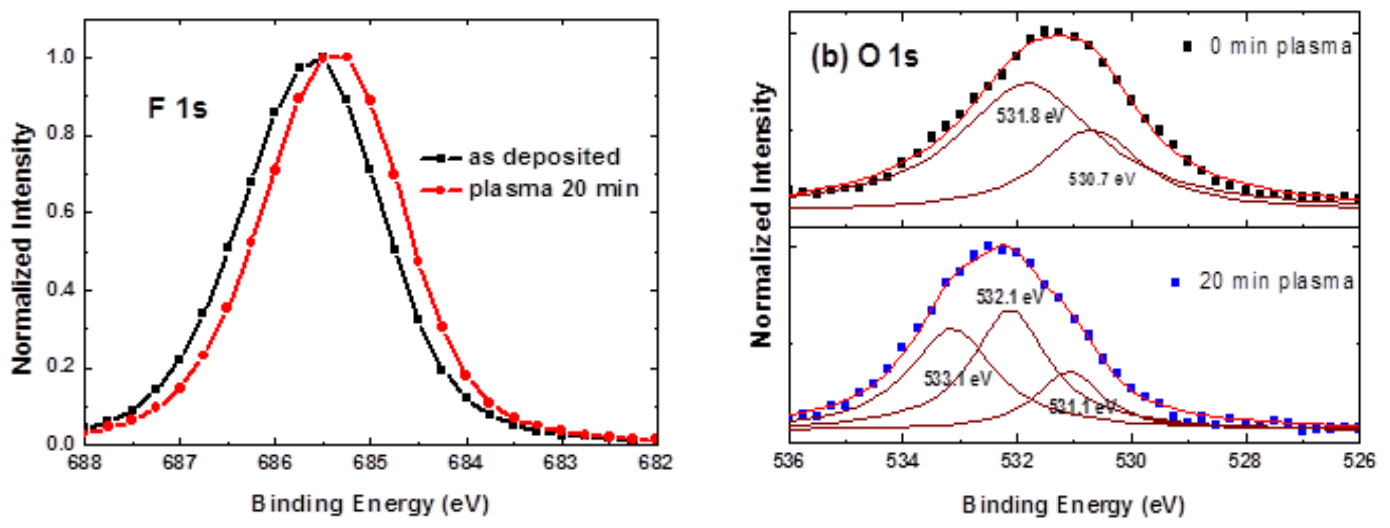

Fig. 4-5. (a) F $1 \mathrm{~s}$ XPS spectra of a $1 \mathrm{~nm} \mathrm{LiF} \mathrm{film} \mathrm{following} 0$ and 20 min plasma treatment. (b) XPS spectra of the $O 1$ s for a $20 \mathrm{~nm}$ LiF film air-plasma treated for 0 and 20 min, with simulated Lorentzian lineshape fits. The sum of the Lorentzian lines, which matches the experimental data, is also shown

To avoid the detection of In or Sn, we tested four $20 \mathrm{~nm}$-thick LiF films that rendered the ITO invisible to XPS. These films were plasma treated for 0, 10, 20, or $30 \mathrm{~min}$. As expected, air-plasma treatment of the $20 \mathrm{~nm} \mathrm{LiF}$ film for 0 to 30 min resulted in a gradual increase in the measured $\mathrm{O}$ level from $\sim 0.5 \%$ to $\sim 9 \%$. Li and $\mathrm{F}$ were still the major surface components (the Li level at $\sim 40 \%$ was unaffected by the plasma duration and that of $\mathrm{F}$ decreased from $\sim 53 \%$ for $0-20$ min of plasma to $\sim 46 \%$ after 30 min of treatment). 
We note that the binding energy of $\mathrm{Li} 1 \mathrm{~s}$ was unchanged for the different plasma durations, which is expected as the binding energy of $\mathrm{Li} 1 \mathrm{~s}$ is almost the same in $\mathrm{LiF}$, $\mathrm{Li}_{2} \mathrm{O}$ and $\mathrm{LiOH}$ [41]. As shown in Fig. 4-5(b), significant changes occurred in the $\mathrm{O} 1 \mathrm{~s}$ line shape, which indicate increased surface $\mathrm{O}$ level stemming from the plasma. Fitting of the $\mathrm{O} 1 \mathrm{~s}$ experimental data to two or three bands is also shown in Fig. 4-5(b). In the nontreated film the peak binding energies are at 531.8 and $530.7 \mathrm{eV}$, which corresponds to $\mathrm{LiOH}(531.5 \mathrm{eV})$ and $\mathrm{Li}_{2} \mathrm{O}(530.6 \mathrm{eV})$, respectively [42]. Following 10 and $20 \mathrm{~min}$ of plasma etching a peak at $\sim 533 \mathrm{eV}$ appears, which corresponds to $\mathrm{Li}_{2} \mathrm{O}_{2}(533.1 \mathrm{eV})$ [42]. This behavior suggests, as expected, the increased formation of (near) surface Li-O bonds as the plasma duration increases. These results are consistent with improved device performance for an optimized concentration of surface $\mathrm{Li}-\mathrm{F}$ and $\mathrm{Li}-\mathrm{O}$ bonds, which possibly improve the energy level alignment and a contact that is closer to Ohmic.

\section{AFM results}

Fig. 4-6 shows tapping mode AFM images of ITO/CuPc and ITO/treated $1 \mathrm{~nm}$ $\mathrm{LiF} / \mathrm{CuPc}$. The $\mathrm{CuPc}$ surface in the latter structure is rougher and grainier than that grown directly on ITO. The root mean square roughness $R_{\text {rms }}$ of CuPc on ITO and on the treated $\mathrm{LiF}$ are 2.8 and $3.6 \mathrm{~nm}$, respectively. A rougher $\mathrm{CuPc} / \mathrm{C}_{70}$ interface can also improve charge transfer in OSCs due to increased contact area.

\section{NaF and CsF layers}

1. NaF. Deposition of 2-3 nm of $\mathrm{NaF}$ on ITO and air-plasma treatment for $20 \mathrm{~min}$ resulted in a much smaller $\sim 6 \%$ increase in $J_{\mathrm{SC}}$. As with the LiF layer, $4 \mathrm{~nm}$ of plasmatreated $\mathrm{NaF}$ worsened the devices. The $\mathrm{NaF}$ probably increases the workfunction of ITO/NaF to $\sim 5.2 \mathrm{eV}[32]$; this $-5.2 \mathrm{eV}$ level is well-aligned with the $-5.2 \mathrm{eV} \mathrm{CuPc}$ 
HOMO level. As seen in Fig. 4-7, the absorption of $\mathrm{NaF} / \mathrm{CuPc} / \mathrm{C}_{70} / \mathrm{BPhen}$ structures is practically unchanged by the addition of the $\mathrm{NaF}$ layer, but the $\mathrm{EQE}$ of the devices increases. Thus, the observed increase in $J_{\mathrm{SC}}$ likely indicates improved hole extraction.

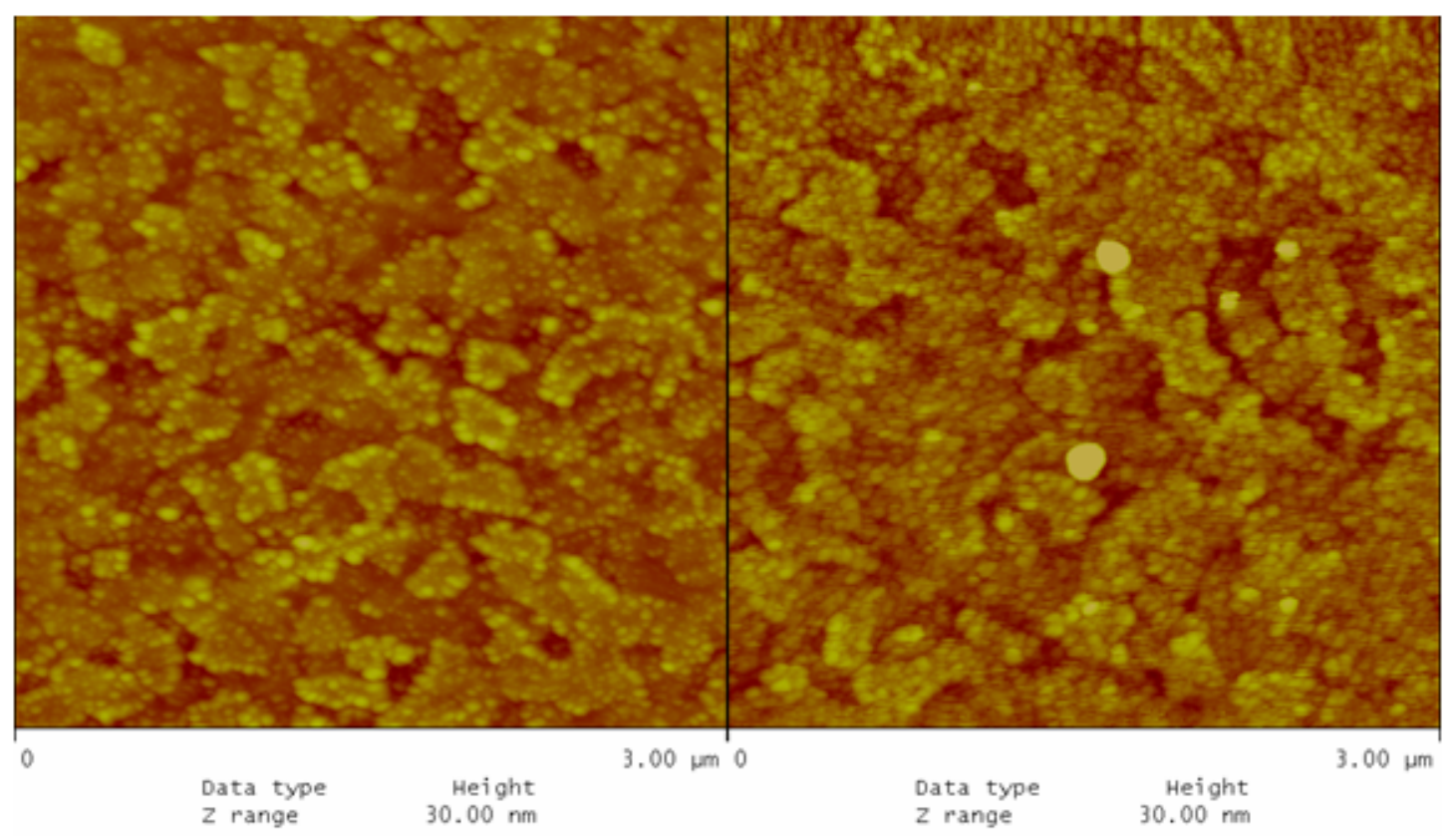

Fig. 4-6. Tapping mode AFM images of ITO/CuPc (left) and ITO/I $\mathrm{nm} \mathrm{LiF/CuPc} \mathrm{(right).}$ The $1 \mathrm{~nm}$ LiF was air-plasma treated for $20 \mathrm{~min}$.

Plasma-treatment of the NaF layer did not have an effect on the surface morphology and roughness as revealed by AFM images. This may also be a factor in the lower enhancement induced by NaF vs LiF. The F level as revealed by XPS decreased from $\sim 42 \%$ to $\sim 29 \%$ following 30 min of plasma treatment of a $30 \mathrm{~nm}$ thick layer. The corresponding $\mathrm{O}$ levels increased from $1 \%$ to $\sim 17 \%$. This situation differs from that with $\mathrm{LiF}$, where the increase in the $\mathrm{O}$ level was milder, up to only $~ 9 \%$, and the final $\mathrm{F}$ level was $\sim 46 \%$. 


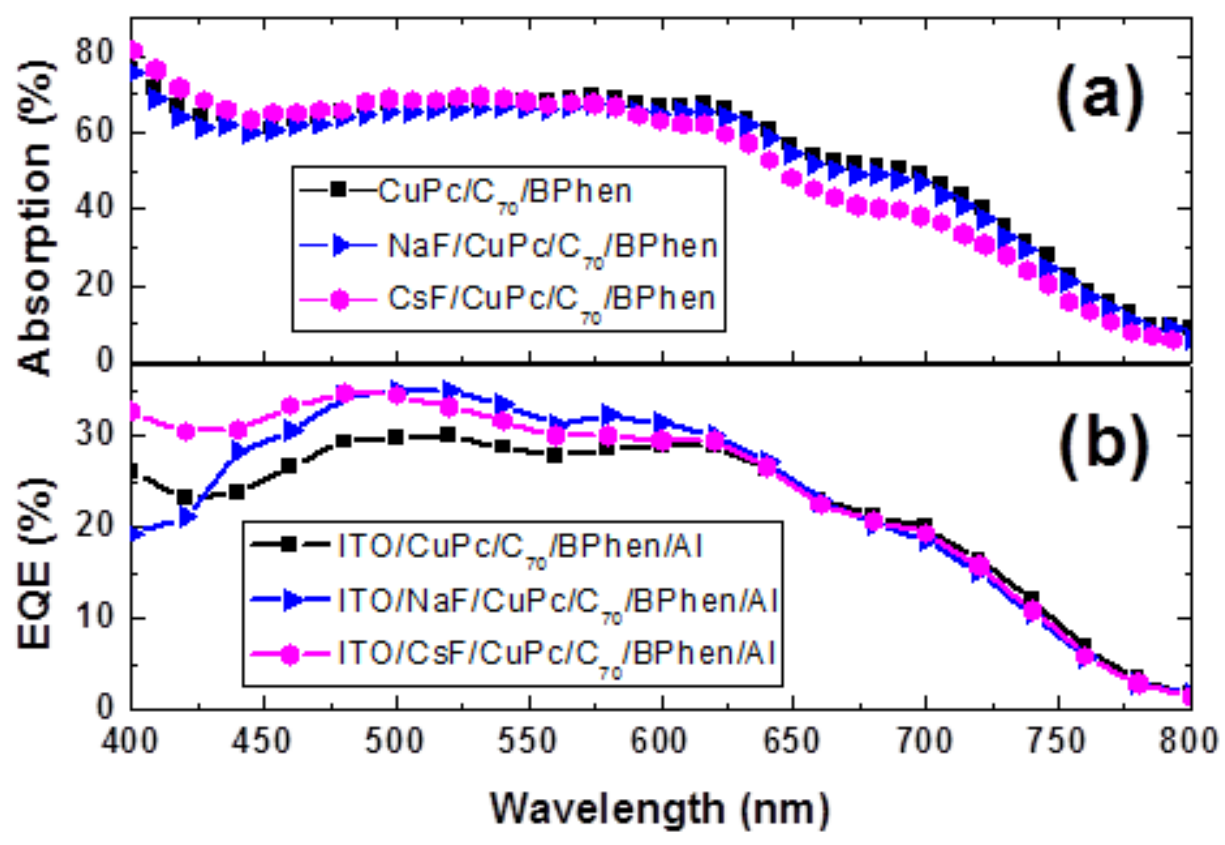

Fig. 4-7. (a) Absorption spectra of structures and (b) EQE spectra of devices with and without $2 \mathrm{~nm} \mathrm{NaF}$ or $1 \mathrm{~nm}$ CsF air-plasma-treated for $20 \mathrm{~min}$.

2. $C s F$. In repeated experiments, devices with untreated $1 \mathrm{~nm} C s F$ completely failed to operate as an OSC due to a high $R_{s}$. This behavior contrasts that of devices with untreated LiF and NaF layers. However, it is in agreement with previous use of untreated CsF layers next to the ITO anode in conventional $\mathrm{CuPc} / \mathrm{C}_{60}$-based solar cells [43]. In these cells, inserting $1 \mathrm{~nm} \mathrm{CsF}$ between ITO and CuPc decreased $V_{\mathrm{OC}}$ from $0.46 \mathrm{~V}$ to $0.25 \mathrm{~V}$ and $J_{\mathrm{SC}}$ from $6.4 \mathrm{~mA} / \mathrm{cm}^{2}$ to $2.5 \mathrm{~mA} / \mathrm{cm}^{2}$ [43]. However, similar to the case of $\mathrm{NaF}$, deposition of $1 \mathrm{~nm}$ of $\mathrm{CsF}$ on the ITO and air-plasma treatment for 20 min (optimal thickness and duration) improved $J_{\mathrm{SC}}$ by $7 \%$ relative to devices with no CsF. As supported by the unchanged absorption of $\mathrm{CsF} / \mathrm{CuPc} / \mathrm{C}_{70} / \mathrm{BPhen}$ structures but increased EQE (Fig. 4-7), this enhancement is, again, probably due largely to improved hole extraction. Plasma treatment of devices with $3-4 \mathrm{~nm}$ of $\mathrm{CsF}$ also resulted in a strong 
drop in cell performance. These different aspects in the behavior of devices with CsF are currently not entirely clear, but may be associated with worsening energy level alignment. We note that XPS of the CsF layers showed the presence of indium (due, of course, to the ITO) even on the surface of a $20 \mathrm{~nm}$ thick layer, unlike the case with $\mathrm{LiF}$ and $\mathrm{NaF}$.

Finally, as mentioned, in all plasma-treated thin alkali fluoride layers (including $1 \mathrm{~nm}$ thick), O, F, and the alkali atoms were detected at the surface. Hence, though the improvement upon addition of treated $\mathrm{NaF}$ and $\mathrm{CsF}$ layers is small, their use assisted in supporting the conclusion that enhanced hole extraction is the main reason for the enhanced OSC performance, given their unaffected light absorption.

\section{Conclusions}

We have shown that a thin $1 \mathrm{~nm}$ layer of $\mathrm{LiF}$ on the ITO anode in $\mathrm{CuPc} / \mathrm{C}_{70}$-based OSCs enhances $J_{\mathrm{SC}}$ and PCE by up to $\sim 17 \%$ following air-plasma treatment due mainly to improved hole extraction. Similar behavior with a $6-7 \%$ enhancement was observed for plasma-treated $\mathrm{NaF}$ and $\mathrm{CsF}$. These observations may be related to improved energetics and hence a nearly Ohmic contact. Formation of alkali-O bonds, based on XPS analyses, is also believed to contribute to the enhanced hole extraction. The best enhancement was observed for a $1 \mathrm{~nm} \mathrm{LiF}$ layer air-plasma treated for $20 \mathrm{~min}$. UV-ozone treatment of such layers had a smaller effect. The light absorption and the EQE of the devices with treated alkali fluoride layers further support hole extraction from $\mathrm{CuPc}$ to the anode as one mechanism responsible for the observed enhanced performance. Light absorption increased for structures with $\mathrm{LiF}$ and was largely unchanged for $\mathrm{NaF}$ or $\mathrm{CsF}$.

The results consequently demonstrate the viability of air-plasma treated thin fluoride 
layers, and in particular LiF, as interfacial layers between the ITO anode and the donor layer in small molecule $\mathrm{CuPc} / \mathrm{C}_{70}$-based OSCs.

\section{Acknowledgments}

This work was partially supported by the Iowa Power Fund. Ames Laboratory is operated by Iowa State University for the US Department of Energy (USDOE) under Contract No. DE-AC 02-07CH11358. TX, MC, RL, and JWA were supported by Office of Basic Energy Sciences, Division of Materials Science and Engineering, USDOE.

\section{References}

[1] A. Shah, P. Torres, R. Tscharner, N. Wyrsch, H. Keppner, Science 285 (1999) 692.

[2] B. Kippelen, J. L. Bredas, Ener. \& Environ.Sci. 2 (2009) 251.

[3] G. Dennler, N. S. Sariciftci, Proc. IEEE 93 (2005) 1429.

[4] F. C. Krebs, H. Spanggard, T. Kjaer, M. Biancardo, J. Alstrup, Mater. Sci. Eng. B 138 (2007) 106.

[5] P. Peumans, A. Yakimov, S. R. Forrest, J. Appl. Phys. 93 (2003) 3693.

[6] M. Riede, T. Mueller, W. Tress, R. Schueppel, K. Leo, Nanotech. 19 (2008) 424001.

[7] S. Braun, W. R. Salaneck, M. Fahlman, Adv. Mater. 21 (2009) 1450.

[8] W. J. Potscavage, A. Sharma, B. Kippelen, Acct. Chem. Res. 42 (2009) 1758.

[9] R. Steim, S. A. Choulis, P. Schilinsky, C. J. Brabec, Appl. Phys. Lett. 92 (2008) 093303.

[10] T. Xiao, W. Cui, J. Anderegg, J. Shinar, R. Shinar, Org. Electron. 12 (2011) 257.

[11] L. Cattin, F. Dahou, Y. Lare, M. Morsli, R. Tricot, S. Houari, A. Mokrani, K. Jondo, A. Khelil, K. Napo, J. C. Bernede, J. Appl. Phys. 105 (2009) 034507. 
[12] G. Li, C. W. Chu, V. Shrotriya, J. Huang, Y. Yang, Appl. Phys. Lett. 88 (2006) 253503.

[13] M. D. Irwin, B. Buchholz, A. W. Hains, R. P. H. Chang, T. J. Marks, Proc. Nat. Acad. Sci. 105 (2008) 2783.

[14] C. J. Brabec, S. E. Shaheen, C. Winder, N. S. Sariciftci, P. Denk, Appl. Phys. Lett. 80 (2002) 1288.

[15] X. X. Jiang, H. Xu, L. G. Yang, M. M. Shi, M. Wang, H. Z. Chen, Sol. Ener. Mater. Sol. Cells 93 (2009) 650.

[16] H.-H. Liao, L.-M. Chen, Z. Xu, G. Li, Y. Yang, Appl. Phys. Lett. 92 (2008) 173303.

[17] J. Y. Kim, S. H. Kim, H. H. Lee, K. Lee, W. L. Ma, X. Gong, A. J. Heeger, Adv. Mater. 18 (2006) 572.

[18] L. S. Hung, C. W. Tang, M. G. Mason, Appl. Phys. Lett. 70 (1997) 152.

[19] S. E. Shaheen, G. E. Jabbour, M. M. Morrell, Y. Kawabe, B. Kippelen, N. Peyghambarian, M. F. Nabor, R. Schlaf, E. A. Mash, N. R. Armstrong, J. Appl. Phys. 84 (1998) 2324.

[20] T. M. Brown, R. H. Friend, I. S. Millard, D. J. Lacey, J. H. Burroughes, F. Cacialli, Appl. Phys. Lett. 79 (2001) 174.

[21] P. Piromreun, H. Oh, Y. L. Shen, G. G. Malliaras, J. C. Scott, P. J. Brock, Appl. Phys. Lett. 77 (2000) 2403.

[22] G. Greczynski, M. Fahlman, W. R. Salaneck, Appl. Surf. Sci. 166 (2000) 380.

[23] G. Greczynski, M. Fahlman, W. R. Salaneck, J. Chem. Phys. 114 (2001) 8628.

[24] R. Schlaf, B. A. Parkinson, P. A. Lee, K. W. Nebesny, G. Jabbour, B. Kippelen, N. Peyghambarian, N. R. Armstrong, J. Appl. Phys. 84 (1998) 6729. 
[25] W. J. Song, S. K. So, K. W. Wong, W. K. Choi, L. L. Cao, Appl. Surf. Sci. 228 (2004) 373.

[26] T. M. Brown, R. H. Friend, I. S. Millard, D. J. Lacey, J. H. Burroughes, F. Cacialli, Appl. Phys. Lett. 77 (2000) 3096.

[27] S. Prada, U. Martinez, G. Pacchioni, Phys. Rev. B 78 (2008) 235423.

[28] T. D. Pawlik, D. Y. Kondakov, W. J. Begley, R. H. Young, J. Soc. Inf. Dis. 18 (2010) 277.

[29] S. K. M. Jonsson, E. Carlegrim, F. Zhang, W. R. Salaneck, M. Fahlman, Jap. J. Appl. Phys. 44 (2005) 3695.

[30] J. M. Zhao, S. T. Zhang, X. J. Wang, Y. Q. Zhan, X. Z. Wang, G. Y. Zhong, Z. J. Wang, X. M. Ding, W. Huang, X. Y. Hou, Appl. Phys. Lett. 84 (2004) 2913.

[31] S. H. Choi, S. M. Jeong, W. H. Koo, H. K. Baik, Jap. J. Appl. Phys. 44 (2005) L603.

[32] Y. C. Chen, P. C. Kao, S. Y. Chu, Opt. Exp. 18 (2010) A167.

[33] M. G. Helander, Z. B. Wang, J. Qiu, M. T. Greiner, D. P. Puzzo, Z. W. Liu, Z. H. Lu, Science 332 (2011) 944.

[34] Z. Q. Xu, J. Li, J. P. Yang, P. P. Cheng, J. Zhao, S. T. Lee, Y. Q. Li, J. X. Tang, Appl. Phys. Lett. 98 (2011) 253303.

[35] N. N. Wang, J. S. Yu, H. Lin, Y. D. Jiang, Chin. J. Chem. Phys. 23 (2010) 84.

[36] S. Samarin, O. M. Artamonov, A. A. Suvorova, A. D. Sergeant, J. F. Williams, Sol. St. Comm. 129 (2004) 389.

[37] J. G. Xue, S. Uchida, B. P. Rand, S. R. Forrest, Appl. Phys. Lett. 84 (2004) 3013.

[38] K. Cho, S. W. Cho, C. N. Whang, K. Jeong, S. J. Kang, Y. Yi, Appl. Phys. Lett. 91 (2007) 122101. 
[39] K. Kanamura, S. Shiraishi, H. Takezawa, Z. Takehara, Chem. Mater. 9 (1997) 1797.

[40] J. Mun, Y. S. Jung, T. Yim, H. Y. Lee, H.-J. Kim, Y. G. Kim, S. M. Oh, J. Power Sources 194 (2009) 1068.

[41] C. D. Wagner, W. M. Riggs, L. E. Davis, J. F. Moulder, G. E. Muilenberg, Handbook of X-Ray Photoelectron Spectroscopy (Perkin-Elmer Corp., Physical Electronics Div., Eden Prairie, MN, 1979).

[42] Q. H. Wu, A. Thissen, W. Jaegermann, Appl. Surf. Sci. 250 (2005) 57.

[43] M. F. Lo, T. W. Ng, T. Z. Liu, V. A. L. Roy, S. L. Lai, M. K. Fung, C. S. Lee, S. T. Lee, Appl. Phys. Lett. 96 (2010) 113303. 


\title{
Chapter 6. A novel hybrid inorganic-organic tandem junction solar cell
}

\author{
A paper submitted to the \\ 2012 IEEE Proceedings of the International Reliability Physics Symposium \\ Sambit Pattnaik, Teng Xiao, Robert W. Mayer, Ruth Shinar, \\ Joseph Shinar, and Vikram L. Dalal
}

\begin{abstract}
Due to their potentially ultralow-cost, organic solar cells (OSCs) are a promising technology. Bulk heterojunction OSCs have achieved power conversion efficiencies (PCE) of $8 \%$. Yet even this is far below those of inorganic cells. Typical OSCs suffer from poor solar radiation absorption, in particular beyond $\sim 650 \mathrm{~nm}$. Previous efforts addressed this problem by fabricating tandem OSCs, with cells absorbing complementary bands. However, their efficiency remains far below that of inorganic tandem cells, and they do not address the problem of OSC degradation. This paper describes a radically new design of inorganic/organic hybrids based on an amorphous (Si,C):H/P3HT:PCBM tandem junction cell. The unoptimized PCE is $\sim 5.6 \%$, a $\sim 22 \%$ increase compared to the OSC alone. It also addresses the critical problem of light-induced degradation, as that degradation is reduced significantly in the hybrid tandem. The cells can be connected electrically in series or in parallel, thus avoiding difficult current matching problems.
\end{abstract}

\section{Introduction}

Organic solar cells (OSCs) are an important photovoltaic technology for solar energy conversion due to their potential low cost and promise as easy to fabricate, flexible and 
high-performance energy sources [1]. Recent bulk heterojunction OSCs, where a polymeric donor is coupled to an electron acceptor molecule, have achieved solar power conversion efficiencies (PCEs) of $\sim 8 \%$ [1-5]. However, as is well known, unencapsulated OSCs typically suffer from severe degradation upon exposure to short-wavelength light, moisture, and oxygen, with the decrease in $I_{\mathrm{SC}}$ in some cases amounting to almost $45 \%$ over $\sim 200$ hours of illumination [5-13]. One of the reasons for the limits on the efficiency of the current generation of OSCs is the relatively poor absorption of organic cells. For example, the commonly used P3HT:PCBM (where P3HT is poly(3-hexylthiophene) and PCBM is 1-(3-methoxycarbonyl)-propyl-1-phenyl-(6,6) $\left.\mathrm{C}_{61}\right)$ system has a strong absorption in the $\sim 450-625 \mathrm{~nm}$ range, but poorer absorption below $\sim 450$ or beyond $\sim 650$ $\mathrm{nm}$. Previous work has attempted to address this problem by using two OSCs in a tandem junction arrangement [14-22], each cell typically absorbing in a different spectral region. However, such systems are not optimal from a design viewpoint, in that they do not approach the $\sim 42 \%$ efficiency of inorganic crystalline tandem junction cells [4], or the $\sim 20 \%$ efficiency of inorganic thin film cells [4], nor do they address the critical problem of light-induced and environmental degradation. In this paper, we show that a radically new design of tandem cells, which includes a combination of an inorganic thin-film cell with an organic cell and with an intermediate transparent conductor, can approach the high efficiency expected from a tandem cell arrangement. This design also addresses the critical problem of degradation due to constant illumination of the OSC. The design is such that one can electrically connect the cells either in series or in parallel (i.e., with separate electrical connections), as the need may be, and thus potentially avoid the difficult problem of current matching between the two cells. The experiments prove the 
concept and demonstrate the expected high open circuit voltage $V_{\mathrm{OC}} \sim 1.5 \mathrm{~V}$ in a seriesconnected tandem combination of amorphous a-(Si,C):H and P3HT:PCBM-based cells. The quantum efficiency data measured on the individual cells confirm that both cells contribute to the power.

\section{Experimental procedures}

For tandem device fabrication, the inorganic cell was fabricated first on a transparent, conducting RF sputter-deposited $\mathrm{ZnO}$ layer (on a glass substrate) of $1 \mu \mathrm{m}$ with a sheet resistance of $4.5 \mathrm{Ohm} / \square$. The a-(Si,C):H layer was deposited using VHF (45 MHz) plasma-enhanced CVD from a mixture of silane, methane, and hydrogen at a substrate temperature of $\sim 200^{\circ} \mathrm{C}$. The cell is of the standard $p-i-n$ or $n-i-p$ types, with all three layers, $\mathrm{p}, \mathrm{i}$, and $\mathrm{n}$ containing $\mathrm{Si}, \mathrm{C}, \mathrm{H}$ and appropriate dopants. The i-layer thickness was $\sim 0.09 \mu \mathrm{m}$ and the $\mathrm{n}+$ layer $(0.1 \mu \mathrm{m})$ was deposited by doping phosphine into the gas

mixture. The $\mathrm{p}+$ layer was very thin $(<20 \mathrm{~nm})$; diborane was used as the dopant. ITO was deposited on top covering the whole area or a partial area for designs A and B, respectively.

In design A (shown in Fig.5-1(a)), the organic cell was fabricated on ITO covering the inorganic cell. In design B (shown in Fig. 5-1(b)) it was fabricated directly on ITO on glass (with the inorganic cell on the opposite side of the glass). A PEDOT:PSS (from H.C. Starck) layer ( 40 nm thick as obtained from AFM data) was fabricated by spin-coating on cleaned ITO at $5000 \mathrm{rpm}$ for $60 \mathrm{~s}$ and baked for $\sim 1 \mathrm{~h}$ at $120^{\circ} \mathrm{C}$ under ambient conditions; it was then transferred into an argon-filled dual-sided MBraun glovebox. The oxygen level in the glovebox was $\sim 30 \mathrm{ppm}$ and that of water $<0.1 \mathrm{ppm}$. The 
P3HT:PCBM (purchased from Rieke Metals and nano-C, respectively) solution (1:1 weight ratio in 1,2-dichlorobenzene, with a concentration of $30 \mathrm{mg} / \mathrm{mL}$ ) was spin-coated on top of the PEDOT:PSS layer at the optimized $400 \mathrm{rpm}$ rate for $60 \mathrm{~s}$, and immediately placed under a petri dish for $2 \mathrm{~h}$ before baking at $160^{\circ} \mathrm{C}$ for 1 min and gradually decreasing the temperature to $110^{\circ} \mathrm{C}$ for another $11 \mathrm{~min}$. The $\mathrm{Ca}(25 \mathrm{~nm}) / \mathrm{Al}(100 \mathrm{~nm})$ were deposited on the P3HT:PCBM layer by low vacuum $\left(\sim 10^{-6}\right.$ mbar $)$ thermal evaporation. $I-V$ curves were obtained using a $100 \mathrm{~mW} / \mathrm{cm}^{2} \mathrm{ELH}$ bulb

The external quantum efficiency (EQE) measurements were performed using a monochromatic light source $(400-700 \mathrm{~nm})$ in conjunction with a chopper and a Stanford System lockin amplifier, and referenced to a standard $\mathrm{Si}$ photodiode, To estimate the current density from EQE data, we integrate the QE over the measurement range, using the known AM 1.5 photon flux. To measure the EQE on tandem devices a secondary light source was used to saturate the top and bottom cells by external blue and red bias light illumination, respectively. That is, saturation with blue light yields the EQE for the organic cell, and with red light, for the inorganic cell.

Degradation measurements were performed at room temperature in a high vacuum chamber that enables in-situ measurements of device performance (e.g., $I$ - $V$ curves, EQE data) in vacuum or in controlled environments, i.e., $\mathrm{N}_{2}$, Ar, or air with controlled humidity and/or oxygen. An Oriel Solar Simulator with a Xe arc lamp was used for illumination at 2-suns intensity for the OSC without the a-(Si,C):H filter. For a meaningful degradation comparison, the intensity of the lamp was increased when the filter was used, so that the OSC still generated the same initial $I_{\mathrm{SC}}$ of $\sim 20 \mathrm{~mA} / \mathrm{cm}^{2}$. 


\section{Results and discussion}

The two fundamental designs tested are shown in Fig. 5-1. In Fig. 5-1(a) the organic cell is fabricated on indium tin oxide (ITO) that covers the inorganic cell with both units on the same side of the substrate (design A). In the design shown in Fig. 5-1(b) the inorganic cell is fabricated on one side of the glass substrate, and the organic cell is fabricated on ITO on the opposite side of the same glass substrate (design B).

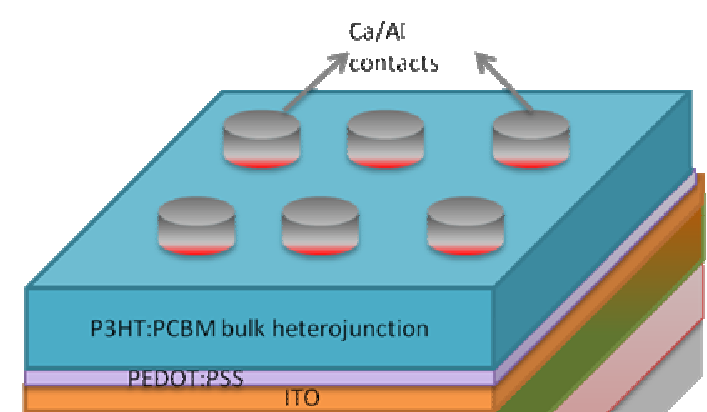

(a) $(\mathrm{p}-\mathrm{i}-\mathrm{n}) \mathrm{a}-(\mathrm{Si}, \mathrm{C}): \mathrm{H}$

$\mathrm{ZnO}$

Glass

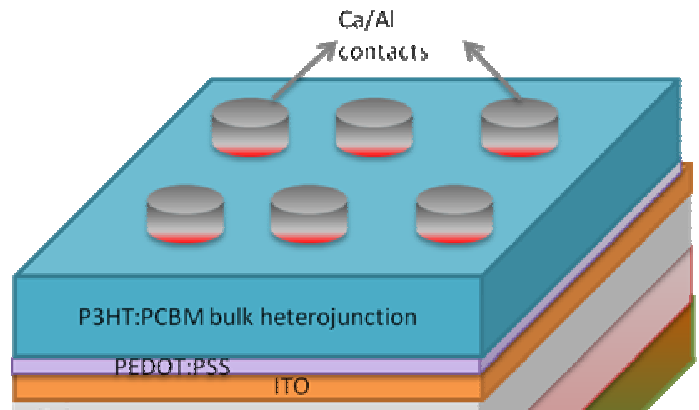

(b) Glass $\mathrm{ZnO}$

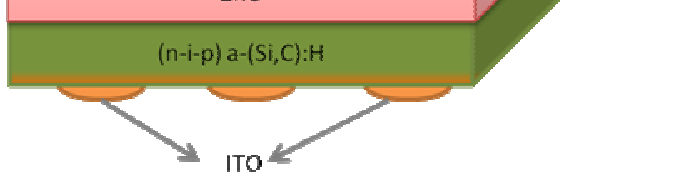

Fig. 5-1. Tandem cell designs: (a) both cells are on one side of the glass substrate (Design A) (b) the organic cell and the a-(Si,C):H-based cell are on opposite sides of a common glass substrate (design B).

The inorganic cell is of the standard p-i-n or n-i-p type [23-25], with all three layers, $p$, i, and n containing $\mathrm{Si}, \mathrm{C}, \mathrm{H}$ and appropriate dopants. The Tauc bandgap of the a-(Si,C):H intrinsic layer $(\sim 2 \mathrm{eV})$ and its thickness $(\sim 0.09 \mu \mathrm{m})$ are selected so as to match the current produced in the organic cell if a series electrical connection is to be used. Such current matching is not necessary if the two cells are not electrically in series, but are 
connected to their respective loads in independent circuits. In that case, both cells can be used separately, though they are optically connected, with the light passing first through the top inorganic cell. The additional advantage of this design is in filtering of highenergy photons that may otherwise damage the organic cell. The a- $(\mathrm{Si}, \mathrm{C}): \mathrm{H}$ cell is provided with a transparent conducting oxide (TCO) contact to let in light. The illuminated $I-V$ curve for the thin inorganic cell is shown in Fig. 5-2(a); it shows an efficiency of $3.9 \%$ with $V_{\mathrm{OC}} \sim 0.95 \mathrm{~V}$.

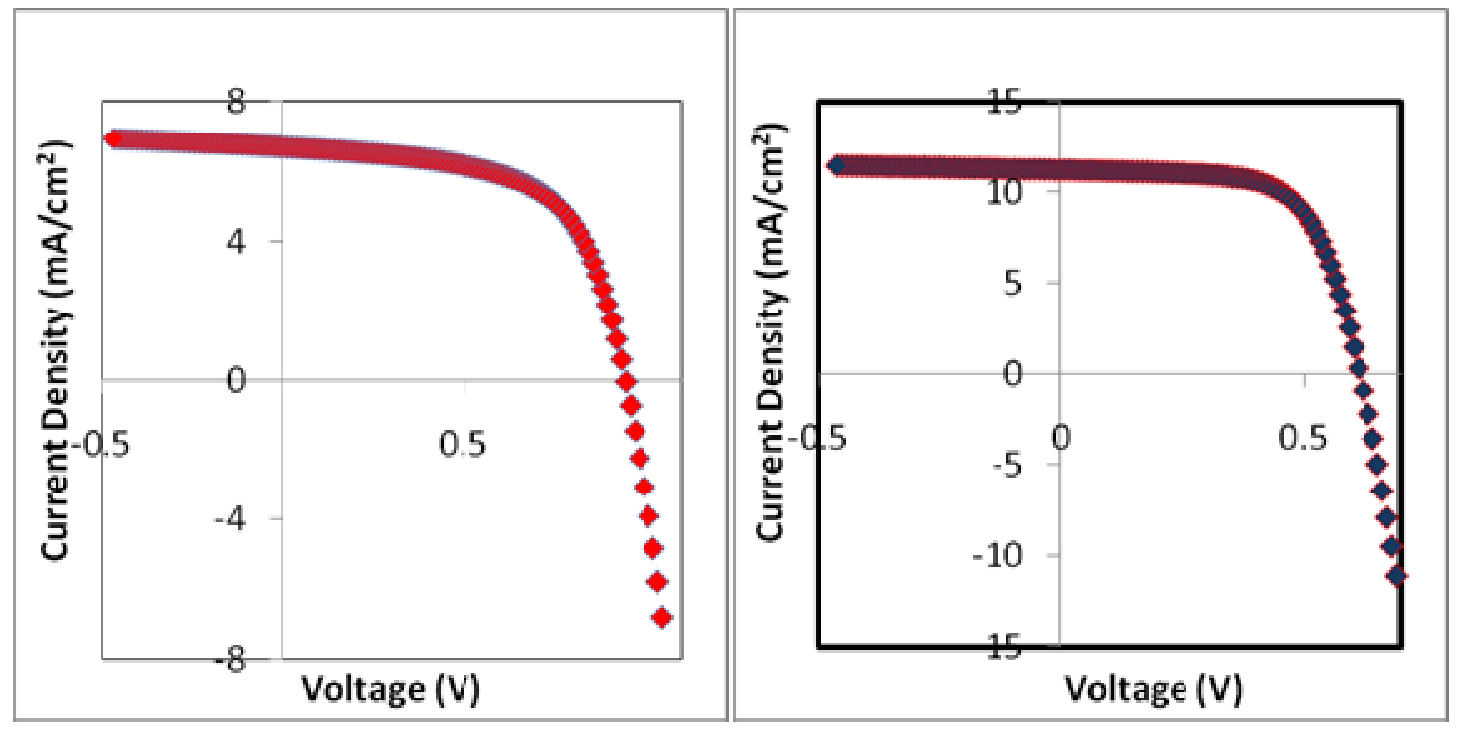

Fig. 5-2. I-V curves of (a) the thin a-(Si,C):H-based cell and $(b)$ the organic cell.

As mentioned, the organic cell is fabricated on ITO deposited either on the opposite side of the glass, or on the a-( $\mathrm{Si}, \mathrm{C}): \mathrm{H}$ cell. It is deposited using standard spin-coating techniques, and consists of the usual PEDOT:PSS/P3HT:PCBM/metal configuration [26]. The cell is typically capable of $\sim 4.6 \%$ efficiency with $V_{\mathrm{OC}} \sim 0.61 \mathrm{~V}$, as seen in the illuminated $I-V$ curve of Fig. 5-2(b). 
Fig. 5-3 shows the $I-V$ curve for the tandem structure with the two cells connected optically and electrically in series (see structure in Fig 5-1(b)). Light is incident on the inorganic cell where the band gap of the a- $(\mathrm{Si}, \mathrm{C}): \mathrm{H}$ is $\sim 2 \mathrm{eV}$. The $I-V$ curve clearly shows $V_{\mathrm{OC}} \sim 1.5 \mathrm{~V}$, the approximate sum of the voltages of each cell, proving that both cells are contributing to the $V_{\mathrm{OC}}$.

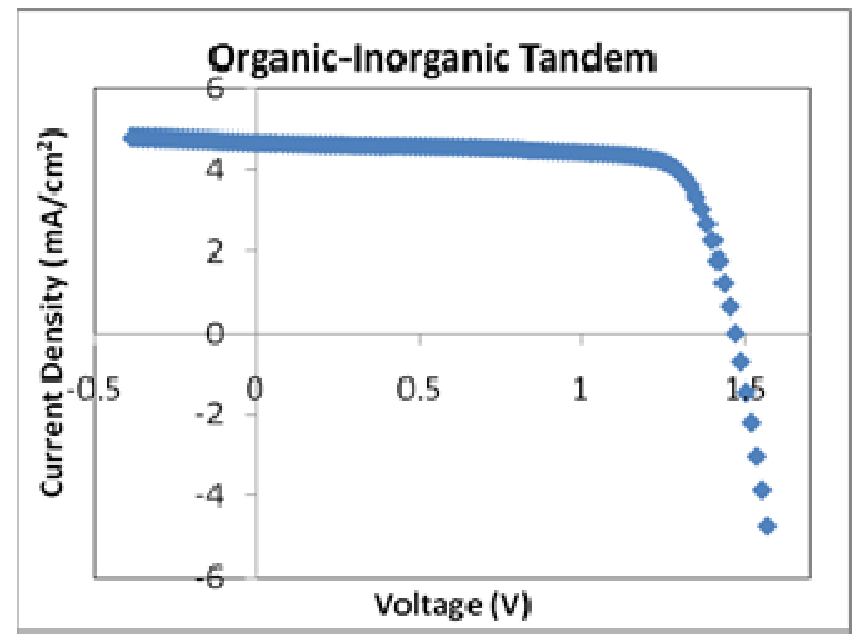

Fig. 5-3. I-V curve of the series organic-inorganic tandem device.

Further proof that both cells are contributing to the current comes from measuring the quantum efficiency (QE) curve for each cell, which is shown in Fig. 5-4. Very clearly, from the $\mathrm{QE}$ data, the a-(Si,C):H-based cell primarily absorbs blue photons, and the organic cell primarily absorbs the green-yellow-red photons, as illustrated in Fig. 5-5. We note that the absorbance of the inorganic cell in the $\sim 400-475 \mathrm{~nm}$ range is stronger than that of the OSC and while this strong absorbance by the inorganic cell reduces the absorption by the organic cell in that wavelength range, the overall performance of the tandem structure improved relative to the performance of the OSC alone. The PCE of the 


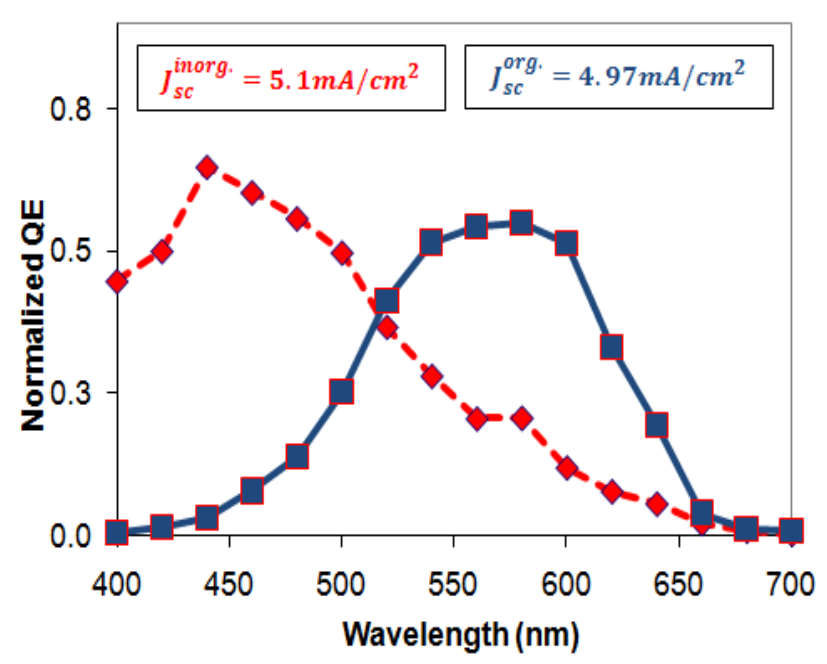

Fig. 5-4. QE of the a-(Si,C):H-based device (diamonds) and of the organic solar cell (squares) in the series tandem design.

unoptimized tandem junction cell is $\sim 5.6 \%$ (an increase of $\sim 22 \%$ compared to the OSC), and though this structure was not yet optimized, it shows a promising new concept.

A major advantage of this new structure is that the high-energy photons are absorbed in the top inorganic cell. Therefore, they are not available to contribute to the degradation of the OSC. Thus, the intrinsic stability should be better than that of an organic cell by itself. This expected behavior is shown in Fig. 5-6 that compares the degradation in $\mathrm{N}_{2}$ atmosphere at $\sim 23^{\circ} \mathrm{C}$ of an organic cell to that of a similar cell with an a-( $\left.\mathrm{Si}, \mathrm{C}\right): \mathrm{H}$ filter. As seen, while a reduction of $\sim 9 \%$ in the short circuit current $\left(I_{\mathrm{SC}}\right)$ and $\sim 4 \%$ in the $V_{\mathrm{OC}}$ were observed for the organic cell in $\sim 100$ hours of 2 -suns irradiation (initial $I_{\mathrm{SC}} \sim 20$ $\mathrm{mA} / \mathrm{cm}^{2}$ ) with a filtered $\mathrm{Xe}$ arc lamp, those values were reduced to $\sim 4 \%$ and $<2 \%$, respectively, due to the presence of the a- $(\mathrm{Si}, \mathrm{C}): \mathrm{H}$ layer. We note that the initial $I_{\mathrm{SC}}$ and 
PCEs (4.6\%) of both organic cells tested were similar prior to the degradation measurements. In addition, a tandem arrangement automatically reduces the degradation

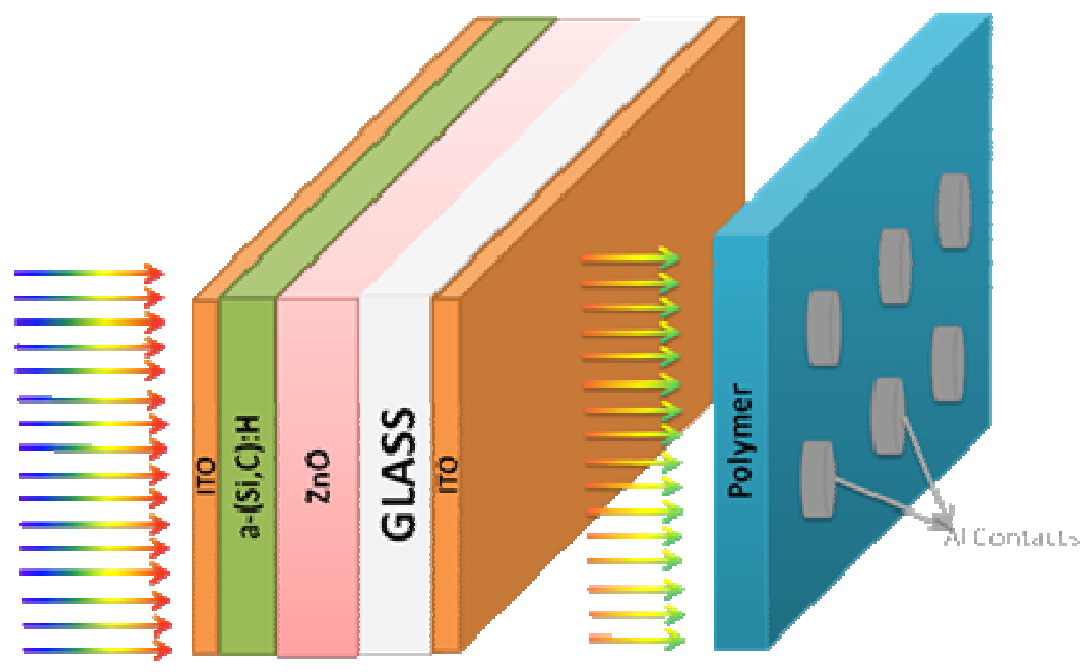

Fig. 5-5. Demonstration of the light absorption by the tandem inorganic-organic cell with the high-energy photons absorbed by the inorganic cell.

in the fill factor, since the top cell, being relatively stable, anchors the fill factor of the tandem arrangement at a high value even in the presence of degradation of the bottom (organic) cell.

Note that state-of-the-art amorphous Si cells suffer from little degradation (a few \%), with the Staebler-Wronski instability problem reduced significantly [27-29]. Note also that while we have used an a-(Si,C):H-based cell for demonstrating the concept, other materials, such as (Zn,Cd)Te [30], with appropriate bandgaps, can also be used for the inorganic cell. Since this cell is deposited first, the deposition can be done at elevated 
temperatures, followed by lower-temperature deposition of the organic cell on the other side of the substrate or on a transparent conducting electrode on the inorganic cell.

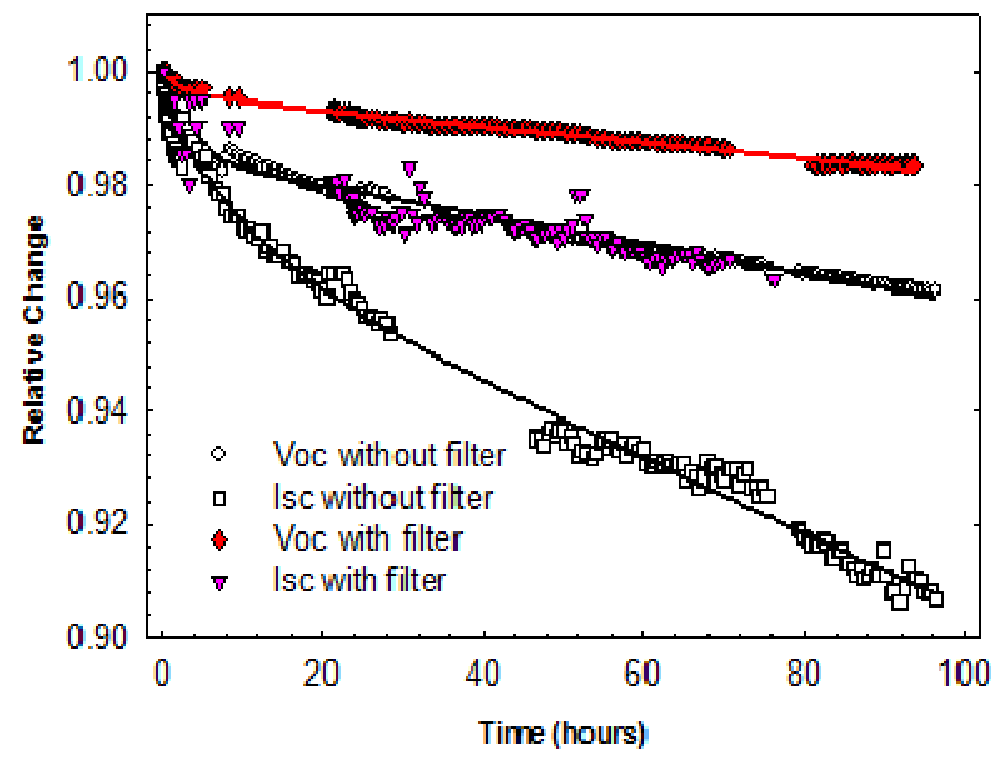

Fig. 5-6. $V_{O C}$ and $I_{S C}$ over $\sim 100$ h of 2-suns illumination of the OSCs with and without a thin a-(Si,C):H film in $\mathrm{N}_{2}$ atmosphere at $23^{\circ} \mathrm{C}$. (initial $I_{S C} \sim 20 \mathrm{~mA} / \mathrm{cm}^{2}$ ).

It was previously shown that under constant one-sun illumination in an inert atmosphere the P3HT as well as the P3HT:PCBM are stable for at least $1000 \mathrm{~h}$ [31]. The strong photodegradation observed in devices similarly illuminated in a glovebox [7] was therefore attributed to degradation due to the illumination effect on the charge collection layers and device interfaces, rather than on the active layer. As seen in Fig. 5-6, the degradation of the unencapsulated OSCs of this study in $\mathrm{N}_{2}$ was relatively milder, and it was further decreased by filtering the blue and shorter-wavelength photons with the a$(\mathrm{Si}, \mathrm{C}): \mathrm{H}$ thin layer. Hence, it appears that the blue and shorter wavelength photons are 
largely responsible for affecting the collection layers and interfaces. They may also be largely responsible for reducing photochemical degradation due to the presence of trace $\mathrm{O}_{2}$ and moisture. The role of the $\mathrm{Ca}$ layer (in the $\mathrm{Ca} / \mathrm{Al}$ electrode of the OSC) in the observed degradation requires additional investigation.

\section{Conclusions}

In summary, we have shown how a novel tandem cell arrangement, comprising a thin amorphous (Si,C):H-based inorganic top cell, and an organic bottom cell results in an improved PCE of $5.6 \%$ in an unoptimized series design, which is a $\sim 22 \%$ increase relative to that of the OSC alone. The $V_{\mathrm{OC}}$ of the tandem junction cell, $\sim 1.5 \mathrm{~V}$, is the sum of the values of the separate cells, as expected. Optimization of such tandem cells, deposited on a transparent, insulating substrate, can lead to significantly higher efficiencies. One can optimize the structures by manipulating the thickness of the cell and changing the $\mathrm{C}$ content so that the bandgap varies and the absorption in $\mathrm{a}-(\mathrm{Si}, \mathrm{C}): \mathrm{H}$ precisely complements that of the organic cell. The new device materials and architecture allow for either series connection or electrically independent tandem arrangements, thereby eliminating the current matching problem, and also reducing the degradation of the structure by filtering the high-energy photons.

One can visualize using other polymers, which give higher currents in OSCs [2], and use an appropriate inorganic cell bandgap to match half of that current. Then the efficiency can reach $\sim 11 \%$ for our design, $4 \%$ from the current best organic cell (half of the reported $\sim 8 \%$, since half the photons are absorbed in the top inorganic cell), and $7 \%$ from the optimized inorganic amorphous cell. For increasing the efficiency further, one 
can use a photonic or plasmonic approach to enhance infrared light absorption in the organic cell [20, 32-36], thereby increasing its current significantly.

\section{Acknowledgements}

We thank Max Noack for designing and assisting in fabrication of the degradationmeasurements chamber. This work was supported partially by the Iowa Power Fund and by the U.S. Department of Energy, Basic Energy Sciences, Materials Sciences and Engineering Division under Contract No. DE-AC 02-07CH11358 (TX).

\section{Author contributions}

Teng Xiao fabricated the organic cells, characterized them, and commented on the paper draft. Sambit Pattnaik fabricated the inorganic solar cells, characterized the inorganic and tandem cells, and assisted in paper writing. Robert W. Mayer assisted in fabrication of the degradation-measurements chamber and performed the degradation measurements.

\section{References}

[1] F. Krebs, Polymeric Solar Cells Materials, Design, Manufacture (DEStech publication, Inc., Lancaster, PA, 2010).

[2] Y. Y. Liang, Z. Xu, J. B. Xia, S.-T. Tsai, Y. Wu, G. Li, C. Ray, L. P. Yu, Adv. Mater. 22 (2010) E135.

[3] S. Sista, M.-H. Park, Z. R. Hong, Y. Wu, J. H. Hou, W. L. Kwan, G. Li, Y. Yang, Adv. Mater. 22 (2010) 380. 
[4] M. A. Green, K. Emery, Y. Hishikawa, W. Warta, Prog. Photovoltaics 19 (2011) 84.

[5] C. J. Brabec, S. Gowrisanker, J. J. M. Halls, D. Laird, S. J. Jia, S. P. Williams, Adv. Mater. 22 (2010) 3839.

[6] M. Jorgensen, K. Norman, F. C. Krebs, Sol. Energy Mater. Sol. Cells 92 (2008) 686.

[7] M. O. Reese, A. J. Morfa, M. S. White, N. Kopidakis, S. E. Shaheen, G. Rumblesa, D. S. Ginley, Sol. Energy Mater. Sol. Cells 92 (2008) 746.

[8] K. Kawano, R. Pacios, D. Poplavskyy, J. Nelson, D. D. C. Bradley, J. R. Durrant, Sol. Energy Mater. Sol. Cells 90 (2006) 3520.

[9] B. Zimmermann, U. Wurfel, M. Niggemann, Sol. Energy Mater. Sol. Cells 93 (2009) 496.

[10] H. Neugebauer, C. Brabec, J. C. Hummelen, N. S. Sariciftci, Sol. Energy Mater. Sol. Cells $61(2000) 35$.

[11] E. A. Katz, S. Gevorgyan, M. S. Orynbayev, F. C. Krebs, Eur. Phys. J-Appl. Phys. 36 (2006) 307.

[12] F. C. Krebs, K. Norrman, Prog. Photovoltaics 15 (2007) 697.

[13] B. Paci, A. Generosi, V. R. Albertini, P. Perfetti, R. de Bettignies, C. Sentein, Sol. Energy Mater. Sol. Cells 92 (2008) 799.

[14] J. Y. Kim, K. H. Lee, N. E. Coates, D. Moses,T.-Q. Nguyen, M. Dante, A. J. Heeger, Science 317 (2007) 222.

[15] A. Hadipour, B. de Boer, J. Wildeman, F. B. Kooistra, J. C. Hummelen, M. G. R. Turbiez, M. M. Wienk, R. A. J. Janssen, P. W. M. Blom, Adv. Funct. Mater. 16 (2006) 1897. 
[16] T. Ameri, G. Dennler, C. Lungenschmied, C. J. Brabec, Energ. Environ. Sci. 2 (2009) 347.

[17] C. F. Zhang, S. W. Tong, C. Y. Jiang, E. T. Kang, D. S. H. Chan, C. X. Zhu, Appl. Phys. Lett. 92 (2008) 083310.

[18] O. Hagemann, M. Bjerring, N. C. Nielsen, F. C. Krebs, Sol. Energy Mater. Sol. Cells 92 (2008) 1327.

[19] R. Schueppel, R. Timmreck, N. Allinger, T. Mueller, M. Furno, C. Uhrich, Karl Leo, M. Riede1, J. Appl. Phys. 107 (2010) 044503.

[20] K. Tvingstedt, V. Andersson, F. Zhang, O. Inganas, Appl. Phys. Lett. 91 (2007) 123514.

[21] F.-C. Chen, C.-H. Lin, J. Phys. D: Appl. Phys. 43 (2010) 025104.

[22] A. Colsmann, J. Junge, C. Kayser, U. Lemmer, Appl. Phys. Lett. 89 (2006) 203506.

[23] I. A. Yunaz, H. Nagashima, D. Hamashita, S. Miyajima, M. Konagai, Sol. Energy Mater. Sol. Cells 95 (2011) 107.

[24] J. Shinar, R. Shinar, D. L. Williamson, S. Mitra, H. Kavak, V. L. Dalal, Phys. Rev. B 60 (1999) 15875.

[25] A. Catalano, J. Newton, A. Rothwarf, IEEE Transactions on Electron Devices 37 (1990) 15875.

[26] T. Xiao, W. Cui, J. Anderegg, J. Shinar, R. Shinar, Org. Electron. (2011) 12257.

[27] D. L. Staebler, C. R. Wronski, Appl. Phys. Lett. 31 (1977) 292.

[28] N. L. Wang, V. L. Dalal, J. Non-Cryst. Solids 352 (2006) 1937.

[29] A. Kolodziej, P. Krewniak, S. Nowak, Opto-Electron. Rev. 11 (2003) 281.

[30] T. L. Chu, S. S. Chu, C. Ferekides, J. Britt, J. Appl. Phys. 71 (1992) 5635. 
[31] M. O. Reese, A. M. Nardes, B. L. Rupert, R. E. Larsen, D. C. Olson, M. T. Lloyd, S. E. Shaheen, D. S. Ginley, G. Rumbles, N. Kopidakis, Adv. Funct. Mater. 20 (2010) 3476.

[32] S.-S. Kim, S.-I. Na, J. Jo, D.-Y. Kim, Y.-C. Nah, Appl. Phys. Lett. 93 (2008) 073307.

[33] K. Tvingstedt, N.-K. Persson, O. Inganäs, A. Rahachou, I. V. Zozoulenk, Appl. Phys. Lett. 91 (2007) 113514.

[34] B. P. Rand, P. Peumans, S. R. Forrest, J. Appl. Phys. 96 (2004) 7519.

[35] S.-B. Rim, S. B. Zhao, S. R. Scully, M. D. McGehee, P. Peumans, Appl. Phys. Lett. 91 (2007) 243501.

[36] D. Duche, P. Torchio, L. Escoubas, F. Monestier, J.-J. Simon, F. Flory, G. Mathian, Sol. Energy Mater. Sol. Cells 93 (2009) 1377. 


\title{
Chapter 7. Fabrication and properties of hybrid polymer/small-molecular phosphorescent OLEDs based on poly( $N$-vinyl carbazole $)$
}

A paper published in the 2009 SPIE Conference Proceedings

Teng Xiao, Min Cai, Ying Chen, Ruth Shinar and Joseph Shinar

\begin{abstract}
The properties of phosphorescent $f a c$ tris(2-phenylpyridine) iridium [ $\left.\operatorname{Ir}\left(\mathrm{ppy}_{3}\right)\right]$-doped poly(N-vinyl carbazole) (PVK)/4,7-diphenyl-1,10-phenanthroline (Bphen) polymer/small molecular hybrid OLEDs are described. For optimal BPhen thickness, the power efficiency of the devices exceeds $30 \mathrm{~lm} / \mathrm{W}$. The low-temperature electroluminescencedetected magnetic resonance (ELDMR) exhibits the well-known negative spin $1 / 2$ resonance attributed to enhanced formation of trions, but the positive spin 1/2 resonance, typically observed at low temperature or at high current density, is not observed. The OLEDs' performance and the ELDMR results are discussed in relation to the nature of the defects and their density in these devices.
\end{abstract}

\section{Introduction}

Following the pioneering work on phosphorescent small molecular OLEDs (PhSMOLEDs), which are much more efficient than fluorescent SMOLEDs [1], phosphorescent polymer LEDs (Ph-PLEDs) were also developed, to exploit the low-cost, ease of solution processing, and more accurate control of dopants in such devices [2]. However, for improved performance, they require balancing of the charge injection and 
prevention of quenching effects. Hence, with the incorporation of a single layer of organic small molecules, the performance of the devices can be improved.

In 2004 Young et al. [2] developed a single layer, highly efficient Ph-PLED with the structure indium tin oxide (ITO) / poly(3,4-ethylenedioxythiophene) (PEDOT):polystyrene sulfonate (PSS) / poly(N-vinyl carbazole (PVK):N,N'- diphenylN,N'-bis(3-methylphenyl)-1,1'-biphenyl-4,4'-diamine $\quad$ (TPD):methyl fac $\quad \operatorname{tris(2-}$ phenylpyridine $) \quad$ iridium $\quad\left[\operatorname{Ir}(\mathrm{mppy})_{3}\right]: 2-(4-B i p h e n y l y l)-5-(4-t e r t-b u t y l p h e n y l)-1,3,4-$ oxadiazole (PBD) / CsF / Al. They used PVK as the base material of the emitting layer, which could prevent luminescence quenching by confining the triplet states in the $\operatorname{Ir}(\mathrm{mppy})_{3}$ guest molecules. With the incorporation of TPD and PBD as hole and electron transport moieties, respectively, they achieved a power conversion efficiency (PCE) of 24 $\operatorname{lm} / \mathrm{W}$ at $100 \mathrm{Cd} / \mathrm{m}^{2}$. In 2005, Choulis et al. [3] improved the power efficiency to a maximum of $38 \mathrm{~lm} / \mathrm{W}$ by adding an interfacial poly(9,9-dioctyl-fluorene-co-N-(4butylphenyl)-diphenylamine)) (TFB) layer between the PEDOT:PSS and the emitting layer. But neither of these reports provided any information regarding device stability.

This work presents data on the lifetime of similar device structures, with the potential to enhance the efficiency at a higher luminescence. High efficiency hybrid OLEDs with the structure ITO / PEDOT:PSS / PVK:TPD:Ir(mppy) $)_{3}:$ PBD / Bphen / Bphen:LiF / Al were fabricated. A combinatorial pixel array was made to determine the optimal Bphen:LiF thickness, which was found to be $20 \mathrm{~nm}$. The optimal device showed a maximum power conversion efficiency of $31 \mathrm{~lm} / \mathrm{W}$ and a maximum luminous efficiency of $44 \mathrm{Cd} / \mathrm{A}$. The brightness was $19,000 \mathrm{Cd} / \mathrm{m}^{2}$ at $10 \mathrm{~V}$. However, at an initial brightness 
$L_{0}=5204 \mathrm{Cd} / \mathrm{m}^{2}$ and a constant current density $J=30 \mathrm{~mA} / \mathrm{cm}^{2}$, the lifetime (to $50 \%$ of $\left.L_{0}\right) t_{1 / 2}=4.3 \mathrm{~min} ;$ at $L_{0}=520 \mathrm{Cd} / \mathrm{m}^{2}$ and $J=1.8 \mathrm{~mA} / \mathrm{cm}^{2}, t_{1 / 2}=116 \mathrm{~min}$. When extrapolated to $L_{0}=100 \mathrm{Cd} / \mathrm{m}^{2}, t_{1 / 2} \sim 13 \mathrm{~h}$.

\section{Experimental procedures}

PEDOT: PSS was purchased from H. C. Starck; PVK, TPD, and PBD were purchased from Sigma-Aldrich; $\operatorname{Ir}(\mathrm{mppy})_{3}$ was purchased from American Dye Source. All materials were used with no further purification.

PLEDs were fabricated on Colorado Concept Coatings ITO-coated glass substrates. The $R_{\square} \sim 20 \Omega / \square, 140$ nm-thick ITO-coated $2 " \times 2 "$ glass substrates were cleaned by detergent and organic solvents and then treated in a UV/ozone oven to increase the ITO work function and facilitate hole injection, as described elsewhere [4]. The PEDOT: PSS layer was spin-coated on the substrate at $1000 \mathrm{rpm}$ for $60 \mathrm{~s}$, and was then baked for 30 min at $120{ }^{\circ} \mathrm{C}$. The PVK-based light emitting layer was then spin-coated from a 17 $\mathrm{mg} / \mathrm{mL}$ PVK solution in chlorobenzene solution at $1000 \mathrm{rpm}$ for $60 \mathrm{~s}$, and then baked for $30 \mathrm{~min}$ at $60^{\circ} \mathrm{C}$. Finally, the $\mathrm{CsF}$ and $\mathrm{Al}$ layers were deposited by thermal evaporation. It should be emphasized, however, that the chlorobenzene solution containing PVK, TPD, $\operatorname{Ir}(\mathrm{mppy})_{3}$, and PBD was prepared in air before introduction into the glove box for spin coating.

To improve the efficiency of the devices, a Bphen layer was thermally evaporated on the PVK layer, to generate the hybrid PLED/SMOLED ITO / PEDOT: PSS / PVK: TPD: $\operatorname{Ir}(\mathrm{mppy})_{3}: \mathrm{PBD} / \mathrm{Bphen} / \mathrm{LiF} / \mathrm{Al}$. The Bphen layer increases the electron injection and thus improved the maximum efficiency to $23 \mathrm{~lm} / \mathrm{W}$ [5]. The Bephen thickness was varied in a combinatorially-fabricated array to obtain an optimal thickness. The polymer layers 
were spin-coated and baked in the same way mentioned above. Bphen, LiF, and Al layers are then fabricated by thermal evaporation. The lifetime of this hybrid OLED was $6.3 \mathrm{~h}$ at $L_{0}=100 \mathrm{Cd} / \mathrm{m}^{2}$. The short lifetime [6-8] may stem from instability of the source PVK, TPD, PBD and/or Bphen materials, or from contamination by oxygen and/or water. As doping LiF into Bphen was shown to increase the lifetime of other OLEDs [9], in some devices Bphen was doped with LiF, resulting in the device structure ITO / PEDOT:PSS / PVK:TPD:Ir(mppy) $)_{3}:$ PBD / $10 \mathrm{~nm}$ Bphen / $20 \mathrm{~nm}$ Bphen:LiF / Al. Both the efficiency and lifetime were improved when using the LiF dopant. The maximal power conversion efficiency was $\sim 31 \mathrm{~lm} / \mathrm{W}$, and the lifetime (to $50 \%$ of $L_{0}$ ) $t_{1 / 2}$ was $\sim 13 \mathrm{~h}$ at $L_{0}=100$ $\mathrm{Cd} / \mathrm{m}^{2}$.

Electroluminescence (EL)-detected magnetic resonance (ELDMR) measurements were conducted on the device with $35 \mathrm{~nm}$ Bphen as the ETL layer. The ELDMR system used in this study was described previously [10-14]. In brief, the PLED was inserted into the quartz "finger" dewar of an Oxford Instruments He gas flow cryostat; the quartz "finger" dewar was inserted into an optically accessible X-band microwave cavity. Bias was applied to the PLED and the EL was collected by a Si photodiode. The ELDMR was measured by lock-in detection of the changes in the EL induced by the $810 \mathrm{~mW}, 9.35$ GHz microwaves chopped at $500 \mathrm{~Hz}$.

\section{Results and discussion}

\section{Device Performance:}

(i) ITO/PEDOT:PSS / PVK:TPD:Ir(mppy) $)_{3}: \mathrm{PBD} / 1 \mathrm{~nm}$ CsF / Al. Four samples of different combinations of the spin-coating rates of the PEDOT:PSS layer and that of the emitting layer (EML) were prepared to determine the optimal spin-coating rate 
combination. The spinning rates were $1000 \& 1000 \mathrm{rpm}, 1000 \& 2000 \mathrm{rpm}, 2000 \& 1000$ rpm, and 2000 \& $2000 \mathrm{rpm}$. The PEDOT:PSS and EML layers were baked for $30 \mathrm{~min}$ at $200^{\circ} \mathrm{C}$ and $60^{\circ} \mathrm{C}$, respectively.

Fig. 6-1 shows the device performance for these four PLEDs. As expected, charge injection increased for a thicker PEDOT:PSS layer and a thinner EML. The charge injection, however, is more balanced when the thicknesses of the PEDOT:PSS layer and
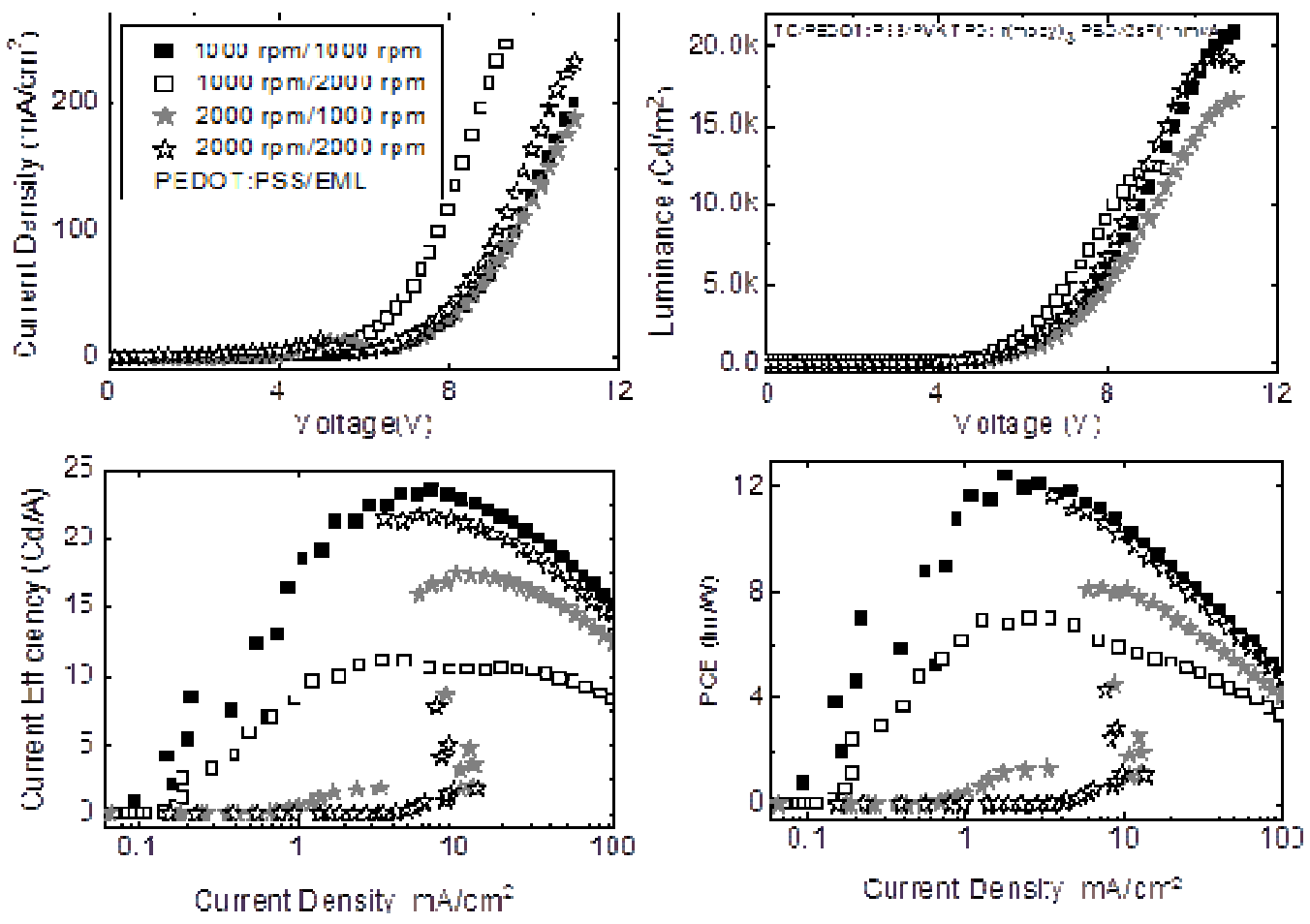

Fig. 6-1. Device performance for different spin-coating rates of the PEDOT: PSS and the emitting layers. Solid squares for 1000 \& 1000 rpm, open squares for 1000 \& 2000 rpm, solid stars for 2000 \& 1000 rpm, and open stars for 2000 \& $2000 \mathrm{rpm}$.

that of the EML are comparable. The device fabricated at 1000 \& $1000 \mathrm{rpm}$ structure was found to be somewhat better than the $2000 \& 2000 \mathrm{rpm}$ structure. The thicker layers in the former device result in pixels with reduced current leakage (see Fig. 6-1) and better 
uniformity. A maximum current efficiency of $23.4 \mathrm{Cd} / \mathrm{A}$ was obtained at a brightness of $1671 \mathrm{Cd} / \mathrm{m}^{2}$, while a maximum PCE of $12.3 \mathrm{~lm} / \mathrm{W}$ was achieved at $373 \mathrm{Cd} / \mathrm{m}^{2}$.

(ii) A combinatorial array was fabricated to compare the performance of devices with $\mathrm{CsF}, \mathrm{LiF}$, and Bphen/LiF. Three different basic structures were tested:

Structure 1: ITO / PEDOT:PSS / PVK:TPD:Ir(mppy) 3 :PBD / 1nm CsF / Al, Structure 2: ITO / PEDOT:PSS / PVK:TPD:Ir(mppy) 3 :PBD / LiF / Al , Structure 3: ITO / PEDOT:PSS / PVK:TPD:Ir(mppy) $3:$ PBD / Bphen / LiF / Al.

In structure 3, the Bphen layer was 30, 40, or $50 \mathrm{~nm}$ thick; the thickness of the $\mathrm{LiF}$ layer was 0.5 or $1.0 \mathrm{~nm}$. Thus, a total of 9 different pixel sets were generated. The pixels with the $50 \mathrm{~nm}$ Bphen layer, however, crystallized, so that a total of seven sets of pixels were used for data collection and analysis. The spin-coating rates were $1000 \& 1000 \mathrm{rpm}$ for the PEDOT:PSS/EML.

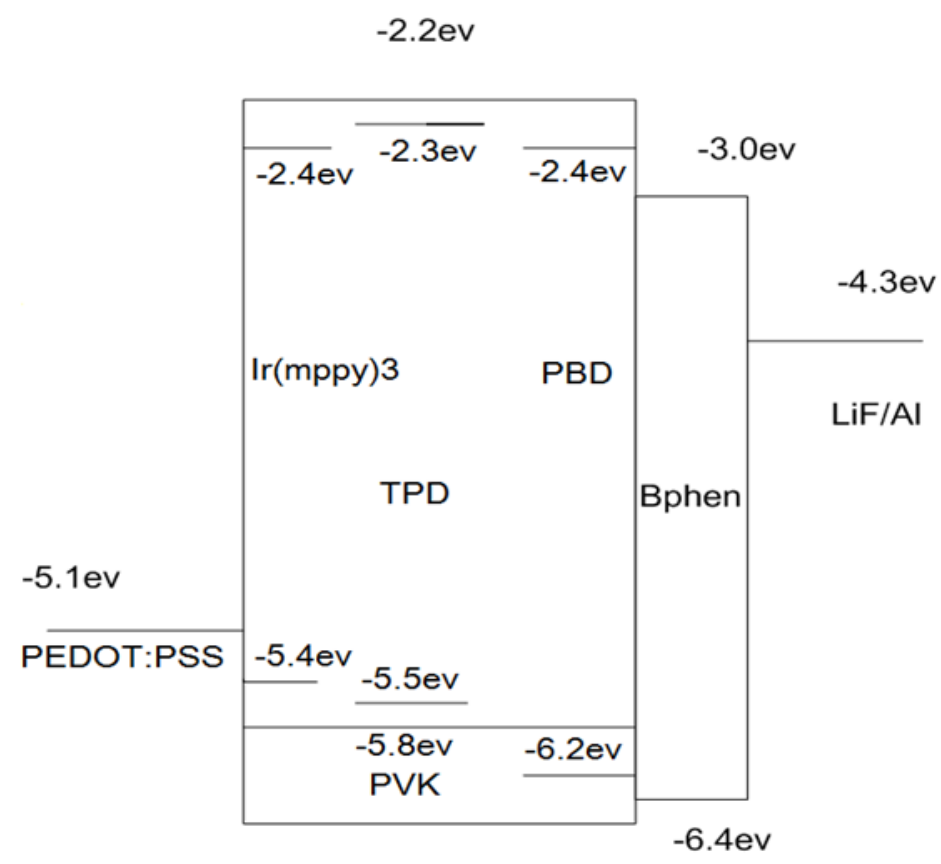

Fig.6-2. The energy level diagram of ITO / PEDOT:PSS / PVK:TPD:Ir(mppy) $3: P B D /$ Bphen / LiF /Al device structure. 
Fig. 6-2 shows the energy level diagram of the ITO / PEDOT:PSS / PVK:TPD:Ir(mppy) 3 :PBD / Bphen / LiF /Al devices. Devices with CsF, however, were
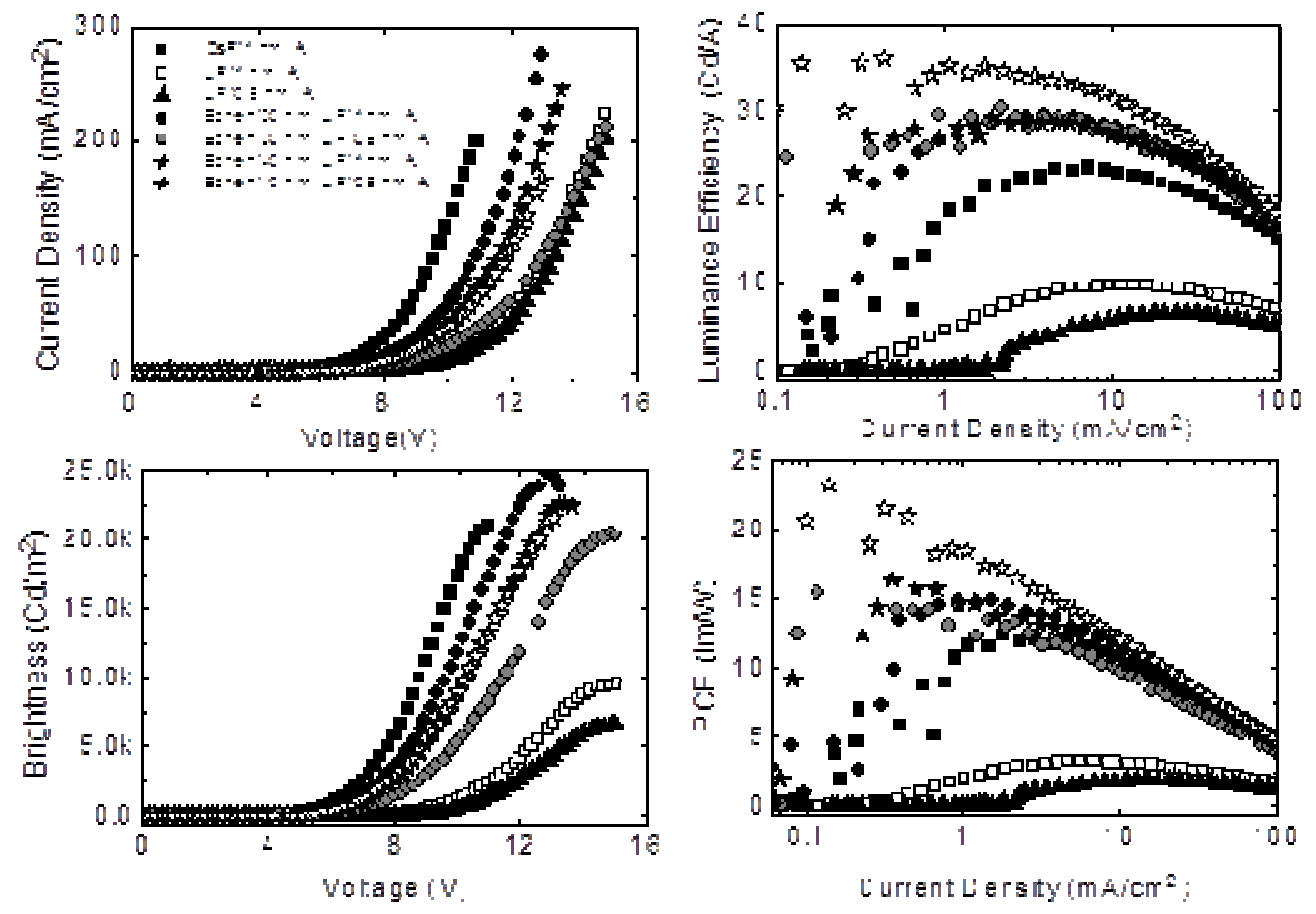

Fig. 6-3. The device performance of structures $1-3$; the spin-coating rates were 1000 \& $1000 \mathrm{rpm}($ see text).

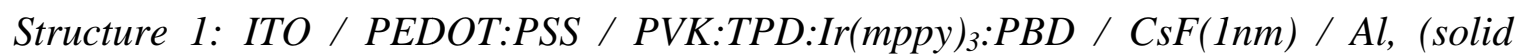
squares);

Structure 2: ITO / PEDOT:PSS / PVK:TPD:Ir(mppy) $)_{3}: P B D$ / LiF / Al (open squares - 1 nm LiF; triangles $-0.5 \mathrm{~nm} \mathrm{LiF);}$

Structure 3: ITO / PEDOT:PSS / PVK:TPD:Ir(mppy) 3:PBD / Bphen / LiF / Al (solid and gray circles $-1 \mathrm{~nm} \mathrm{LiF,} 30$ and $40 \mathrm{~nm}$ Bphen, respectively; solid and open stars $-0.5 \mathrm{~nm}$ LiF, 30 and $40 \mathrm{~nm}$ Bphen, respectively). 
superior to those with $\mathrm{LiF}$, as shown in Fig. 6-3, where the spin-coating rates were 1000 \& $1000 \mathrm{rpm}$. Although $\mathrm{LiF}$ reduces the barrier for electron injection from the $\mathrm{Al}$, it probably does not dissociate and its $4.3 \mathrm{eV}$ work function is much higher than the $2.3 \mathrm{eV}$ of $\mathrm{Li}$. In contrast, $\mathrm{CsF}$ dissociates, independently of the underlying material, resulting in a work function that is almost as low as the $1.9 \mathrm{eV}$ of Cs. Free Cs atoms n-dope the ETL,
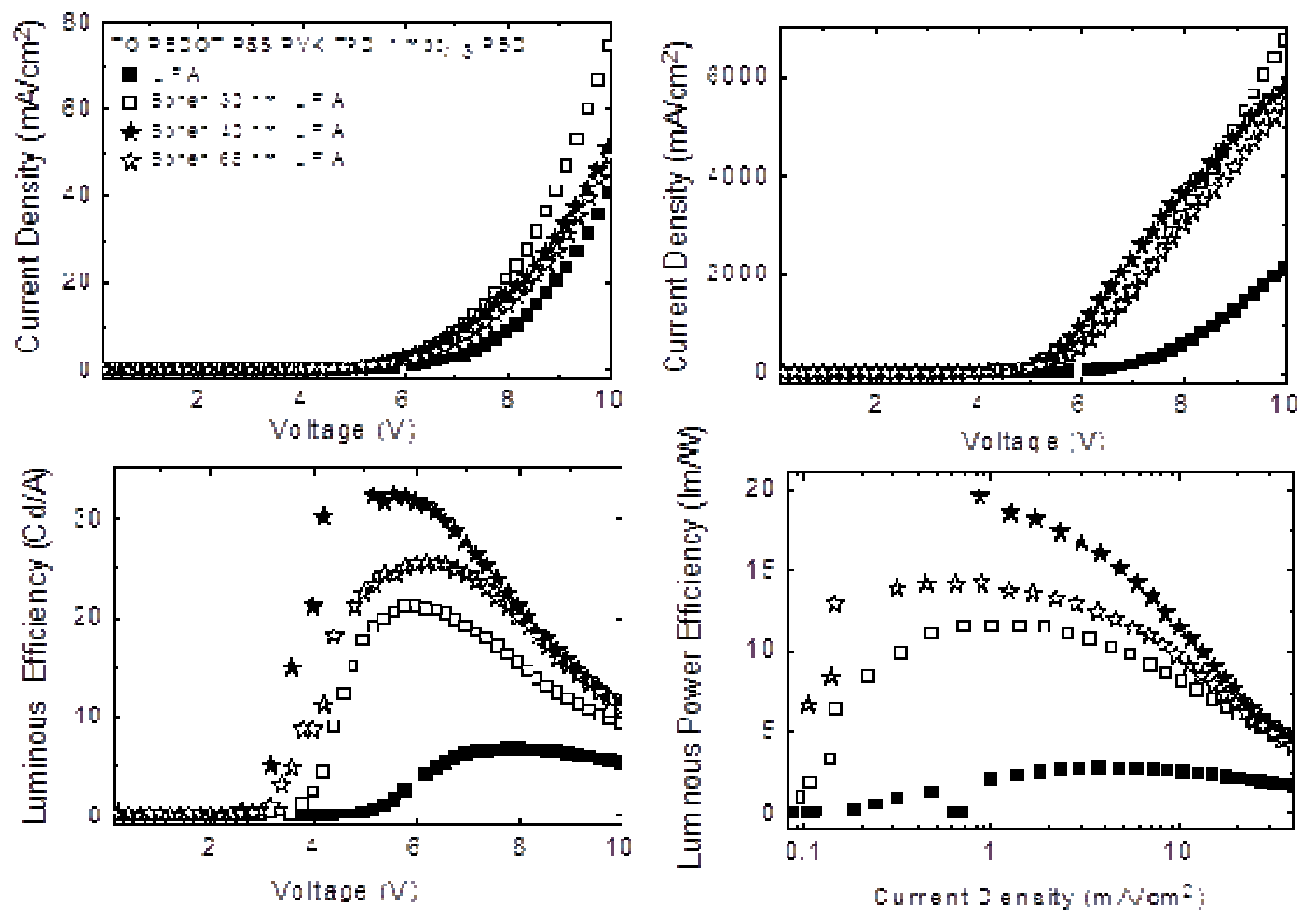

Fig. 6-4. Behavior of ITO / PEDOT:PSS / PVK:TPD:Ir(mppy) $)_{3}: P B D /$ Bphen / LiF / Al. Spin-coating rates $2000 \& 2000$ rpm (see text). Solid squares, open squares, solid stars, and open stars correspond to Bphen thicknesses of 0, 30, 40, and $60 \mathrm{~nm}$.

which can enhance electron injection and improve device performance [15-18]. When a Bphen/LiF bilayer is employed as a substitute for $\mathrm{CsF}$, the efficiency of the device is further improved. Although the $3.6 \mathrm{~V}$ turn-on voltage with Bphen/LiF is higher than the 2.9 $\mathrm{V}$ with $\mathrm{CsF}$, the maximum current efficiency improved from 23.4 to $36 \mathrm{Cd} / \mathrm{A}$ at a 
Bphen/Li thickness of $40 / 0.5 \mathrm{~nm}$, and the maximum PCE increased from 12.4 to 23.3 $1 \mathrm{~m} / \mathrm{W}$. The enhancement in the efficiency may be attributed to the high $\sim 10^{-4} \mathrm{~cm}^{2} / \mathrm{Vs}$ electron mobility of Bphen. Additionally, Bphen has a LUMO level at $-3.0 \mathrm{eV}$ (although $-2.4 \mathrm{eV}$ has also been reported), which minimizes the gap between the EML and LiF/Al and thus enhances the electron injection. Similar results to those shown in Fig. 6-3 were obtained when the spin-coating rates were $2000 \mathrm{rpm} / 2000 \mathrm{rpm}$, as shown in Fig. 6-4.
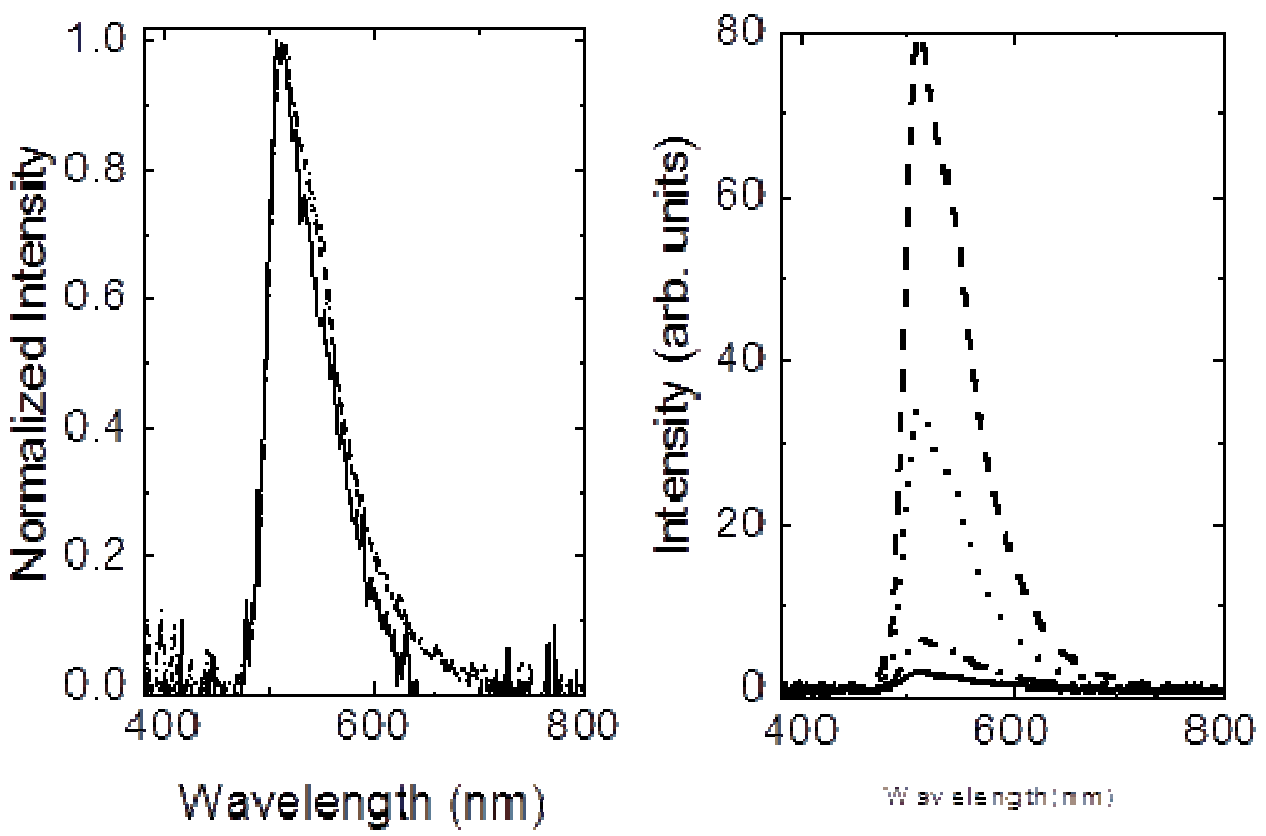

Fig. 6-5. The original and normalized spectra of device Structures 2 and 3 at $7 \mathrm{~V}$. The solid, dashed, dotted, and dashed-dotted lines are the spectra for 0, 30, 40, and $50 \mathrm{~nm}$ Bphen, respectively.

The EL spectrum of each individual structure was stable under increasing bias. However, as shown in Fig. 6-5, at a given voltage, the spectra of these different structures are slightly different. The peak is somewhat broadened when the Bphen layer is added. This broadening may result from the better electron injection. That is, the higher electron 
mobility allows for electron penetration further into the emitting layer, thus enlarging the emission zone, and therefore the width of the EL band.
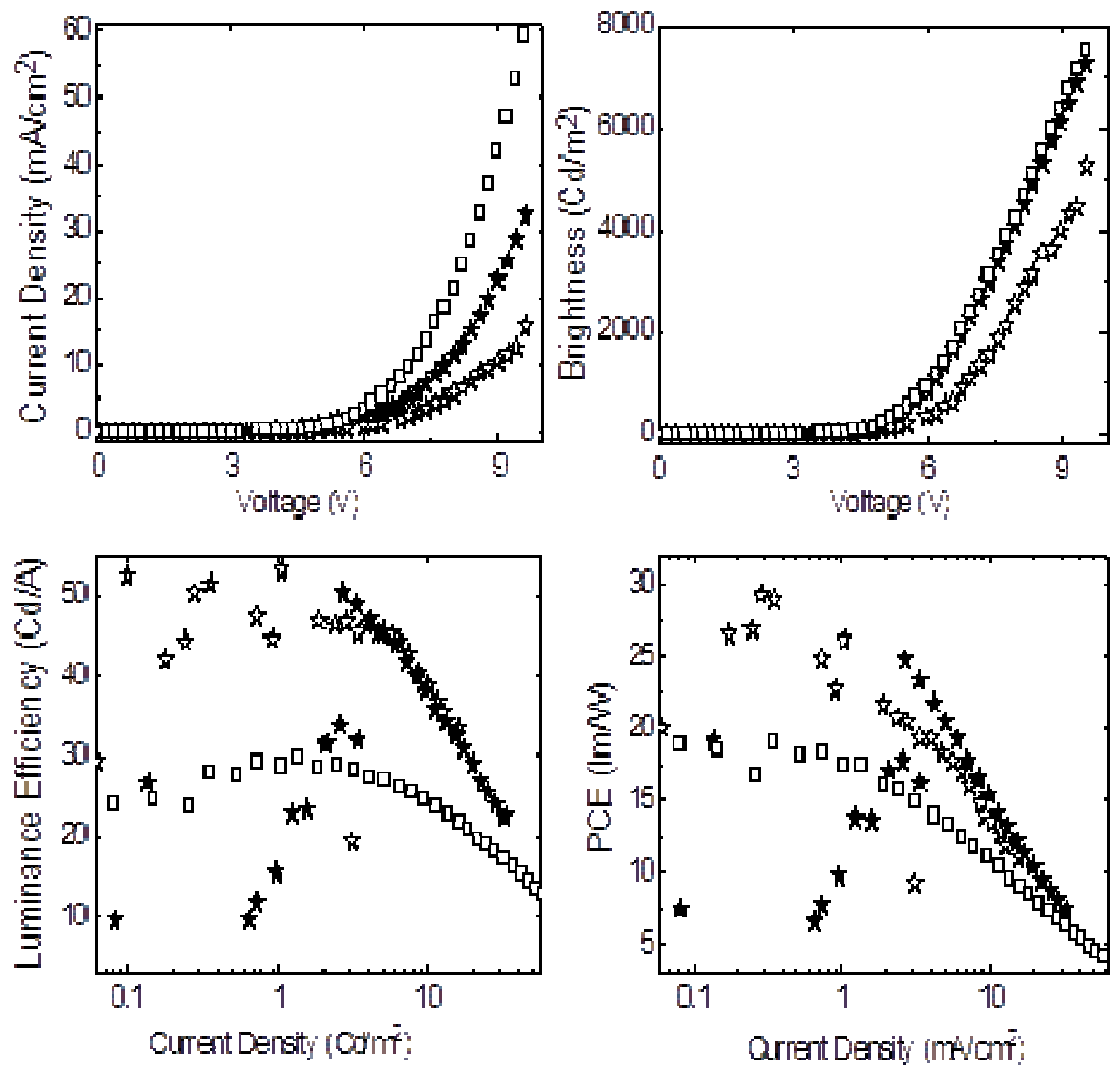

Fig. 6-6. Performance of ITO / PEDOT:PSS/PVK:TPD:PBD: $\operatorname{Ir}(\text { mppy })_{3} / 10 \mathrm{~nm}$ Bphen / $x$ nm Bphen:Li / $1 \mathrm{~nm} \mathrm{LiF} \mathrm{/} \mathrm{Al.} \mathrm{Open} \mathrm{squares,} \mathrm{solid} \mathrm{stars,} \mathrm{and} \mathrm{open} \mathrm{stars} \mathrm{are} \mathrm{for} x=10$, 20 , and $30 \mathrm{~nm}$, respectively.

ETL was tested; the device efficiency was comparable to that of the undoped device. This behavior may be due to the much lower electron mobility in $\mathrm{Alq}_{3}$ in comparison to that in Bphen. Next, a structure using Li- doped Bphen as an electron-injection layer was tested. As seen in Fig. 6-6, a maximal PCE of $\sim 30 \mathrm{~lm} / \mathrm{W}$, which is $\sim 2$ fold larger than that of the device with pure Bphen $(16 \mathrm{~lm} / \mathrm{W})$, was obtained. The optimal device structure 
was ITO / PEDOT:PSS / PVK:TPD:PBD:Ir(mppy) $)_{3} / 10$ nm Bphen / 20 nm Bphen:Li / 1 $\mathrm{nm} \mathrm{LiF} / \mathrm{Al}$. Although the EL spectrum was independent of the bias, the device lifetime was no more than one hour at $L_{0}=100 \mathrm{Cd} / \mathrm{m}^{2}$, which is a great hindrance in its application. The short lifetime may be due to the diffusion of Li into the light-emitting
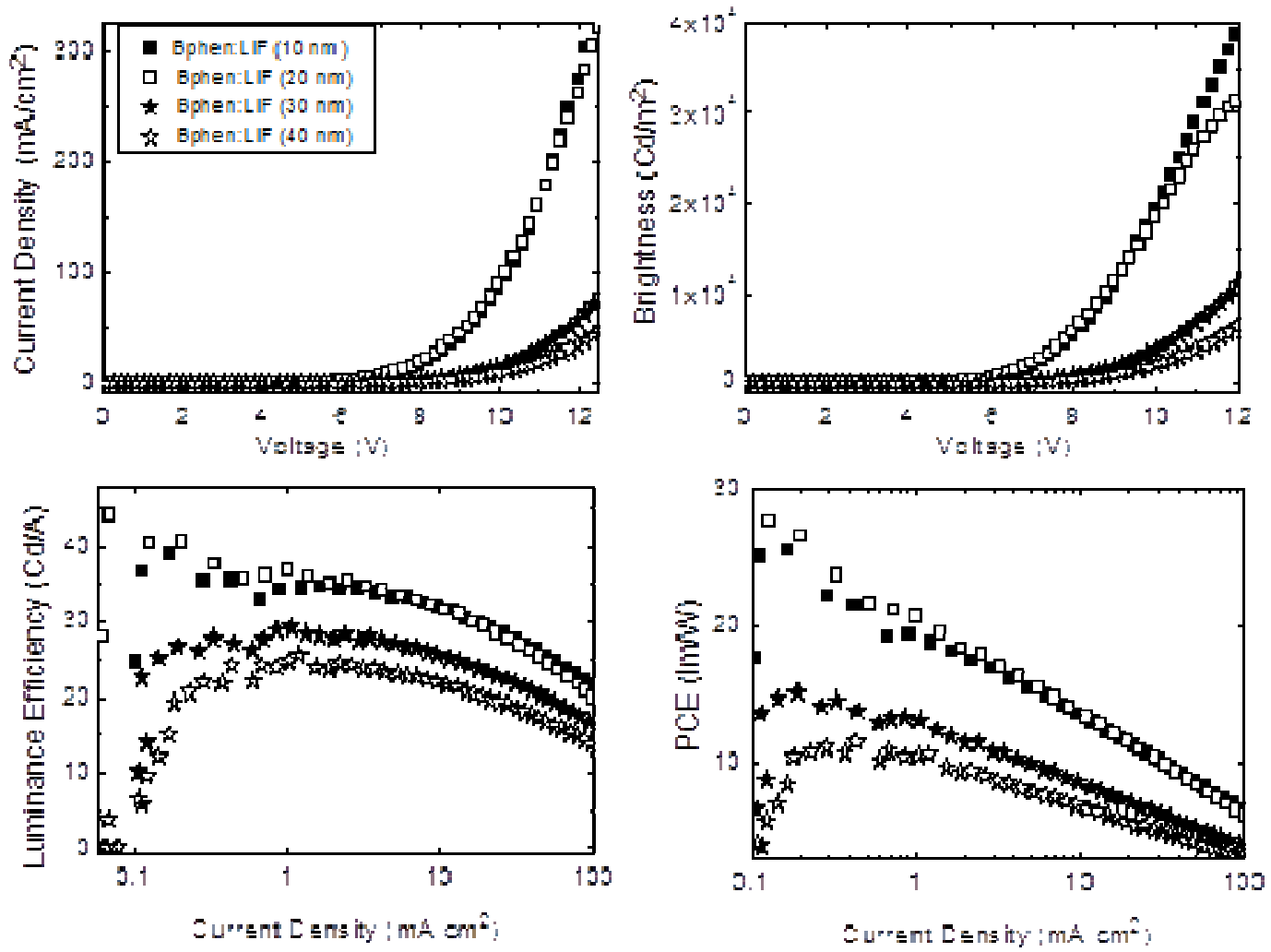

Fig. 6-7. The performance of ITO / PEDOT:PSS / PVK:TPD:Ir(mppy) $)_{3}: P B D / 10 \mathrm{~nm}$ Bphen / x nm Bphen:LiF / Al. Solid squares, open squares, solid stars, and open stars correspond to $x=10,20,30$, and $40 \mathrm{~nm}$, respectively.

polymer layer, or to degradation of the PVK due to oxygen or water contamination. In the former case, either doping Bphen with a larger alkali atom such as Cs, or applying a different dopant, may result in a more stable device. To check this hypothesis, LiF was 
chosen to substitute $\mathrm{Li}$ since it increases the device lifetime when doped into small molecular organic layers [19].

The best performance for the devices evaluated in this study was of ITO / PEDOT:PSS / PVK:PBD:Ir(mppy)3:PBD / $10 \mathrm{~nm}$ Bphen / $x \mathrm{~nm}$ Bphen:LiF / Al. The polymer layers were fabricated by spin-coating as described above. The only modification was the replacement of $\mathrm{Li}$ by $\mathrm{LiF}$, where a molar ratio of 1:1 was adopted for the Bphen:LiF layer. A better stability was obtained together with a comparable efficiency for this device. A combinatorial array with changing thickness of the doped layer was fabricated to find the optimal doping thickness. Pixels of $10 \mathrm{~nm}, 20 \mathrm{~nm}, 30 \mathrm{~nm}$, and $40 \mathrm{~nm}$ doped layers were studied. The devices' performance is shown in Fig. 6-7. As seen, the device with the $20 \mathrm{~nm}$ Bphen:LiF layer has the highest efficiency; the maximum luminous efficiency is $\sim 44 \mathrm{Cd} / \mathrm{A}$, and the maximum PCE is $\sim 31 \mathrm{~lm} / \mathrm{W}$.

\section{Device Lifetime:}

The stability of ITO / PEDOT:PSS / PVK:TPD:Ir(mppy) 3 :PBD / 10 nm Bphen / $20 \mathrm{~nm}$ Bphen:LiF / Al at constant current density was studied using $2 \times 2 \mathrm{~mm}^{2}$ pixels. The devices were encapsulated with transparent glass covers. Figs. 6-8 and 6-9 show the brightness vs. time at various $L_{0}$. A device with $L_{0}=256 \mathrm{Cd} / \mathrm{m}^{2}$ and its $t_{1 / 2}$ was chosen as the reference level. In other words, the $L_{0}$ and corresponding $t_{1 / 2}$ values obtained 


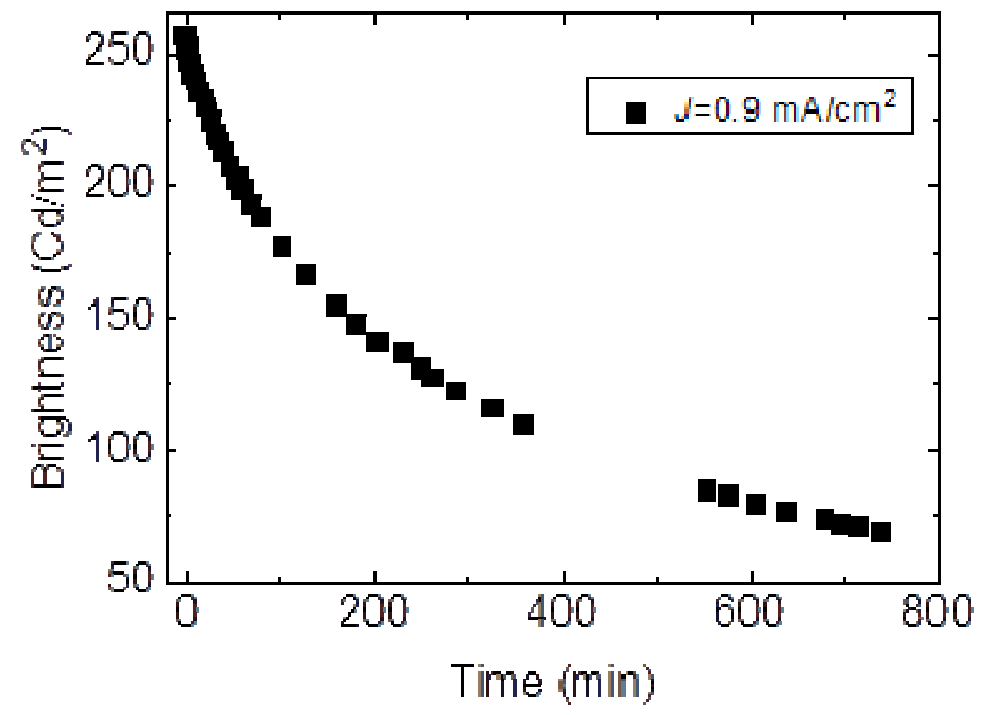

Fig. 6-8. Brightness versus time with $L_{0}=256 \mathrm{Cd} / \mathrm{m}^{2}$ and a constant current density $J=$ $0.9 \mathrm{~mA} / \mathrm{cm}^{2}$.
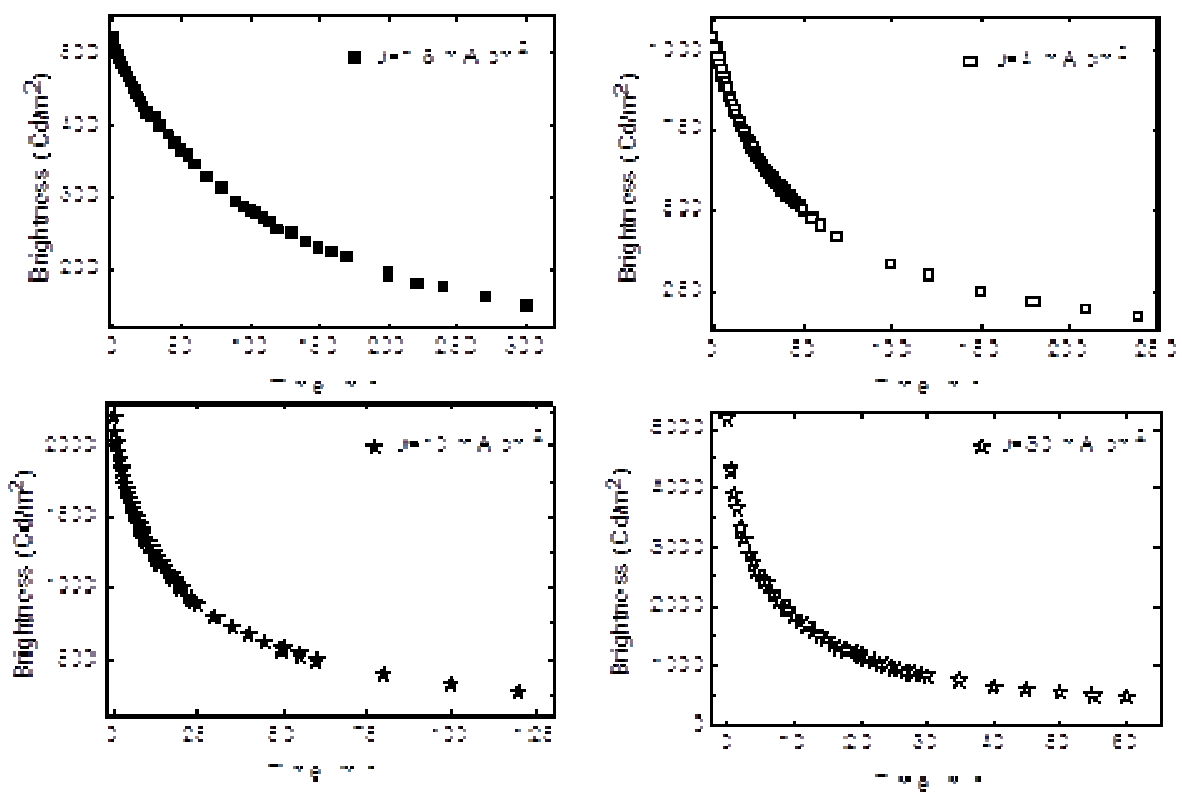

Fig. 6-9. Brightness vs time for different $L_{0}$ at constant current densities $J=1.8,4,10$, and $30 \mathrm{~mA} / \mathrm{cm}^{2}$. 
for the other devices were normalized to this reference level, as shown in Fig. 6-10. The straight line shown in that figure is based on the equation [20]

$$
L_{01}^{n} \cdot t_{1 / 2_{1}}=L_{02}^{n} \cdot t_{1 / 2_{2}}
$$

where the slope of this line is the acceleration factor $n$, which was found to be 1.32 . The good fit with the straight line demonstrates the validity of this relationship for the pixels used in this work. Thus, the half-lifetime at $100 \mathrm{Cd} / \mathrm{m}^{2}$ was calculated to be $\sim 13 \mathrm{~h}$. Under the same fabrication condition and measurement steps, the half-lifetime of the device ITO / PEDOT:PSS / PVK:TPD:Ir(mppy)3:PBD / Bphen / LiF / Al, without LiF doping, was $\sim 6 \mathrm{~h}$ [9]. Thus, the lifetime was significantly improved with the incorporation of the LiF dopant.
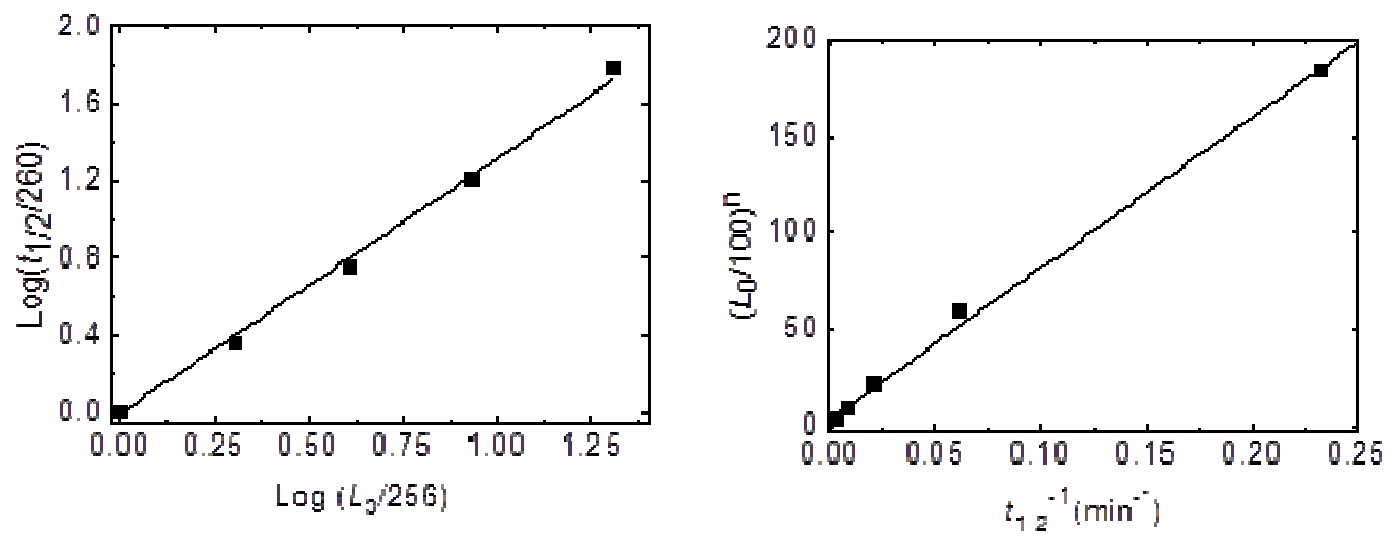

Fig. 6-10. (a) Log-log plot of $t_{1 / 2}$ normalized to that at $L_{0}=256 \mathrm{Cd} / \mathrm{m}^{2}$ vs the normalized $L_{0}=256 \mathrm{Cd} / \mathrm{m}^{2}, t_{1 / 2}=260 \mathrm{~min}$. The straight line is the fit of Eq. (1) with an acceleration factor (slope) $n=1.32$. (b) $L_{0}$ vs $1 / t_{1 / 2}$. The slope is $t_{1 / 2}=801 \mathrm{~min}$ at $L_{0}=100 \mathrm{Cd} / \mathrm{m}^{2}$. ELDMR:

Fig. 6-11(a) shows the negative (EL-quenching) spin $1 / 2$ ELDMR at $T=20 \mathrm{~K}$ of the green $\operatorname{Ir}(\text { mppy })_{3}$ emission in the device: ITO / PEDOT:PSS / PVK:TPD:PBD:Ir(mppy $)_{3} /$ 
$35 \mathrm{~nm}$ Bphen / $1 \mathrm{~nm} \mathrm{LiF} \mathrm{/} \mathrm{Al;} \mathrm{Fig.} \mathrm{6-11(b)} \mathrm{shows} \mathrm{the} \mathrm{amplitude} \mathrm{of} \mathrm{this} \mathrm{resonance}$ $\left|\Delta I_{E L} / I_{E L}\right|$ vs the voltage at room temperature. We note that the first generation of very low efficiency PPV PLEDs also exhibited a negative spin 1/2 resonance at all temperatures and no positive (EL-enhancing) spin 1/2 resonance [21]. However, improved PLEDs exhibited both a positive and a negative resonance [22], and SMOLEDs typically exhibit a positive resonance at low temperature and a negative resonance at room temperature [10-11]. The positive resonance is due to reduced quenching of singlet excitons (SEs) by triplet excitons (TEs) and polarons [10-14]. The negative resonance is due to enhanced formation of localized trions (i.e., bipolarons stabilized by adjacent deeply trapped counterpolarons) $[10-11,14,21-22]$. However, in all previously studied devices $\left|\Delta I_{E L} / I_{E L}\right|$ decreased with increased current
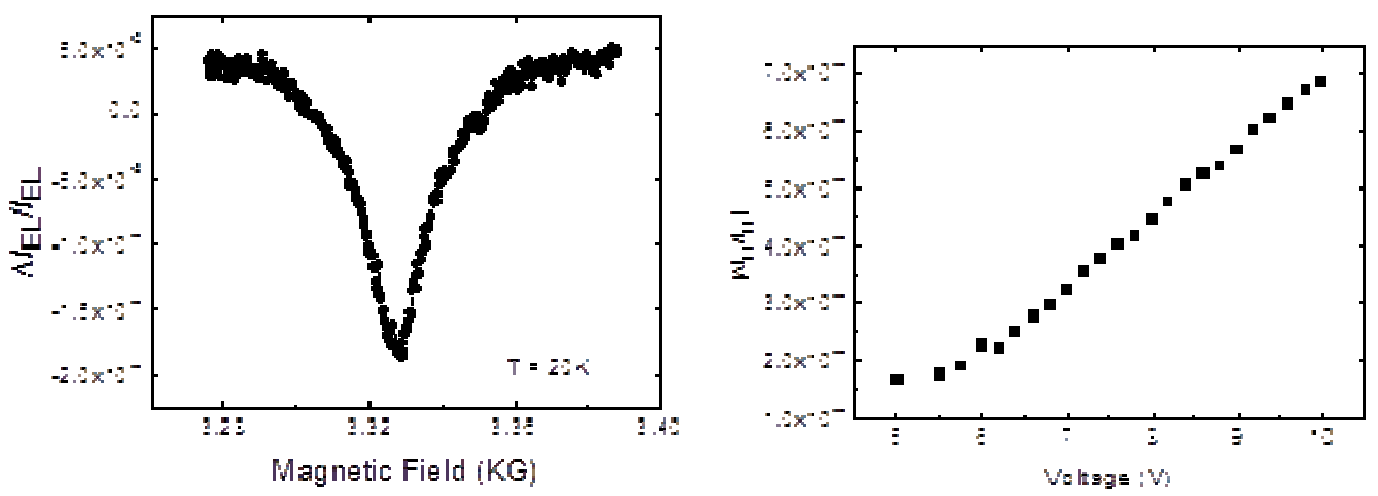

Fig. 6-11. (a) The full-field spin 1/2 ELDMR of the green phosphorescence in Ir(mppy) $3^{-}$ doped PVK PLED at 20K, (b) Negative spin $1 / 2\left|\Delta I_{E L} / I_{E L}\right|$ vs the bias at room temperature. Note the strong increase in $\left|\Delta I_{E L} / I_{E L}\right|$ with increasing bias, which also coincided with degradation of the device and is likely due to the high defect density in these PLEDs. 
density $J$, but in the PVK devices it increases strongly with increasing bias, from $\sim 1.5 \times 10^{-4}$ at $5 \mathrm{~V}$ to $\sim 7.0 \times 10^{-4}$ at $10 \mathrm{~V}$. This behavior may be associated with the observed PLED degradation. This increase of the negative ELDMR is also consistent with a relation between trion formation and the degradation mechanism [14].

\section{Conclusions}

The properties of ITO / PEDOT:PSS / PVK:TPD:Ir(mppy) $)_{3}: \mathrm{PBD} / x \mathrm{~nm}$ Bphen / $y \mathrm{~nm}$ Bphen:LiF / LiF / Al hybrid polymer/small molecular OLEDs were described. The devices with the LiF dopant exhibited the highest power efficiency, up to $31 \mathrm{~lm} / \mathrm{W}$, and the longest $t_{1 / 2}$ of $800 \mathrm{~min}$ at $L_{0}=100 \mathrm{Cd} / \mathrm{m}^{2}$. The ELDMR results, which showed that the negative spin $1 / 2$ resonance amplitude increases with bias and degradation, suggest the presence of a high density of defect sites promoting trion formation, which may be related to the short lifetimes of the devices.

\section{Acknowledgements}

Ames Laboratory is operated by Iowa State University for the US Department of Energy (USDOE) under Contract No. DE-AC 02-07CH11358. This work was-supported by the Director for Energy Research, Office of Basic Energy Sciences, USDOE.

\section{References}

[1] Y. R. Sun, N. C. Giebink, H. Kanno, B. W. Ma, M. E. Thompson, S. R. Forrest, Nature 440 (2006) 908.

[2] X. H. Yang, D. C. Muller, D. Neher, K. Meerholz, Adv. Mater. 18 (2006) 948.

[3] S. A. Choulis, V.-E. Choong, M. K. Mathai, F. So, Appl. Phys. Lett. 87 (2005) 113503. 
[4] G. Li, C. H. Kim, Z. Zhou, J. Shinar, K. Okumoto, Y. Shirota, Appl. Phys. Lett. 88 (2006) 253505.

[5] D. Y. Kondakov, J. Appl. Phys. 99 (2006) 024901.

[6] H. Aziz, Z. D. Popovic, N.-X. Hu, Appl. Phys. Lett. 81 (2002) 370.

[7] D. C. Zou, M. Yahiro, T. Tsutsui, Synth. Met. 91 (1997) 191; M. Yahiro, D. C. Zou, T. Tsutsui, Synth. Met. 111-112 (2000) 245.

[8] L. Qian, D. Bera, P. H. Holloway, Appl. Phys. Lett. 90, (2007) 103511.

[9] Y. M. Kim, J. W. Lee, J. H. Jung, K.-K. Paek, M. Y. Sung, J. K. Kim, B. K. Ju, IEEE Electr. Device L. 27(7) (2006) 558.

[10] G. Li, C.-H. Kim, P. A. Lane, J. Shinar, Phys. Rev. B 69 (2004) 165311.

[11] G. Li, J. Shinar, G. E. Jabbour, Phys. Rev. B 71 (2005) 235211.

[12] M.-K. Lee, M. Segal, Z. G. Soos, J. Shinar, M. A. Baldo, Phys. Rev. Lett. 94 (2005) 137403.

[13] M. Segal, M. A. Baldo, M. K. Lee, J. Shinar, Z. G. Soos, Phys. Rev. B 71 (2005) 245201.

[14] A. Kadashchuk, V. I. Arkhipov, C.-H. Kim, J. Shinar, D.-W. Lee, Y.-R. Hong, J.-I. Jin, P. Heremans, H. Bässler, Phys. Rev. B 76 (2007) 235205.

[15] Y. Yuan, D. Grozea, S. Han, Z. H. Lu, Appl. Phys. Lett. 85(21) (2004) 4959.

[16] H. J. Ding, K. W. Park, Y. L. Gao, D. Y. Kim, F. So, Chem. Phys. Lett. 473 (2009) 92.

[17] W. Xu, K.-U. Haq, Y. Bai, X. Y. Jiang, Z. L. Zhang, Sol. St. Comm. 146 (2008) 311.

[18] M. Y. Chan, S. L. Lai, C. S. Lee, S. T. Lee, Chem. Phys. Lett. 380 (2003) 298. 
[19] Y. Yuan, D. Grozea, S. Han, Z. H. Lu, Appl. Phys. Lett. 85, (2004) 4959.

[20] R. Meerheim, K. Walzer, M. Pfeiffer, K. Leo, Appl. Phys. Lett. 89 (2006) 061111.

[21] L. S. Swanson, J. Shinar, A. R. Brown, D. D. C. Bradley, R. H. Friend, P. L. Burn, A. Kraft, A. B. Holmes, Phys. Rev. B 46 (1992) 15072.

[22] N. C. Greenham, J. Shinar, J. Partee, P. A. Lane, O. Amir, F. Lu, R. H. Friend, Phys. Rev. B 53 (1996) 13528. 


\title{
Chapter 8. High efficiency solution-processed small molecule electrophosphorescent OLEDs
}

\author{
A paper published in Advanced Materials \\ Min Cai, Teng Xiao, Emily Hellerich, Ying Chen, Ruth Shinar and Joseph Shinar
}

\begin{abstract}
We demonstrate very high efficiency (forward power and luminous efficiencies up to $60 \mathrm{~lm} / \mathrm{W}$ and $69 \mathrm{Cd} / \mathrm{A}$, respectively) spin-coated small molecule electrophosphorescent OLEDs (SMOLEDs) based on a green-emitting iridium complex doped into a 4,4'-bis(9carbazolyl)-biphenyl (CBP) host. Electron- and hole- transporting molecules were blended with the host to improve the transport balance of the charge carriers. An additional electron- transporting/hole-blocking BPhen layer was thermally evaporated on the spin-coated active layer, followed by the LiF/Al cathode. The peak efficiency of these largely-solution-processed SMOLEDs is higher than that of any polymer or solutionprocessed OLED reported to date, and almost as high as that of the most efficient thermally evaporated (SM)OLED, when excluding the contribution of outcouplingenhancing structures such as microlens arrays. When such outcoupling enhancement is included, the peak power efficiency would be $120 \mathrm{~lm} / \mathrm{W}$, essentially the highest of any OLED reported to date. The high efficiency is attributed to the relatively high carrier mobility in CBP, the enhanced mobility due to the additional electron- and holetransporting dopants, and the smoothness of the doped CBP-based films, whose RMS
\end{abstract}


surface roughness is only $\sim 0.50 \mathrm{~nm}$. The enhanced performance of the spin-coated SMOLEDs implies that such devices are an attractive alternative to the fabrication of multi-component SMOLEDs, e.g., white OLEDs, reducing the cost and complexities of co-evaporation of multiple dopants and host materials in the thermal vacuum deposition processes.

\section{Introduction}

Extensive research on organic light-emitting diodes (OLEDs) continues due to their promise in applications such as flat panel displays and solid state lighting [1-5]. Commonly, thermal high-vacuum evaporation technology is used for fabrication of small molecule-based OLEDs (SMOLEDs) and solution processing technology is used for those based on polymers (PLEDs). Thermal evaporation deposition enables complicated multilayer device architectures and renders excellent devices with high efficiencies [6,7]. In contrast, solution-based deposition limits fabrication of composite device structures because the solvent used for one layer can redissolve or otherwise damage the previous layers [8]. Therefore, thermally evaporated SMOLEDs are typically more efficient and longer-lived than solution-processed PLEDs. However, thermal evaporation deposition has its own disadvantages. First, it requires high vacuum and is consequently much more costly. Second, making multi-dopant OLEDs, such as white OLEDs (WOLEDs), requires precise control of the doping concentration of each dopant in the emitting layer (EML) to obtain the desired emission $[9,10]$. These reasons usually lead to a fabrication process of greater complexity and higher cost. On the other hand, solution processing, such as spincoating, inkjet printing, and screen printing, is advantageous over thermal evaporation processing, due to its low-cost and large area manufacturability [10,11]. Additionally, it 
is possible to realize co-doping of several dopants by mixing the dopants and host material in solution. Hence, the fabrication of SMOLEDs via a solution process is of great importance. To that end, we demonstrate high efficiency (forward power and luminous efficiencies up to $60 \mathrm{~lm} / \mathrm{W}$ and $69 \mathrm{Cd} / \mathrm{A}$, respectively) spin-coated electrophosphorescent SMOLEDs based on green-emitting tris[2-(p-tolyl)pyridine] iridium(III) (Ir(mppy) $)_{3}$ doped into a 4,4'-bis(9-carbazolyl)-biphenyl (CBP) host, probably due to the materials and film morphology. This is the highest reported efficiency of any solution-processed OLED and among the highest of any OLED without outcoupling enhancement. The electron- transporting 2-(4-biphenylyl)-5-(4-tertbutylphenyl)- 1,3,4-oxadiazole (PBD) and hole- transporting N,N'-diphenyl-N,N'-bis(3methyl-phenyl)- [1,'biphenyl]-4,4'-diamine (TPD) are blended with the host to improve the transport balance of the charge carriers. A poly(3,4-ethylenedioxy thiophene):poly(4styrenesulfonate) (PEDOT:PSS) hole-injection layer is first spin-coated on the indium tin oxide (ITO)/glass substrate, and an additional electron- transporting/hole-blocking 4,7diphenyl-1,10-phenanthroline (BPhen) layer is thermally evaporated on the spin-coated active layer. Hence, the structure of the devices is ITO/spin-coated PEDOT:PSS/spincoated CBP:TPD:PBD: $\operatorname{Ir}(\mathrm{mppy})_{3} /$ thermally evaporated BPhen/LiF/Al. In particular, the performance of these SMOLEDs is superior to that of PLEDs with a similar structure based on poly(N-vinyl carbazole) (PVK) as the host (device structure: ITO/spin-coated PEDOT:PSS/spin-coated PVK:TPD:PBD:Ir(mppy) 3 /thermally evaporated BPhen/LiF/Al). The enhanced performance of the spin-coated SMOLEDs implies that such devices are an attractive and alternative route to the fabrication of small-molecular multi-component OLEDs, such as white OLEDs, reducing the cost of devices and avoiding the 
complexities of the co-evaporation of multiple dopants and host material in the vacuum deposition.

\section{Experimental procedures}

PEDOT:PSS was purchased from H. C. Starck and used as the hole injection layer (HIL). CBP and PVK, the host materials, TPD and PBD, the hole- and electrontransporting molecules, respectively, and BPhen, an electron-transporting and holeblocking material, were purchased from Sigma-Aldrich. $\operatorname{Ir}(\mathrm{mppy})_{3}$, the dopant material, was purchased from American Dye Source. These materials were used without further purification.

Films were fabricated on $1 " \times 1 "$ nominally $20 \Omega /$ square, 140 nm-thick ITO-coated glass substrates (Colorado Concept Coatings). The ITO substrates were first cleaned by a surfactant in an ultrasonic bath, and then rinsed in flowing de-ionized water. This was followed by consecutive ultrasonications, first in isopropanol and then in acetone to remove dust and organic residue. Finally, the cleaned ITO substrates were dried by blowing nitrogen and then treated in a UV ozone oven to increase the work function of the ITO and hence facilitate hole injection, as described elsewhere. The PEDOT:PSS was first filtered through a $0.45 \mu \mathrm{m}$ syringe filter. It was then spin coated at $1000 \mathrm{rpm}$ for $60 \mathrm{~s}$ on the ITO to generate a $60 \mathrm{~nm}$ layer that was baked in air at $160^{\circ} \mathrm{C}$ for 1 hour. $\mathrm{CBP}$, a blends of CBP: $\operatorname{Ir}(\mathrm{mppy})_{3}$, CBP: PBD: TPD: $\operatorname{Ir}(\mathrm{mppy})_{3}$, or a blend of PVK: PBD: TPD: $\operatorname{Ir}(\mathrm{mppy})_{3}$ in chlorobenzene were spin-coated on top of the PEDOT:PSS layer inside an Ar-filled glove box in which the oxygen level is generally below $10 \mathrm{ppm}$. These blends form the light emitting layers. After spin-coating at $4000 \mathrm{rpm}$ for $60 \mathrm{~s}$, the resulting light- 
emitting layers were annealed at $60^{\circ} \mathrm{C}$ for $30 \mathrm{~min}$. The morphology of the spin-coated thin films was measured by atomic force microscopy (AFM) (model MM AFM-2 from Digital Instruments, working at contact mode).

Following the annealing step, the films were transferred to a thermal evaporator chamber within the glove box. BPhen, $\mathrm{LiF}$ and $\mathrm{Al}$ layers were deposited sequentially by thermal evaporation using tungsten-heating baskets. The background pressure in the chamber was $\sim 2 \times 10^{-6}$ mbar. The evaporation rate of the BPhen layer was $\sim 1 \AA / \mathrm{s}$ while that of LiF was $0.2 \AA / s$. The thickness of the BPhen layer was $40 \mathrm{~nm}$ and that of $\mathrm{LiF}$ was $1 \mathrm{~nm}$. The Al cathode was deposited through a shadow mask containing $1.5 \mathrm{~mm}$ diameter circular holes; the evaporation rate of the $\mathrm{Al}$ was $\sim 4-5 \AA / \mathrm{s}$ and its thickness was $100 \mathrm{~nm}$. Bias voltages across the OLEDs were supplied by a Kepco DPS 40-2M programmable power supply and the current was measured using a Keithley 2000 multimeter. The OLEDs' EL was measured by a Minolta LS110 luminance meter and the EL spectra were obtained using an Ocean Optics CHEM2000 spectrometer.

\section{Results and discussion}

In spin-coated PLEDs, small molecule guests are typically blended with a polymer host in a suitable solvent as is the case for PVK:Ir(mppy) ${ }_{3}$ PLEDs [12,13]. However, when using this approach, phase separation may occur either after some time of operation or immediately following fabrication due to differences between small molecules and conjugated polymers in attributes such as viscosity and boiling point [14]. To address this issue, many other solution-processible organic molecules were designed and synthesized, including dendrimers, oligomers, spiro-molecules, and binuclear metal chelates [15-18]. 
Recently, efficient OLEDs based on solution-processed small molecules have been reported [19-26]. For example, He et al. reported that fluorescent SMOLEDs fabricated by spin-coating blends of N, N"-bis-(3-naphthyl)-N, N"-biphenyl-(1,1"-biphenyl)-4,4"diamine (NPB) and tris-(8-hydroxyquinoline)-aluminum $\left(\mathrm{Alq}_{3}\right)$ as the emitting layer exhibited maximum brightness and luminous efficiency exceeding $10,000 \mathrm{Cd} / \mathrm{m}^{2}$ and 3.8 $\mathrm{Cd} / \mathrm{A}$, respectively [23]. These values are comparable to those of thermally evaporated $\mathrm{Alq}_{3}$-based devices. Thus, the development of solution-processed SMOLEDs based on materials used in high-efficient OLEDs fabricated via vacuum deposition is promising.

$\operatorname{Ir}(\text { mppy })_{3}$ is a widely used phosphorescent dopant in OLEDs. The energy of the lowest lying triplet state of $\operatorname{Ir}(\mathrm{mppy})_{3}$ is $E_{T 1} \sim 2.38 \mathrm{eV}$, while that of the CBP host is $E_{T 1} \sim$ $2.56 \mathrm{eV}$, which satisfies the obvious requirement that $E_{T 1}$ of the host be $\geq$ to that of the guest $[27,28]$. Previous studies showed that in the case of PVK: $\operatorname{Ir}(\mathrm{mppy})_{3}$ PLEDs, carrier trapping and subsequent recombination on the guest molecule is, in general, the dominant triplet excitation path of the phosphorescent guest [12,29-31]. This is due to the energy of the highest occupied molecular orbital $E_{\text {НОмо }}=-5.4 \mathrm{eV}$ and the lowest unoccupied molecular orbital $E_{L U M O}=-2.4 \mathrm{eV}$ of $\operatorname{Ir}(\mathrm{mppy})_{3}$ being within those of PVK $\left(E_{\text {Номо }}=-5.8\right.$ $\mathrm{eV}, E_{L U M O}=-2.2 \mathrm{eV}$ ); see Fig. 7-1(a)) [32,33]. Even though the direct formation of the guest triplet state is the most elegant way to achieve good color purity and high efficiency, this direct formation often requires a high operating voltage due to the buildup of a spacecharge field [32]. In order to improve the performance of the PVK:Ir(mppy $)_{3}$ PLEDs, electron-transporting PBD $\left(\mu_{e} \sim 2 \times 10^{-5} \mathrm{~cm}^{2} / \mathrm{Vs}\right)$ and hole transporting TPD $\left(\mu_{h} \sim 2 \times 10^{-3}\right.$ $\left.\mathrm{cm}^{2} / \mathrm{Vs}\right)$ were co-doped with the $\operatorname{Ir}(\mathrm{mppy})_{3}[34,35]$. The introduction of PBD and TPD 
diminishes to a certain extent the buildup of the space charge field in the device and improves the balance of charge injection and transport due to their high carrier mobilities [12,29-32]. It was found that the optimized concentrations of PVK,TPD, PBD and $\operatorname{Ir}(\mathrm{mppy})_{3}$ in the EML were 61, 9, 24 and 6 wt. \%, respectively [12, 29-32].

(a)

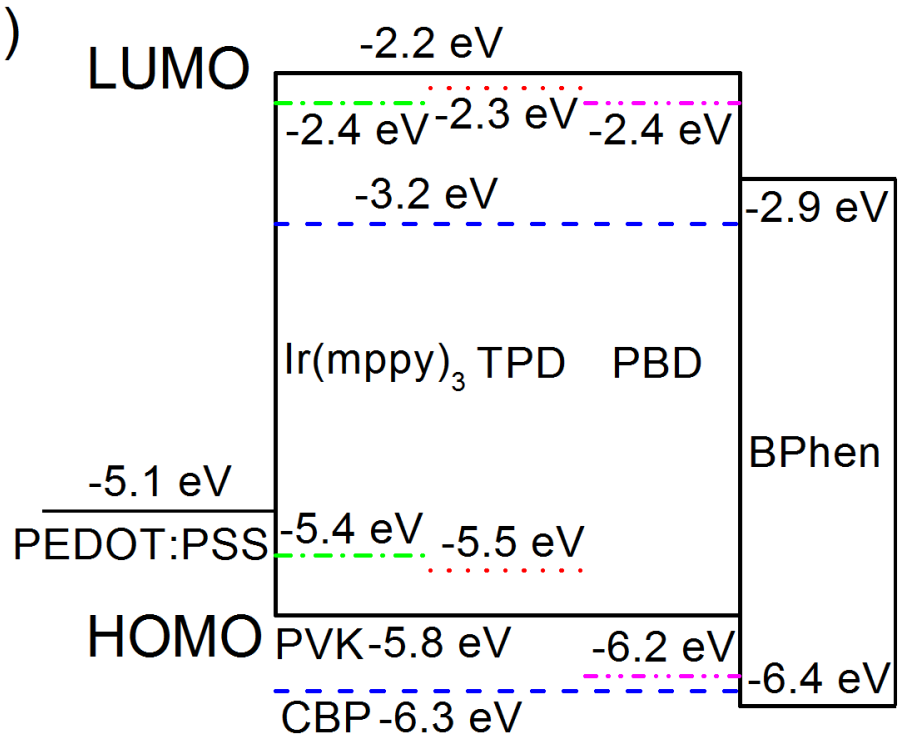

(b)

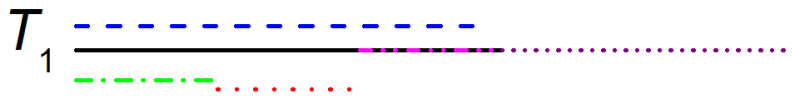

$$
\begin{aligned}
& \text { PVK, } 2.5 \mathrm{eV} \\
& \text {...... TPD, } 2.34 \mathrm{eV} \\
& \text {-.... Ir(mppy) }, 2.38 \mathrm{eV} \\
& \text { - - - CBP, } 2.6 \mathrm{eV} \\
& \text {-...... PBD, } 2.5 \mathrm{eV} \\
& \text { BPhen, } 2.5 \mathrm{eV} \\
& S_{0}
\end{aligned}
$$

Fig. 7-1. (a) HOMO and LUMO energy levels and (b) triplet energy $\left(T_{1}\right)$ levels of the various OLED materials. 
On the other hand, the carbazole-containing CBP host is a very common host material in thermally-evaporated phosphorescent SMOLEDs that yield highly efficient devices with emission colors across the entire visible spectrum [36-39]. However, systematic studies on solution-processing of CBP and CBP-based SMOLEDs have not been reported. Therefore in this study, a series of CBP and CBP-based multilayer SMOLEDs with the following structures were fabricated:

Device A: ITO/spin-coated PEDOT:PSS/spin-coated CBP/thermally evaporated BPhen $(40 \mathrm{~nm}) / \mathrm{LiF}(1 \mathrm{~nm}) / \mathrm{Al}(100 \mathrm{~nm})$,

Device $\quad$ B: $\quad$ ITO/spin-coated PEDOT:PSS/spin-coated $\quad$ CBP (0.94): $\operatorname{Ir}(\operatorname{mppy})_{3}(0.06) /$ thermally evaporated BPhen $(40 \mathrm{~nm}) / \mathrm{LiF}(1 \mathrm{~nm}) / \mathrm{Al}(100 \mathrm{~nm})$, and Device C: ITO/spin-coated PEDOT:PSS/spin-coated $\mathrm{CBP}(0.61): \operatorname{TPD}(0.09): \operatorname{PBD}(0.24): \operatorname{Ir}(\mathrm{mppy})_{3}(0.06) /$ thermally evaporated BPhen $\quad$ (40 $\mathrm{nm}) / \mathrm{LiF}(1 \mathrm{~nm}) / \mathrm{Al}(100 \mathrm{~nm})$.

PLEDs based on PVK similar to Device C were also fabricated for comparison:

$\begin{array}{lll}\text { Device } & \text { D: } & \text { ITO/spin-coated }\end{array}$ $\operatorname{PVK}(0.61): \operatorname{TPD}(0.09): \operatorname{PBD}(0.24): \operatorname{Ir}(\mathrm{mppy})_{3}(0.06) /$ thermally evaporated BPhen $\quad(40$ $\mathrm{nm}) / \mathrm{LiF}(1 \mathrm{~nm}) / \mathrm{Al}(100 \mathrm{~nm})$. This structure differed from previously reported structures by the addition of the BPhen layer [12,32-33].

The optimized fractions of each component by weight in the EML were 0.61 CBP or PVK, 0.09 TPD, 0.24 PBD, and $0.06 \operatorname{Ir}(\mathrm{mppy})_{3} . E_{\text {HOMO }}, E_{L U M O}$, and $E_{T 1}$ of the materials in these devices are also shown in Fig. 7-1 [32,33,36,40-43]. 
In order to determine the possible effect of morphology on device performance, we examined the films by atomic force microscopy (AFM). Some polymer blend systems phase separate and AFM has been shown to be a powerful tool in the analysis of this behavior [44]. AFM images of the spin-coated emitting films are shown in Fig. 3-2; all show pinhole-free surfaces.

The root-mean-square (RMS) surface roughness spin-coated CBP and PVK films are 0.98 and $0.87 \mathrm{~nm}$, respectively. They are shown in Figs. 7-2(a)-(b). These values are significantly smaller than the 1.5 and $1.3 \mathrm{~nm}$ roughness of the thermally evaporated films measured in our work and by Liu et al., respectively [45]. This demonstrates that a typical amorphous SM EML can be fabricated effectively not only by thermal vacuum deposition but also by a solution process.

Figs. 7-2(c)-(f) show the surface morphology of the spin-coated films of the CBP (0.94):Ir(mppy) $)_{3}$ (0.06), PVK (0.94):Ir(mppy) $)_{3}$ (0.06), CBP (0.61):TPD (0.09): PBD (0.24):Ir(mppy) $)_{3}(0.06)$ and PVK (0.61):TPD (0.09):PBD (0.24): $\operatorname{Ir}(\mathrm{mppy})_{3}(0.06)$ blends, respectively. The RMS surface roughness values of these films are $0.47,1.16,0.57$ and $1.10 \mathrm{~nm}$, respectively. Thus, replacing $P V K$ with $C B P$ as the host matrix reduces the EML's surface roughness by $>50 \%$. A possible explanation for this behavior may be related to the difference between the small molecules and polymers. The latter often show improved mechanical strength due to a stronger intermolecular forces and steric hindrances. Hence, during spin-coating, the films formed by small molecules and polymers show different degrees of phase separation [46,47]. Thus, for these particular compositions of the CBP- and PVK-based blends, phase separation likely occurs more 

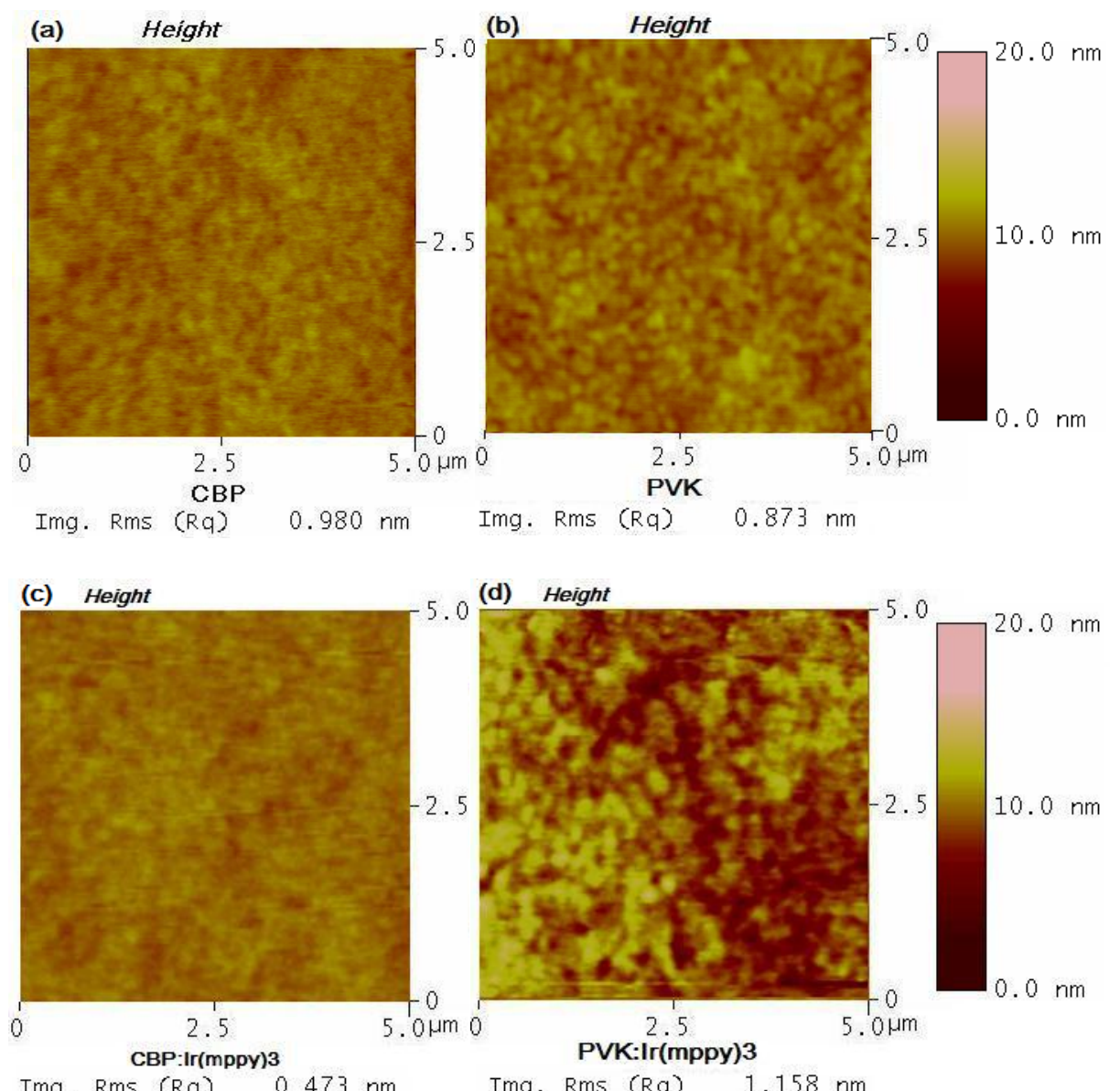
Img. Rms (Rq) $0.473 \mathrm{~nm} \quad$ Img. Rms (Rq) $1.158 \mathrm{~nm}$

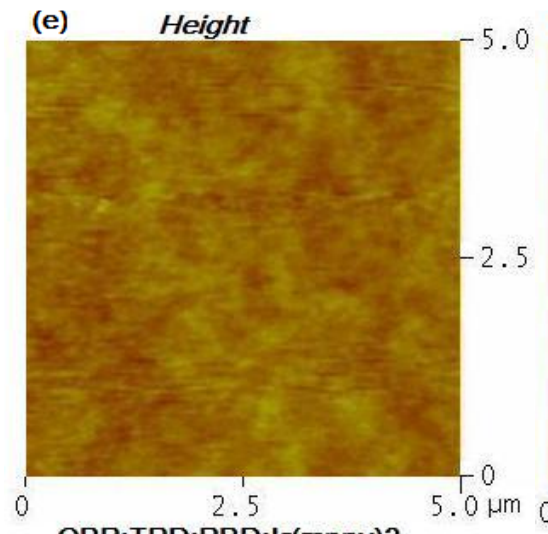

CBP:TPD:PBD:Ir(mppy)3 Imq. Rms (Rq) $0.564 \mathrm{~nm}$

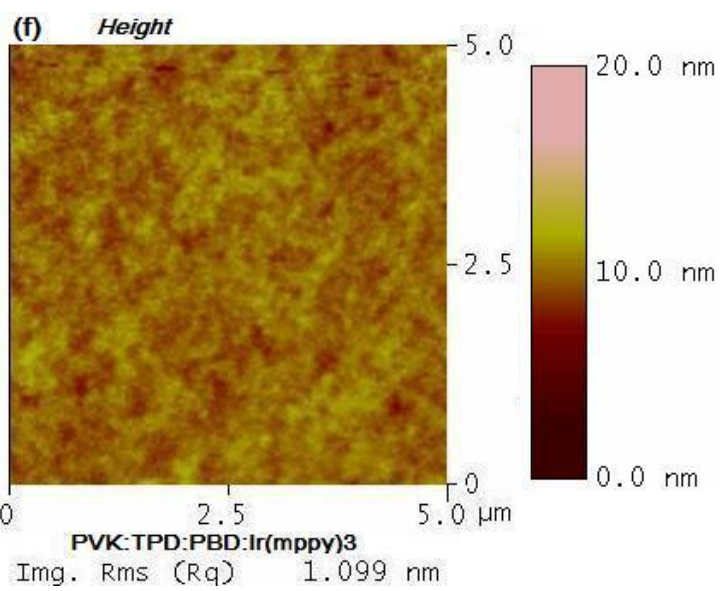

Fig. 7-2. AFM images of thin films formed by spin-coating (a) CBP, (b) $P V K$, (c) CBP:Ir(mppy $)_{3}, \quad$ (d) $\quad P V K: \operatorname{Ir}(\text { mppy })_{3} \quad$, (e) CBP:TPD:PBD:Ir(mppy $)_{3}$ and $(f)$ PVK:TPD:PBD:Ir(mppy) $)_{3}$ 
readily in the PVK-based films than in the CBP-based films prepared under similar conditions. The increased phase separation would then increase the surface roughness in the PVK-based films. The better uniformity of the EML in Device C (in comparison to Device D) may be partially responsible for the

better device performance described next. Note, however, that the morphology and phase separation in the blends are expected to strongly depend on the composition, and the conclusions drawn in this work are valid only for these particular compositions.

It is noteworthy that the thin films of the spin-coated blends of $6 \mathrm{wt} . \% \operatorname{Ir}(\mathrm{mppy})_{3}$ in CBP are surprisingly smoother, as their RMS surface roughness is $\sim 50 \%$ lower than that of the CBP-only films. This intriguing result indicates that $\operatorname{Ir}(\operatorname{mppy})_{3}$ reduces the roughness of the $\mathrm{CBP}$-based films and it warrants further investigation. Indeed, it is made all the more surprising in view of the observation that adding TPD and PBD into the blend increases the RMS surface roughness only slightly, from $0.47 \mathrm{~nm}$ to $0.56 \mathrm{~nm}$.

As mentioned, in our experiments, all devices have a spin-coated PEDOT:PSS holeinjection layer, which precedes the spin-coated EML. The BPhen electron-transporting layer is thermally evaporated on the spin-coated EML. It is one of the most attractive electron-transporting materials, with $\mu_{e} \sim 2.8 \times 10^{-4} \mathrm{~cm}^{2} / \mathrm{Vs}$ at room temperature and a high $E_{T 1}=2.5 \mathrm{eV}$ (Fig. 7-1(b)) $[42,48]$. Thus, the role of the BPhen layer is two-fold: First, it improves the electron injection and transport due to its high electron mobility, thus providing better charge balance in the devices. Second, its high $E_{T 1}$ and deep HOMO level $(-6.4 \mathrm{eV})$ confine holes and excitons within the EML, resulting in high efficiencies [42]. 
The spin-coated EML of Device A consists of CBP only. The EL spectrum, which peaked at $\sim 409 \mathrm{~nm}$, is apparently due to bulk emission from CBP. This spin-coated CBP device shows a peak brightness of $\sim 200 \mathrm{Cd} / \mathrm{m}^{2}$ and a peak luminous efficiency of 0.23 $\mathrm{Cd} / \mathrm{A}$, which corresponds to an external quantum efficiency of $0.73 \%$. These values are comparable to those of the thermally evaporated devices [49-50], demonstrating that spin-coated CBP-based OLEDs are viable and promising.
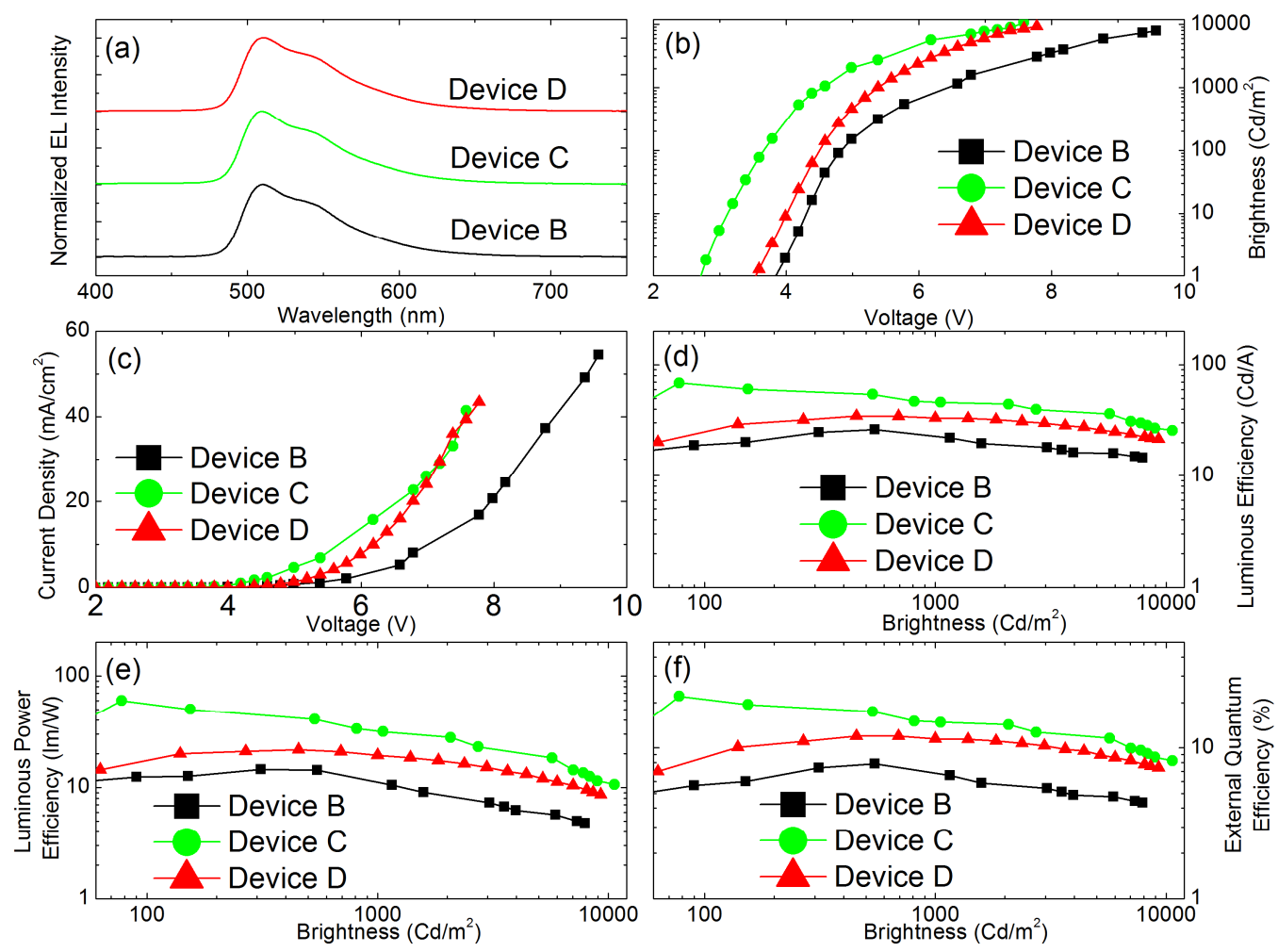

Fig. 7-3. Comparison of device characteristics (a) EL spectra, (b) Brightness vs. voltage,

(c) Current density vs. voltage, (d) Luminous efficiency vs. brightness, (e) Luminous power efficiency vs. brightness, (f) External Quantum Efficiency vs. brightness of Device B (square), Device C (circle) and Device D (triangle). 
The normalized electroluminescence (EL) spectra of devices B, C and D, driven at 57 $\mathrm{mA} / \mathrm{cm}^{2}$, are shown in Fig. 7-3(a). As clearly seen, the spectra peak at $\sim 510 \mathrm{~nm}$, and their EL bands are nearly identical. Hence, the EL originates only from the $\operatorname{Ir}(\mathrm{mppy})_{3}$ molecule, indicating an essentially complete energy or charge transfer from the other components of the blend to the $\operatorname{Ir}(\mathrm{mppy})_{3}$.

Fig. 7-3 also shows the brightness and current density vs. voltage, and the luminous efficiency, luminous power efficiency and external quantum efficiency vs. brightness for Devices B, C and D. The spin-coated EML of Device B, made of CBP (0.94): $\operatorname{Ir}(\operatorname{mppy})_{3}$ (0.06), shows a peak luminous efficiency of $26 \mathrm{Cd} / \mathrm{A}$, a peak luminous power efficiency of $14 \mathrm{~lm} / \mathrm{W}$ and a peak external quantum efficiency of $7.9 \%$. These results indicate that spin-coated $\operatorname{Ir}(\mathrm{mppy})_{3}: \mathrm{CBP}$-based devices are comparable to the thermally evaporated ones $[36,51]$.

As expected from Ref. 32 the performance of Device C, where the EML includes TPD and PBD, is much better than Device B. The turn-on voltage (i.e., the voltage at $1 \mathrm{Cd} / \mathrm{m}^{2}$ ) is $2.8 \mathrm{~V}$ for Device $\mathrm{C}$, which is $\sim 1.0 \mathrm{~V}$ lower than that of Device $\mathrm{B}$, and the current density of Device $\mathrm{C}$ is larger throughout the whole bias range. This reduction of the turnon voltage and larger current density are clearly due to the increased hole conductivity of TPD and electron conductivity of PBD. In addition, TPD, with a HOMO level similar to $\operatorname{Ir}(\text { mppy })_{3}$ (see Fig. 7-1) likely prevents saturation of the $\operatorname{Ir}(m p p y)_{3}$ with trapped holes, and eliminates the buildup of the hole space charge. This behavior is consistent with previous studies on PVK:Ir(mppy) $)_{3}$ PLEDs [12,29-33]. As a result of the improved balance of the charge injection and transport due to TPD and PBD, the maximum 
luminous efficiency, luminous power efficiency and external quantum efficiency reach $69 \mathrm{Cd} / \mathrm{A}, 60 \mathrm{~lm} / \mathrm{W}$ and $22 \%$, respectively. We note that with an outcoupling enhancement of $100 \%$ such as reported recently [52], the maximal luminous power efficiency of Device C would reach $120 \mathrm{~lm} / \mathrm{W}$, i.e., it would be one of the highest reported to date on any OLED.

The turn-on voltage of Device D is $3.5 \mathrm{~V}$, or $0.7 \mathrm{~V}$ higher than that of Device C, and the current density is lower in comparison to Device C. This clearly demonstrates a reduced conductivity of Device D. The higher conductivity and higher efficiencies of Device C are probably due to the much higher hole mobility of CBP $\left(\mu_{h} \sim 10^{-3} \mathrm{~cm}^{2} / \mathrm{Vs}\right)$ than of PVK $\left(\mu_{h} \sim 10^{-9} \mathrm{~cm}^{2} / \mathrm{Vs}\right)$, but may also be related to the smoother surface of the CBP-based layer [53,54]. The corresponding efficiencies of Device D are shown in Fig. 7-3. The peak luminous, luminous power, and external quantum efficiencies are $35 \mathrm{Cd} / \mathrm{A}$, $22 \mathrm{~lm} / \mathrm{W}$, and $12 \%$, respectively. The results therefore demonstrate that using CBP as the host material instead of PVK improves the quality of the spin-coated film, enhancing the overall device performance.

The high efficiency of Device $\mathrm{C}$ is likely due to the following factors:

(i) The relatively high carrier mobility in CBP:Ir(mppy) 3 :TPD:PBD blends. Choulis et al. reported highly efficient spin-coated PVK:Ir(mppy)3:TPD:PBDbased PLEDs [33]. However, the replacement of PVK by CBP probably improves the devices' carrier mobility significantly, as the intrinsic mobility in the connecting PVK tissue is very low $\left(\sim 10^{-9} \mathrm{~cm}^{2} / \mathrm{Vs}\right)$. 
(ii) The considerable amounts of the hole- transporting TPD and electrontransporting PBD likely improve charge balance, as they probably do in the PVK:Ir(mppy) $)_{3}:$ TPD:PBD-based PLEDs to yield the high efficiency of these latter devices.

(iii) The addition of the BPhen layer blocks holes from reaching the cathode, and, importantly separates the recombination zone from the cathode region. This largely eliminates quenching of the excitons by the cathode.

(iv) Given the AFM images shown in Fig. 7-2, the apparently smoother morphology of the CBP-based SMOLEDs likely results in higher carrier mobility and reduced quenching of excitons at defect sites.

Although efficient solution-processed SMOLEDs have drawn increasing attention recently, there are only a few reports on the operational lifetime of these devices $[22,26$, 55]. Lee et al. fabricated other spin-coated SMOLEDs with thermally evaporated $\mathrm{Alq}_{3}$ (or TPBI)/LiF/A1.[22] Their operational lifetimes $L_{50}$, i.e., the time at which the brightness decreased to $50 \%$ of its initial value, were $\sim 3 \mathrm{~h}$ at an initial brightness $L_{0}=600 \mathrm{Cd} / \mathrm{m}^{2}$. Ooe et al.[55] fabricated SMOLEDs with a solution- processed $\alpha$-NPD:CBP:Ir(tpy $)_{3}$ active layer, on which they thermally evaporated a hole-blocking layer of bathocuproine (BCP), followed by LiF/Al. Their $L_{50}$ was $\sim 4.5 \mathrm{~h}$ at $L_{0}=1,000 \mathrm{Cd} / \mathrm{m}^{2}$. Preliminary stability measurements on the CBP-based Device C yielded $L_{50} \sim 2.4 \mathrm{~h}$ at $L_{0}=810 \mathrm{Cd} / \mathrm{m}^{2}$. This is more than twice that of the PVK-based Device D, where $L_{50} \sim 0.83 \mathrm{~h}$ at $L_{0}=1,000$ $\mathrm{Cd} / \mathrm{m}^{2}$, and it is actually higher than the $\sim 3 \mathrm{~h}$ at $L_{0}=600 \mathrm{Cd} / \mathrm{m}^{2}$ reported by Lee et al. [22], but somewhat lower than the $\sim 4.5 \mathrm{~h}$ at $L_{0}=1,000 \mathrm{Cd} / \mathrm{m}^{2}$ reported by Ooe et al. [55]. We suspect that the higher $96^{\circ} \mathrm{C}$ glass-transition temperature $T_{g}$ of $\alpha$-NPD as compared to the 
$65^{\circ} \mathrm{C}$ of TPD, and the relatively low $T_{g}$ of BPhen reduced $L_{50}$. We also suspect that a lower film density caused by the presence of free volume between aggregates may also accelerate degradation. If that scenario is vindicated, optimizing several key parameters such as the use of materials with high $T_{g}$, spin coating speed and time, and the thermal treatment (temperature and time) should improve the stability. In addition, we note that the devices were encapsulated by lining the edges of the glass substrate with torr-seal epoxy and attaching a glass cover on the device. While such encapsulation is usually sufficient for brief measurements, it is believed that encapsulation by, e.g., the polymer multilayer technique would improve the protection of the device from water and enhance its stability [56,57]. A detailed study is in progress and will be reported later.

\section{Conclusions}

In conclusion, we described solution-processed CBP-based SMOLEDs and compared their performance to that of PVK-based PLEDs, demonstrating SMOLEDs with peak power efficiency higher than any solution-processed device and among the highest of any OLED reported to date. Uniform SMOLED EMLs of CBP:PBD:TPD:Ir(mppy) ${ }_{3}$ (in comparison to the PLED EMLs PVK:PBD:TPD:Ir(mppy) $)_{3}$ ) were obtained by spincoating. The improved performance of these spin-coated SMOLEDs is believed to be due to the higher conductivity of CBP and the smoother spin-coated SMOLED EML. Consequently, solution-processing of SMOLEDs is expected to be a new and growing route for fabricating multi-components OLEDs, such as WOLEDs, to reduce manufacturing costs, increase device size, and avoid the complexity of the vacuum codeposition process. 


\section{Acknowledgements}

Research supported by the U.S. Department of Energy, Basic Energy Sciences, Materials Sciences and Engineering Division under Contract No. DE-AC 02-07CH11358.

\section{Author contributions}

Teng Xiao fabricated the PVK-based spin-coated PLEDs, characterized them, and commented on the paper draft. Min Cai fabricated the CBP-based spin-coated SMOLEDs, characterized them, and prepared the paper. Emily Hellerich and Ying Chen provided useful discussions.

\section{References}

[1] C. W. Tang, S. A. Vanslyke, Appl. Phys. Lett. 51 (1987) 913.

[2] C. W. Tang, S. A. Vanslyke, C. H. Chen, J. Appl. Phys. 65 (1989) 3610.

[3] J. H. Burroughes, D. D. C. Bradely, A. R. Brown, R. N. Marks, K. Mackay, R. H. Friend, P. L. Burn, A. B. Holmes, Nature 347 (1990) 539.

[4] M. A. Baldo, D. F. O'Brien, Y. You, A. Shoustikov, S. Sibley, M. E. Thompson, S. R. Forrest, Nature 395 (1998) 151.

[5] V. Bulovic, P. E. Burrows, S. R. Forrest, Semicond. Semimet. 64 (2000) 255.

[6] C. Adachi, M. A. Baldo, S. R. Forrest, M. E. Thompson, Appl. Phys. Lett. 77 (2000) 904.

[7] J. S. Huang, M. Pfeiffer, A. Werner, J. Blochwitz, K. Leo, S. Y. Liu, Appl. Phys. Lett. 80 (2002) 139.

[8] S. R. Forrest, Nature 428 (2004) 911. 
[9] B. W. D’Andrade, M. E. Thompson, S. R. Forrest, Adv. Mater. 14 (2002) 147.

[10] M. C. Gather, A. Köhnen, K. Meerholz, Adv. Mater. 23 (2011) 2.

[11] J. Huang, G. Li, E. Wu, Q. Xu, Y. Yang, Adv. Mater. 18 (2006) 114.

[12] X. H. Yang, D. C. Muller, D. Neher, K. Meerholz, Adv. Mater. 18 (2006) 948.

[13] X. H. Yang, D. Neher, D. Hertel, T. K. Daubler, Adv. Mater. 16 (2004) 161.

[14] M. H. Jonathan, N. G. Pillow, D. W. Samuel, P. L. Burn, Adv. Mater. 11 (1999) 371.

[15] J. Q. Ding, B. H. Zhang, J. H. Lu, Z. Y. Xie, L. X. Wang, X. B. Jing, F. S. Wang, Adv. Mater. 21 (2009) 1.

[16] R. Pudzich, J. Salbeck, Synth. Met. 21 (2003) 138.

[17] H. Fukagawa, K. Watanabe, S. Tokito, Org. Electron. 10 (2009) 798.

[18] J. Qiao, L. D. Wang, J. F. Xie, G. T. Lei, G. S. Wu, Y. Qiu, Chem. Commun. 5 (2005) 4560.

[19] N. Rehmann, D. Hertel, K. Meerholz, H. Becker, S. Heun, Appl. Phys. Lett. 91 (2007) 103507.

[20] D. D. Wang, Z. X. Wu, X. W. Zhang, B. Jiao, S. X. Liang, D. W. Wang, R. L. He, X. Hou, Org. Electron. 11 (2010) 641.

[21] L. D. Hou, L. Duan, J. Qiao, W. Li, D. Q Zhang, Y. Qiu, Appl. Phys. Lett. 92 (2008) 263301. 
[22] T-W. Lee, T.Y. Noh, H-W. Shin, O. Kwon, J-J. Park, B-K. Choi, M-S. Kim, D. W. Shin, Y-R. Kim, Adv. Funct. Mater. 19 (2009) 1625.

[23] L. He, J. F. Liu, Z. X. Wu, D. D. Wang, S. X. Liang, X. W. Zhang, B. Jiao, D. W. Wang, X. Hou, Thin Solid Films 518 (2010) 3866.

[24] C.-G. Zhen, Z.-K. Chen, Q.-D. Liu, Y.-F. Dai, R. Y. C. Shin, S.-Y. Chang, J. Kieffer, Adv. Mater. 21 (2009) 2425.

[25] Y. Byun, Y.-Y. Lyu, R. R. Das, O. Kwon, T.-W. Lee, Y. J. Park, Appl. Phys. Lett. 91 (2007) 211106.

[26] L. Duan, L. Hou, T.-W. Lee, J. Qiao, D. Zhang, G. Dong, L. Wang, Y. Qiu, J. Mater. Chem. 20 (2010) 6392.

[27] H. H. Liao, H. F. Meng, S. F. Homg, W. S. Lee, J. M. Yang, C. C. Liu, J. T. Shy, F. C. Chen, C. S. Hsu, Phys. Rev. B 74 (2005) 245211.

[28] C. Adachi, R. C. Kwong, P. Djurovich, V. Adamovich, M. A. Baldo, M. E. Thompson, S. R. Forrest, Appl. Phys. Lett. 79 (2001) 2802.

[29] S. Lamansky, P. I. Djurovich, F. Abel-Razzaq, S. Garon, D. L. Murphy, M. E. Thompson, J. Appl. Phys. 92 (2002) 1570.

[30] K. M. Vaeth, C. W. Tang, J. Appl. Phys. 92 (2002) 3447.

[31] X. Gong, M. R. Robinson, J. C. Ostrowski, D. Moses, G. C. Bazan, A. J. Heeger, Adv. Mater. 14 (2002) 581. 
[32] X. H. Yang, D. Neher, Appl. Phys. Lett. 84 (2004) 2476.

[33] S. A. Choulis, V. E. Choong, M. K. Mathai, F. So, Appl. Phys. Lett. 87 (2005) 113503.

[34] Y. Kawabe, J. Abe, Appl. Phys. Lett. 81 (2002) 493.

[35] A. Kuwahara, S. Naka, H. Okada, H. Onnagawa, Appl. Phys. Lett. 89 (2006) 132106.

[36] M. A. Baldo, S. Lamansky, P. E. Burrows, M. E. Thompson, S. R. Forrest, Appl. Phys. Lett. 75 (1999) 4.

[37] G. F. He, M. Pfeiffer, K. Leo, M. Hofmann, J. Birnstock, R. Pudzich, J. Salbeck, Appl. Phys. Lett. 85 (2004) 3911.

[38] R. J. Holmes, S. R. Forrest, Y. J. Tung, R. C. Kwong, J. J. Brown,S. Garon, M. E. Thompson, Appl. Phys. Lett. 82 (2003) 2422.

[39] A. Tsuboyama, H. Iwawaki, M. Furugori, T. Mukaide, J. Kamatani, S. Igawa, T. Moriyama, S. Miura, T. Takiguchi, S. Okada, M. Hoshino, K. Ueno, J. Am. Chem. Soc. 125 (2003) 12971.

[40] M. Y. Chan, C. S. Lee, S. L. Lai, M. K. Fung, F. L. Wong, H. Y. Sun, K. M. Lau, S. T. Lee, J. Appl. Phys. 100 (2006) 094506.

[41] F-C. Chen, S-C Chang, G. F. He, S. M. Pyo, Y. Yang, M. Kurotaki, J. Kido, J. Polym. Sci. Pol. Phys. 41 (2003) 2681.

[42] J. Lee, N. Chopra, S. H. Eom, Y. Zheng, J. Xue, F. So, J. Shi, Appl. Phys. Lett. 93 (2008) 123306. 
[43] M. Suzuki, S. Tokito, F. Sato, T. Igarashi, K. Kondo, T. Koyama, T. Yamaguchi, Appl. Phys. Lett. 86 (2005) 103507.

[44] Y.-Y. Noh, C.-L. Lee, J.-J. Kim, K. Yase, J. Chem. Phys. 118 (2003) 2853.

[45] Z. T. Liu, C. Y. Kwong, C. H. Cheung, A. B. Djurisic, Y. Chan, P. C. Chui, Synth. Met. 150 (2005) 159.

[46] H. Razafitrimo, Y. Gao, W.A. Feld, B.R. Hsieh, Synth. Met. 79 (1996) 103.

[47] C. Liu, X. C. Zou, S. Yin, W. X. Zhang, Thin Solid Films 466 (2004) 279.

[48] M. A. Khan, W. Xu, K. -u. Haq, Y. Bai, Y. Jiang, Z. L. Zhang, W. Q. Zhu, Z. L. Zhang, W. Q. Zhu, J. Appl. Phys. 103 (2008) 014509.

[49] L. Zou, V. Savvate'ev, J. Booher, C.-H. Kim, J. Shinar, Appl. Phys. Lett. 79 (2001) 2282.

[50] J. Shinar, R. Shinar, Z. Zhou, Appl. Surf. Sci. 254 (2007) 749.

[51] D. D. Song, S. L. Zhao, Y. C. Luo, H. Aziz, Appl. Phys. Lett. 97 (2010) 243304.

[52] J.-M. Park, Z. Q. Gan, W. Y. Leung, R. Liu, Z. Ye, K. Constant, J. Shinar, R. Shinar, K. M. Ho, Opt. Exp. 19 (2011) A786.

[53] S. M. Liu, B. Li, L. M. Zhang, H. Song, H. Jiang, Appl. Phys. Lett. 97 (2010) 083304.

[54] P. D’Angelo, M. Barra, A. Cassinese, M. G. Maglione, P. Vacca, C. Minarini, A. Rubino, Solid State Electron. 51 (2007) 123. 
[55] M. Ooe, S. Naka, H. Okada, H. Onnagawa, Jpn. J. Appl. Phys. 45 (2006) 250.

[56] P. E. Burrows, G. L. Graff, M. E. Gross, P. M. Martin, M. Hall, E. Mast, C. Bonham, W. Bennett, L. Michalski, M. Weaver, J. J. Brown, D. Fogarty, L. S. Sapochak, in Organic Light-Emitting Materials and Devices IV, (edited by Z. H. Kafafi), SPIE Conf. Proc. 4105 (2000) 75.

[57] L. Moro, T. A. Krajewski, N. M. Rutherford, O. Philips,R. J. Visser, M. Gross, W. D. Bennett, G. Graff, in Organic Light Emitting Materials and Devices VII, (edited by Z. H. Kafafi, P. A. Lane), SPIE Conf. Proc. 5214 (2004) 83.

[58] Z. Q. Zhou, R. Shinar, A. J. Allison, J. Shinar, Adv. Func. Mater. 17 (2007) 3530. 


\section{Chapter 9. Summary}

A brief introduction to OSCs and OLEDs was provided in Chapters 1 and 2. Chapters 3 to 5 presented approaches to enhance the performance of solar cells and chapters 6 and 7 discuss performance attributes of OLEDs. In Chapter 3, various treatments of the PEDOT:PSS layer in ITO/PEDOT:PSS/ P3HT:PCBM/Ca/Al solar cells were described. These treatments resulted in improved overall device performance. In particular, the use of a PEDOT:PSS film with spin-coated EG on it post-fabrication resulted in an increase of $\sim 27 \%$ in the PCE (from $3.7 \%$ for the untreated cells to $4.7 \%$ for the treated ones). Based on the results, it appears that the improved devices result mostly from an increased surface roughness of the P3HT:PCBM associated with the treatment and consequent graininess of the PEDOT:PSS layers. The increased roughness generates a better contact with the metal electrode, which, possibly, together with the observed PCBM aggregates near the cathode, improves charge extraction. The improved PEDOT:PSS transmission and PEDOT:PSS/P3HT:PCBM absorption, together with the improved PEDOT:PSS conductivity in some of the cases, improved the $I_{\mathrm{SC}}$ and the overall cell performance. This improvement is possibly also due to improved light scattering by the rougher surfaces that results in enhanced absorption in the active layer. The results do not indicate that a change in the thickness of the PEDOT:PSS films is a major contributor to the observed improvements, as optimized spin-coating conditions were employed in each case (untreated and treated PEDOT:PSS) and the optimized thicknesses of the different layers were comparable. Similarly, changes in the PEDOT:PSS conductivity did not correlate 
with the improved performance. The simple routes that led to the significantly increased PCE are expected to be applicable to other organic-based solar cells.

In Chapter 4, the effects of thin interlayers in small-molecule-based OSCs were discussed. A $1 \mathrm{~nm}$ layer of $\mathrm{LiF}$ on the ITO anode in $\mathrm{CuPc} / \mathrm{C}_{70}$-based OSCs enhances $J_{\mathrm{SC}}$ and PCE by up to $\sim 17 \%$ following air-plasma treatment of the LiF. This behavior is due mainly to improved hole extraction. A similar behavior, with a $6-7 \%$ enhancement, was observed for plasma-treated thin $\mathrm{NaF}$ and $\mathrm{CsF}$. These observations may be related to improved energetics and hence a nearly Ohmic contact. Formation of alkali-O bonds, based on XPS analyses, is also believed to contribute to the enhanced hole extraction. The best enhancement was observed for a $1 \mathrm{~nm} \mathrm{LiF}$ layer air-plasma treated for $20 \mathrm{~min}$. UV-ozone treatment of such layers had a smaller effect. The light absorption and the EQE of the devices with treated alkali fluoride layers further support hole extraction from $\mathrm{CuPc}$ to the anode as one mechanism responsible for the observed enhanced performance. Light absorption increased for structures with $\mathrm{LiF}$ and was largely unchanged with $\mathrm{NaF}$ or $\mathrm{CsF}$. The results consequently demonstrate the viability of air-plasma treated thin fluoride layers, and in particular LiF, as interfacial layers between the ITO anode and the donor layer in small molecule $\mathrm{CuPc} / \mathrm{C}_{70}$-based OSCs.

In Chapter 5, a novel tandem cell arrangement, comprising a thin amorphous $(\mathrm{Si}, \mathrm{C}): \mathrm{H}$-based inorganic top cell and an organic bottom cell, was presented. This tandem structure results in an improved PCE of 5.6\% in an unoptimized series design, which is a $\sim 22 \%$ increase relative to that of the OSC alone. The $V_{\mathrm{OC}}$ of the tandem junction cell, $\sim 1.5 \mathrm{~V}$, is the sum of the values of the separate cells, as expected. Optimization of such tandem cells, deposited on a transparent, insulating substrate, can lead to significantly 
higher efficiencies. One can optimize the structures by manipulating the thickness of the cell and changing the $\mathrm{C}$ content so that the bandgap varies and the absorption in a$(\mathrm{Si}, \mathrm{C}): \mathrm{H}$ precisely complements that of the organic cell. The new device materials and architecture allow for either series connection or electrically independent tandem arrangements, thereby eliminating the current matching problem, and importantly, also reducing the degradation of the organic unit by filtering the high-energy photons.

In Chapter 6, the properties of ITO / PEDOT:PSS / PVK:TPD:Ir(mppy) $)_{3}: \mathrm{PBD} / x \mathrm{~nm}$ Bphen / y nm Bphen:LiF / LiF / Al hybrid polymer/small molecular OLEDs were described. The devices with the LiF dopant exhibited the highest power efficiency, up to $31 \mathrm{~lm} / \mathrm{W}$, and the longest $t_{1 / 2}$ of $800 \mathrm{~min}$ at $L_{0}=100 \mathrm{Cd} / \mathrm{m}^{2}$. The ELDMR results, which showed that the negative spin $1 / 2$ resonance amplitude increases with bias and degradation, suggest the presence of a high density of defect sites promoting trion formation, which may be related to the short lifetimes of the devices.

In Chapter 7, solution-processed CBP-based SMOLEDs were described and their performance was compared to that of PVK-based PLEDs, demonstrating SMOLEDs with peak power efficiency higher than any solution-processed devices and among the highest of any OLED reported to date. PLED EMLs PVK:PBD:TPD:Ir(mppy $\left.)_{3}\right)_{\text {) were obtained }}$ by spin-coating. The improved performance of these spin-coated SMOLEDs is believed to be due to the higher conductivity of CBP and the smoother spin-coated SMOLED EML. Consequently, solution-processing of SMOLEDs is expected to be a new and growing route for fabricating multi-components OLEDs, such as WOLEDs, to reduce 
manufacturing costs, increase device size, and avoid the complexity of the vacuum codeposition process.

Future developments will continue to focus on fabricating low-cost highly-efficient OSCs and on their durability, and on developing highly efficient solution processed blueto-red OLEDs, either polymer or small molecule, with long operational stability. 


\section{Acknowledgements}

First of all, I would like to express my deep gratitude to my advisor Professor Joseph Shinar for all the years' guidance, encouragement, support, and help. I also acknowledge his assistance and suggestions for my future career.

A special thanks to my co-major professor Ruth Shinar. I appreciate her guidance particularly in the OSCs related works, and her suggestions, help and support in my research and life.

I would like to thank my family members, especially my husband Min Cai, who are always standing behind me and supporting me. I would like to dedicate this dissertation to them.

My appreciation to former and current collaborators in Dr. Shinar's group: Dr. Zhaoqun Zhou and Dr. Moon-Ky Lee for their guidance and help in my research, Dr. Min Cai, Dr. Ying Chen, Rui Liu, Emily Hellerich and Weipan Cui for their assistance and suggestions in this long journey of pursuing a $\mathrm{PhD}$ degree.

My gratefulness to Dr. Dalal, Max Noack, Dr. Wai Leung, Robert Mayer, Sambit Pattnaik, Shantan Kajjam and Yifen Liu for all their help at the Microelectronics Research Center (MRC).

Finally, many thanks go to the Department of Physics at Iowa State University. I would also like to thank Larry, Lori, Gloria, Diane and Deb for their administrative work. This work was performed at the Ames Laboratory under contract number DEAC02-07CH11358 with the U.S. Department of Energy and at the Microelectronics Research Center of Iowa State University. It was partially supported by the Division 
of Materials Science and Engineering, Basic Energy Sciences Division, DOE, and by the Iowa Power Fund. 